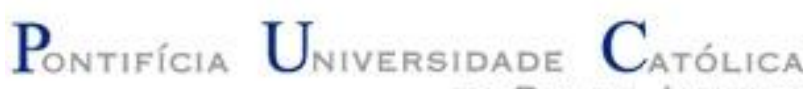

Ludmylla da Silva Moreira

\section{Fatores determinantes para o desempenho operacional dos pequenos negócios do setor de serviços de óleo e gás}

Dissertação de Mestrado

Dissertação apresentada como requisito parcial para obtenção do grau de Mestre pelo Programa de PósGraduação em Engenharia de Produção do Departamento de Engenharia Industrial da PUC-Rio.

Orientador: Prof. Antônio Márcio Tavares Thomé. Coorientador: Prof. Antonio Batista Ribeiro Neto.

Rio de Janeiro

Abril de 2019 


\section{Pontifícia U Uiversidade $C_{\text {atólica }}$

Ludmylla da Silva Moreira

\section{Fatores determinantes para o desempenho operacional dos pequenos negócios do setor de serviços de óleo e}

gás

Dissertação apresentada como requisito parcial para obtenção do grau de Mestre pelo Programa de Pós-graduação em Engenharia de Produção da PUC-Rio. Aprovada pela Comissão Examinadora abaixo.

Prof. Antônio Márcio Tavares Thomé Orientador Departamento de Engenharia Industrial - PUC-Rio

Prof. Antonio Batista Ribeiro Neto Coorientador Universidade do Estado do Pará - UEPA

Prof. Tharcisio Cotta Fontainha Universidade Federal do Rio de Janeiro - UFRJ

Prof. Luiz Felipe Roris Rodriguez Scavarda do Carmo Departamento de Engenharia Industrial - PUC-Rio 
Todos os direitos reservados. É proibida a reprodução total ou parcial do trabalho sem autorização da universidade, da autora e do orientador.

\section{Ludmylla da Silva Moreira}

Graduou-se em Engenharia de Produção pela Universidade do Estado do Pará - UEPA em 2016. Participou ativamente de projetos na universidade, adquirindo experiência nas áreas de Gestão da Qualidade, Serviços, Gestão Ambiental, Gerenciamento de Projetos, Logística e Gerência de Operações.

Ficha Catalográfica

Moreira, Ludmylla da Silva

Fatores determinantes para o desempenho operacional dos pequenos negócios do setor de serviços de óleo e gás / Ludmylla da Silva Moreira ; orientador: Antônio Márcio Tavares Thomé ; coorientador: Antonio Batista Ribeiro Neto. - 2019.

108 f. : il. ; $30 \mathrm{~cm}$

Dissertação (mestrado)-Pontifícia Universidade Católica do Rio de Janeiro, Departamento de Engenharia Industrial, 2019.

Inclui bibliografia

1. Engenharia Industrial - Teses. 2. Pequenos negócios. 3. Desempenho operacional. 4. Inovação. 5. Orientação ao mercado. 6. Óleo e gás. I. Thomé, Antônio Márcio Tavares. II. Ribeiro Neto, Antonio Batista. III. Pontifícia Universidade Católica do Rio de Janeiro. Departamento de Engenharia Industrial. IV. Título. 


\section{Agradecimentos}

Essencialmente aos meus pais, Rosilene e Paulo, por todo esforço, dedicação, apoio e amor. Minha mãe é uma fonte de inspiração, tenho muito orgulho dessa mulher guerreira e sou eternamente grata por tê-la em minha vida. À minha irmã, Anna Paula, que faz a minha vida ser muito mais divertida e que, inevitavelmente, me completa. Agradeço ainda à minha avó, Nazaré, por todo o seu amor.

Aos meus novos amigos que fiz na pós-graduação, Kamila, Leonardo e Diego, especialmente pelo acolhimento, Julia, D’avila, Vinícius e Fabíola, pelo que certamente podemos chamar de melhor turma e pelos melhores momentos. Também agradeço a todos os meus velhos amigos, que mesmo distantes sempre me fortalecem, principalmente ao Gabriel, meu confidente. Saibam que amo vocês e que todos contribuíram para esse ciclo da minha vida ser o mais leve possível.

Ao meu orientador, Márcio Thomé, por todo o conhecimento compartilhado, em todos os aspectos. Seu incentivo e apoio foram fundamentais para eu conseguir concluir essa jornada. Agradeço também ao meu coorientador, Antonio Batista, pela aproximação da pesquisa com o SEBRAE/RJ.

Agradeço também a todos os profissionais que se disponibilizaram para as entrevistas, contribuindo e permitindo o desenvolvimento da pesquisa.

À PUC-Rio pelos auxílios concedidos e a todos os funcionários do DEI pela ajuda e suporte.

Agradeço ainda a banca examinadora pela dedicação em contribuir para o aprimoramento da pesquisa.

Por fim, neste vasto universo, sou grata por ter encontrado na minha vida pessoas que me amam, tenho muita sorte.

O presente trabalho foi realizado com o apoio da Coordenação de Aperfeiçoamento de Pessoal de Nível Superior - Brasil (CAPES) - Código de Financiamento 001. 


\section{Resumo}

Moreira, Ludmylla da Silva; Thomé, Antônio Márcio Tavares (orientador); Ribeiro Neto, Antônio Batista (coorientador). Fatores determinantes para o desempenho operacional dos pequenos negócios do setor de serviços de óleo e gás. Rio de Janeiro, 2018. 108p. Dissertação - Departamento de Engenharia Industrial, Pontifícia Universidade Católica do Rio de Janeiro.

Este trabalho fundamentou-se na teoria da visão baseada em recursos (RBV) e nas cinco forças competitivas de mercado para identificar e analisar os fatores determinantes para o desempenho operacional de pequenos negócios prestadores de serviços, evidenciando os facilitadores e barreiras para o desempenho dos mesmos. Utilizou-se como métodos de pesquisa a revisão sistemática da literatura (RSL) para identificar os principais determinantes e o estudo de caso para explorar como os pequenos negócios abordam esses determinantes em seu desempenho operacional. Neste contexto, este estudo foi realizado junto a quatro pequenos negócios prestadores de serviços do setor de petróleo e gás, parceiras do Serviço Brasileiro de Apoio às Micro e Pequenas Empresas no Estado do Rio de Janeiro (SEBRAE/RJ). Como resultados da RSL, identificou-se a inovação e a orientação ao mercado como os principais determinantes frequentemente relacionados ao desempenho de pequenos negócios em serviços. Os principais facilitadores identificados foram qualidade, capital humano e inovação de produto/serviço, enquanto que recursos limitados e funcionários desqualificados foram identificados como as principais barreiras. Assim, na análise dos resultados dos estudos de caso observou-se que a competitividade e o crescimento no mercado são as forças que direcionam as atividades de inovação, logo, a orientação ao mercado se torna necessária paras as empresas direcionarem suas ações de maneira estrategicamente assertiva e, com a inovação, as organizações visam melhorar seus desempenhos, gerando vantagens competitivas ao oferecer novos serviços.

\section{Palavras-chave}

Pequenos negócios; desempenho operacional; inovação; orientação ao mercado; óleo e gás. 


\section{Abstract}

Moreira, Ludmylla da Silva; Thomé, Antônio Márcio Tavares (advisor); Neto, Antonio Batista Ribeiro (co-advisor). Determining factors for the operational performance of small businesses in the oil and gas services sector. Rio de Janeiro, 2018. 108p. Dissertation - Department of Industrial Engineering, Pontifical Catholic University of Rio de Janeiro.

This work was grounded on the theory of the resource-based view (RBV) and the five competitive market forces to identify and analyze the determining factors for the operational performance of small service providers, showing the facilitators and barriers to an improved performance. The systematic literature review (SLR) was used as a research method to identify the main determinants and a case study to explore how small businesses address these determinants in their operational performance. In this context, this study was carried out with four small oil and gas service providers, which work in partnership with the Brazilian Micro and Small Business Support Service in the State of Rio de Janeiro (SEBRAE/RJ). As SLR results, innovation and market orientation were identified as the main determinants often related to the performance of small businesses in services. The key facilitators identified were quality, human capital, and product/service innovation while limited resources and disqualified employees were identified as the main barriers. Thus, in the analysis of the results of the case studies, it was observed that competitiveness and market growth are the driving forces for innovation activities, so market orientation becomes necessary for companies to target their actions in a strategically assertive way and, with innovation, organizations aim to improve their performance generating competitive advantages by offering new services.

\section{Keywords}

Small businesses; operational performance; innovation; market orientation; oil and gas. 


\section{Sumário}

1. Introdução 12

1.1 Contextualização do tema e problemática 12

$\begin{array}{ll}1.2 \text { Objetivos da pesquisa } & 14\end{array}$

$\begin{array}{ll}1.3 \text { Justificativa } & 15\end{array}$

$\begin{array}{ll}1.4 \text { Estrutura do trabalho } & 16\end{array}$

2. Referencial teórico 18

$\begin{array}{ll}2.1 \text { Serviços } & 18\end{array}$

2.2 Teoria da visão baseada em recursos e as cinco forças competitivas de Porter 20

2.3 Pequenos negócios em serviços: definição e desempenho operacionalદ 2.4 Orientação ao mercado 25

2.5 Orientação à inovação 26

2.6 Perspectiva integrada 28

3. Método de pesquisa 31

3.1 Revisão Sistemática da Literatura (RSL) 31

3.2 Estudo de caso 34

4. Resultados e discussões $\quad 39$

4.1 Resultados obtidos com a RSL 39

4.2 Resultados obtidos com o estudo de caso 45

4.2.1 Estudo de caso A 46

4.2.2 Estudo de caso B $\quad 50$

4.2.3 Estudo de caso C

4.2.4 Estudo de caso D 62

$\begin{array}{ll}\text { 4.2.5 Análise intercasos } & 68\end{array}$

5. Conclusão 79

$\begin{array}{ll}5.1 \text { Considerações finais } & 79\end{array}$ 
5.1.1 Limitações

5.1.2 Implicações e contribuições 81

5.2 Sugestões de trabalhos futuros 82

6. Referências bibliográficas 84

APÊNDICE 1 - Protocolo do estudo de caso 94

APÊNDICE 2 - Roteiro de entrevista 104

APÊNDICE 3 - Lista dos códigos para análise de conteúdo

dos estudos de caso 107 


\section{Lista de figuras}

Figura 1 - O triângulo de serviço 19

Figura 2 - Modelo VRIO 21

Figura 3 - Etapas do estudo de caso 35

Figura 4 - Relação da quantidade de publicações por ano 42

Figura 5 - Principais fontes de publicação 43

Figura 6 - Forças competitivas de mercado dos estudos de caso $\quad 71$

Figura 7- Mapa de facilitadores e barreiras dos estudos de caso $\quad 72$

Figura 8 - Matriz dos temas abordados nos estudos de caso $\quad 75$

Figura 9 - Exemplo ilustrativo do painel de dados 102 


\section{Lista de tabelas}

Tabela 1 - Trabalhos com mais citações

42

Tabela 2 - Facilitadores e barreias ao desempenho de pequenos negócios em serviços 


\section{Lista de quadros}

Quadro 1 - Resumo do referencial teórico 29

Quadro 2 - Proposta do escopo da RSL 32

Quadro 3 - Estudos que abordam fatores determinantes para

o desempenho dos pequenos negócios do setor de serviços 39

Quadro 4 - Principais determinantes do desempenho operacional de serviço em pequenos negócios 43

Quadro 5 - Códigos das informações das empresas 46

Quadro 6 - Painel de dados do estudo de caso A 48

Quadro 7 - Facilitadores e barreiras ao desempenho

do estudo de caso A 50

Quadro 8 - Painel de dados do estudo de caso B 52

Quadro 9 - Facilitadores e barreiras ao desempenho

do estudo de caso B

Quadro 10 - Painel de dados do estudo de caso C 57

Quadro 11 - Facilitadores e barreiras ao desempenho

do estudo de caso $\mathrm{C} \quad 61$

Quadro 12 - Painel de dados do estudo de caso D 63

Quadro 13 - Facilitadores e barreiras ao desempenho

do estudo de caso D 67

Quadro 14 - Classificação dos recursos VRIN dos estudos de caso $\quad 69$

Quadro 15 - Principais facilitadores e barreiras dos estudos de caso $\quad 73$

Quadro 16 - Painel de dados dos estudos de caso 75

Quadro 17 - Síntese dos critérios de seleção das empresas 95

Quadro 18 - Diretrizes para observação 97

Quadro 19 - Descrição das questões abordadas no questionário 99 


\section{Introdução}

Nesta seção são abordados assuntos pertinentes à apresentação do trabalho, incluindo a contextualização do tema, problemática, o objetivo geral e os específicos, motivação, justificativa da escolha do tema e a estrutura do trabalho.

\section{1}

\section{Contextualização do tema e problemática}

O setor de serviços é imprescindível na sociedade, tanto em relação à economia quanto para melhorar a qualidade de vida da população (Fitzsimmons e Fitzsimmons, 2010). Essa afirmativa é complementada por dados do Banco Mundial (World Bank, 2018), indicando que o setor de serviços corresponde a 73,3\% do Produto Interno Bruto (PIB) do Brasil. Essa participação, conforme o Ministério do Desenvolvimento, Industria e Comércio - MDIC (2018), é fundamental e influencia significativamente a economia do país, apesar da desaceleração econômica, sendo responsável por 43,6\% do emprego formal.

Na primeira edição do Atlas Nacional de Comércio e Serviços foi destacada a importância da participação dos pequenos negócios no setor de serviços, pois possuem capacidade de gerar emprego e renda (MDIC, 2013). O Serviço Brasileiro de Apoio às Micro e Pequenas Empresas (SEBRAE) define que os pequenos negócios são compostos pelas micro e pequenas empresas (MPE) e são responsáveis pela geração de 52\% dos empregos com carteira assinada no Brasil (SEBRAE, 2018a). As MPE criam uma maior proporção de valor agregado no setor de serviços, sendo uma parte muito importante da economia (Papadopoulos et al., 2018). Gonçalves et al. (2017) expõem que em 2016 os pequenos negócios representaram doze milhões de organizações, correspondendo a 98,5\% do total de empresas formais do Brasil.

Neste contexto destacam-se os pequenos negócios prestadores de serviços do setor de óleo e gás. Tammela et al. (2014) descrevem que no decorrer do tempo esse setor passou a ser importante e estratégico para o Brasil, principalmente após 
a descoberta de novas reservas de petróleo e gás na região do pré-sal, localizado no Estado do Rio de Janeiro (RJ). Os pequenos negócios localizados nessa região participam da região petrolífera mais importante do país, constituindo uma rede de fornecedores de serviços para dar suporte ao setor, principalmente em serviços relacionados às atividades técnicas e de engenharia (por exemplo, integração de sistemas e componentes complexos, manutenção de equipamentos e sistemas operacionais) e à realização de atividades offshore, além de parcerias na logística e na cadeia de suprimentos (Narcizo et al., 2013).

Apesar dos pequenos negócios apresentarem grande relevância socioeconômica, muitas dessas empresas falham ou sofrem um fechamento antecipado e para agir contra isso é fundamental identificar os fatores determinantes que impactam o seu desempenho (Haase e Franco, 2016).

Fatores de falha, que podem ser individuais quando se referem às características e habilidades dos gerentes e não individuais quando se referem às características das operações internas das organizações ou aos impactos derivados do ambiente externo à empresa (Nikolić, et al. 2015), são considerados neste estudo como barreiras ao desempenho operacional dos pequenos negócios. Por outro lado, fatores de sucesso, que podem ser habilidades, atividades ou recursos em que uma organização pode investir (Alfoqahaa, 2018), são considerados como facilitadores ao desempenho operacional dos pequenos negócios. Já os determinantes podem ser tanto fatores internos quanto externos que influenciam diretamente o desempenho operacional dos pequenos negócios.

$\mathrm{Na}$ literatura, os recursos voltados à inovação (fatores internos) e ao mercado (fatores externos) são frequentemente relacionados como determinantes ao desempenho em pequenos negócios de serviços (por exemplo, Cook e Pandit, 2012; Oly Ndubisi e Agarwal, 2014; Meutia e Ismail, 2015).

Hassani et al. (2017) evidenciam que a inovação é necessária no setor petrolífero para o consumo e produção sustentável, competição com outras industrias, superação de problemas relacionados ao preço do petróleo e acesso aos recursos futuros. Além disso, os autores indicam que a inovação gera impactos positivos para as empresas como redução de custos e de tempo, ganhos de eficiência e crescimento sustentável.

O setor de óleo e gás possui características significantes como os altos riscos, altos custos irrecuperáveis e inovação intensiva, assim, os investimentos 
em atividades de Pesquisa e Desenvolvimento (P\&D) e de inovações são considerados fatores pertinentes que fornecem lucratividade para os pequenos negócios de petróleo (Akinwale, 2017).

$\mathrm{Na}$ indústria brasileira de petróleo e gás há uma evidente necessidade de inovação (Borba et al., 2016). Entretanto, a Pesquisa Nacional de Inovação do Brasil (PINTEC), realizada pelo Instituto Brasileiro de Geografia e Estatística (IBGE) em 2013, demonstrou que no país há um baixo nível de pequenas empresas inovadoras (Carvalho et al., 2017). Narcizo et al. (2013) descrevem que geralmente os pequenos negócios prestadores de serviços no setor de óleo e gás do país desenvolvem melhorias ou pequenas inovações incrementais, não sendo considerado um setor inovador.

Com base no que foi exposto, este estudo se concentra em pequenos negócios prestadores de serviços do setor de petróleo e gás, que atuam em parceria com o Serviço Brasileiro de Apoio às Micro e Pequenas Empresas no estado do Rio de Janeiro (SEBRAE/RJ). Assim, é em relação às dificuldades das pequenas empresas em melhorar seu desempenho por meio da inovação e orientação ao mercado, que esta pesquisa se posiciona, a fim de responder às seguintes perguntas: quais são os principais determinantes do desempenho operacional de serviço em pequenos negócios? Quais são os fatores que favorecem um melhor desempenho em serviços de pequenos negócios? E quais são os obstáculos ao desempenho em serviços de pequenos negócios?

\section{2 \\ Objetivos da pesquisa}

A partir da problemática do tema, para responder as perguntas de pesquisa, o presente estudo visa explorar como os pequenos negócios do setor de óleo e gás abordam os principais determinantes de serviços em seu desempenho operacional, evidenciando os facilitadores e as barreiras para o desempenho dos mesmos.

Os objetivos específicos são:

- Identificar na literatura científica os principais determinantes, facilitadores e barreiras para o desempenho operacional de serviços dos pequenos negócios; 
- Realizar a pesquisa de campo em diferentes organizações para observar e analisar os determinantes, facilitadores e barreiras no contexto operacional das empresas do estudo de caso;

- Identificar as similaridades, contrastes e lacunas sobre determinantes, facilitadores e barreiras existentes entre a literatura acadêmica com as práticas empresariais, a partir dos dados da pesquisa de campo;

- Oferecer sugestões de trabalhos futuros e relatar as implicações práticas decorrentes do estudo.

\section{3}

\section{Justificativa}

Por ter uma relevância econômica crescente, tanto no Brasil quanto no mundo, os serviços estão presentes no centro das discussões sobre competitividade e inovação (MDIC, 2018). No Brasil, pequenos negócios representam mais da metade do total de empresas do setor de serviços (SEBRAE, 2011), porém este grupo de empresas não desempenha de forma efetiva a sua função, não alcançando a dinâmica desejável (Atlas Nacional de Comércio e Serviços, 2013), como por exemplo no setor de óleo e gás, onde os pequenos negócios que prestam serviços possuem baixo índice de inovações (Narcizo et al., 2013).

Carvalho et al. (2017) discorrem que a análise da estrutura e lógicas de mercado (fatores externos), destacados por Porter em 1979, e os recursos, competências e capacidades (fatores internos), destacados por Barney em 1991, geram vantagens competitivas para as empresas e consequentemente melhor desempenho. Campbell e Park (2017), em sua pesquisa nacional de pequenas empresas, também ressaltam que nos resultados foi evidenciado importância da visão baseada em recursos para o desempenho geral.

Com base nessas duas vertentes teóricas, a proposição desta pesquisa é a de que as pequenas empresas têm uma maior propensão ao mercado e à inovação dependendo das forças de mercado explicitadas por Porter (1979) e baseadas nos recursos VRIN (Valiosos, Raros, Inimitáveis e Não-substituíveis) da empresa, postulados pela teoria da visão baseada em recursos (RBV) (Barney, 1991). 
Oly Ndubisi e Agarwal (2014) relatam que a maioria das pesquisas que relacionam recursos e desempenho possuem foco nas grandes empresas, assim, o conhecimento sobre como os recursos interferem no desempenho dos pequenos negócios torna-se limitado, além de destacarem que há uma lacuna na literatura sobre como a inovação contínua melhora o desempenho das pequenas empresas.

Além disso, Akinwale (2017) indica que a maioria dos estudos sobre o impacto da inovação na lucratividade das organizações foi desenvolvida nos setores de manufatura e tecnologia da informação, por exemplo, havendo uma lacuna na literatura desse tipo de estudo no setor de petróleo e gás, e que há predominância dessa área de pesquisa nos continentes da América do Norte, Europa e Ásia.

Narcizo et al. (2013) apontam que a exploração de petróleo no Brasil apresenta problemas complexos, além de vários desafios logísticos e tecnológicos, mas ainda assim há falta de pesquisas abordando inovações nas pequenas empresas do setor de óleo e gás, tendo pouco conhecimento sobre o estado atual da capacidade inovadora dessas organizações.

$\mathrm{Na}$ literatura, algumas pesquisas já abordaram orientação à inovação ou ao mercado das pequenas empresas ou seu desempenho no setor de óleo e gás (por exemplo, Ribeiro Neto, 2008; Narcizo et al., 2013; Perrons, 2014; Akinwale et al., 2018), porém estes estudos abordam cada aspecto isoladamente, não relacionando o desempenho das pequenas empresas com a inovação ou orientação ao mercado, além de não apresentarem uma base teórica do RBV e das forças de mercado de Porter.

Dessa forma, percebe-se a relevância do tema e a motivação em estudá-lo, uma vez que esta pesquisa contribui para preencher uma lacuna na literatura e para melhorar o desempenho das pequenas empresas prestadoras de serviços do setor de óleo e gás.

\section{4 \\ Estrutura do trabalho}

Esta dissertação foi dividida em 5 seções: introdução, referencial teórico, procedimentos metodológicos, resultados e discussões, e conclusão. 
$\mathrm{Na}$ Introdução são abordados a contextualização do tema, problemática, objetivos, relevância, motivação e justificativa da escolha do tema, além da estrutura. $\mathrm{O}$ referencial teórico explora a base teórica da pesquisa, por meio de bibliografias de diversos autores, a fim de detalhar conceitos acerca do tema. Os procedimentos metodológicos demonstram os métodos utilizados para a realização da pesquisa, divididos em duas subseções: revisão sistemática da literatura e estudo de caso. Os resultados e discussão descrevem os dados obtidos a partir da RSL e do estudo de caso. A conclusão resume os principais resultados, com sugestões de pesquisas futuras. 


\section{2 \\ Referencial teórico}

Nesta seção é apresentada a revisão bibliográfica dos principais assuntos relacionados à discussão sobre pequenos negócios do setor terciário, bem como o relato do que está sendo desenvolvido na academia sobre o tema e os conceitos que fundamentam a base teórica do trabalho, como: Serviços; Gestão de Operações de Serviços; Teoria da Visão Baseada em Recursos (RBV); Forças competitivas de mercado; Pequenos negócios prestadores de serviços e seu desempenho operacional; Orientação ao mercado e inovação em pequenos negócios, encontrados em livros e periódicos internacionais.

\section{1 \\ Serviços}

$\mathrm{Na}$ literatura existem diversas definições de serviços. A maioria das abordagens sobre serviços incluem a intangibilidade e a simultaneidade como seus atributos, em distintos níveis (Fitzsimmons e Fitzsimmons, 2010). Tradicionalmente na literatura de gerenciamento de operações, os serviços são diferenciados do produto por quatro características: intangibilidade, heterogeneidade, inseparabilidade e perecibilidade.

Os serviços são intangíveis já que não podem ser tocados; são heterogêneos por terem variabilidade durante a operação; são inseparáveis devido o consumo dos serviços ocorrer simultaneamente com a sua produção; e são perecíveis pois, devido a simultaneidade de consumo e produção, não há a possibilidade de estocálo (Zeithaml et al., 1985; Cowell, 1988; Nogueira, 2008; Paladini et al, 2013).

Este trabalho considera, principalmente, a definição de Spring e Araujo (2009), no qual definem que quando um cliente solicita uma prestação de serviço, essa compra do serviço dá direito à organização, por um determinado período, utilizar capacidades técnicas e humanas (sejam próprias ou controladas pela mesma) para fazer uma operação com o objetivo de modificar a realidade do cliente ou de bens pertencentes ao cliente. 
A definição de Spring e Araujo (2009) é escolhida por ser uma definição mais inclusiva. Corrêa et al. (2007) argumentam que, sob a perspectiva operacional, as quatro características diferenciadoras de serviços definidas na literatura tradicional (intangibilidade, heterogeneidade, inseparabilidade e perecibilidade) não são diferenciadores absolutos, uma vez que algumas dessas características podem estar presentes em alguns produtos, criando assim um quadro incompleto e uma generalização limitada.

Com a evolução da pesquisa em serviços, Subramony e Pugh (2015) relataram, em sua revisão sobre a pesquisa de gestão de serviços, que a definição de serviços passou de uma ênfase das características diferenciadoras para uma perspectiva de que os serviços são aplicações de competências. A Figura 1 apresenta o triângulo de serviço presente na definição de Spring e Araujo (2009).

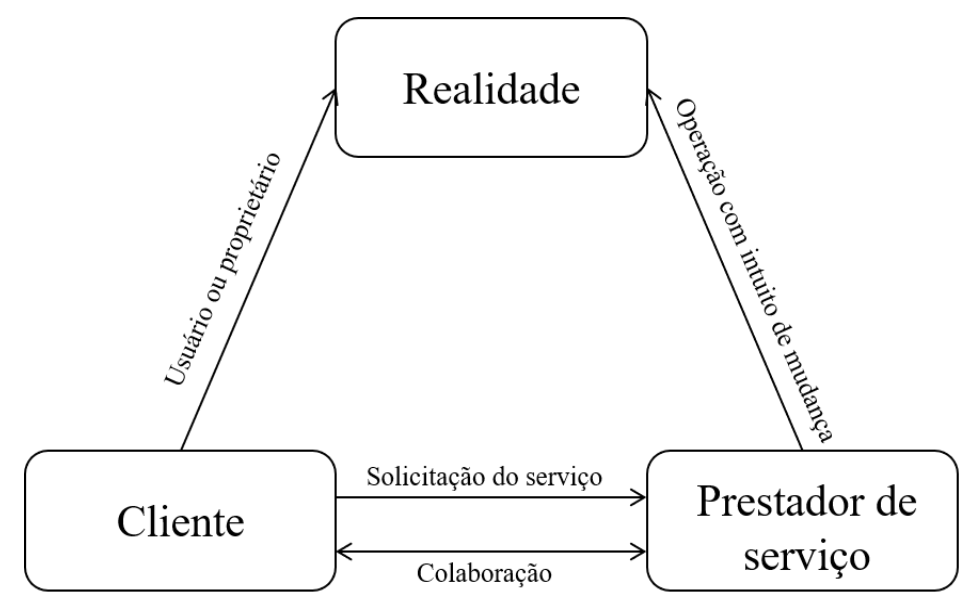

Figura 1 - O triângulo de serviço. Fonte: adaptado de Spring e Araujo (2009)

A partir dessa definição, a Gestão de Operações de Serviço desempenha os meios e métodos que são utilizados para a produção e entrega desses serviços. Os serviços podem ser realizados por pessoas ou por meios tecnológicos, podem ser gerados para algo que pertence ao cliente (por exemplo, concerto de eletrodomésticos), podem ser fornecidos diretamente ao próprio cliente (por exemplo, passeios turísticos) ou podem ser gerados como uma combinação dessas características (Ford et al., 2011).

Nesse sentido, Subramony e Pugh (2015) afirmam que nas pesquisas da área de serviços, o gerenciamento de serviços deve enfatizar os processos organizacionais que geram os resultados da empresa, além de avaliar a prestação do serviço e funcionários na perspectiva dos clientes. 
O setor de serviços possui uma representatividade significante na economia, porém a pesquisa sobre Gestão de Operações de Serviço ainda possui pouca atenção sob a perspectiva da Gestão de Operações, havendo diversas lacunas na literatura nessa área que foram identificadas em diferentes estudos ao longo do tempo (Sigala e Christou, 2006; Machuca et al., 2007; Roth e Menor, 2009; Spring e Araujo, 2009; Subramony e Pugh, 2015; Field et al., 2017; Victorino et al., 2018). Estes estudos evidenciam que o avanço sobre a melhor forma de projetar e gerenciar serviços são de crescente importância na academia e requer investigações continuas para ampliar a compreensão das estratégias e do desempenho da gestão de operações de serviço.

Mais especificamente, nas subseções a seguir são apresentados os pontos chaves deste estudo em gestão de operações de serviços.

\section{2 \\ Teoria da visão baseada em recursos e as cinco forças competitivas de Porter}

A teoria Resource Based View (RBV) proposta por Barney (1991), indica que as organizações necessitam identificar seus recursos-chaves com base em suas capacidades internas e direcionar esforços para as mais apropriadas, afim de alcançar vantagens competitivas. No longo prazo uma potencial vantagem competitiva ampara o crescimento econômico de uma organização e ela é obtida quando os recursos da empresa são Valiosos, Raros, Inimitáveis e Nãosubstituíveis (VRIN). Barney (1991) define os recursos VRIN como:

- Valiosos: quando permitem que uma empresa conceba ou implemente estratégias que melhorem sua eficiência e eficácia e que permitem a neutralização de uma ameaça;

- Raros: quando permitem implementar uma estratégia de criação de valor que não está sendo implementada simultaneamente por muitas empresas, proporcionando disparidade competitiva para a organização;

- Inimitáveis: quando são difíceis de serem replicados por outras empresas devido à sua singularidade, elevado custo ou complexidade, por exemplo;

- Não-substituíveis: quando não há recursos estrategicamente equivalentes.

A teoria RBV visualiza que cada empresa é detentora de um conjunto de recursos de natureza distinta (materiais, financeiros e humanos) e níveis variáveis 
de capacidades (isto é, como a organização distribui seus recursos para alcançar os resultados esperados, realizando processos organizacionais tangíveis ou intangíveis durante um período), sendo que algumas dessas capacidades possuem maior impacto no desempenho da organização do que as demais (Nath et al., 2010). Somente a posse de recursos não gera vantagem competitiva para a organização e o que sustenta a empresa no mercado é a sua capacidade de desenvolver novos recursos e tornar as capacidades mais inimitáveis.

Barney e Hesterly (2011) desenvolveram uma ferramenta denominada modelo VRIO para analisar internamente uma organização com base na teoria RBV. Com esse modelo é possível analisar o potencial que cada recurso ou capacidade tem para gerar vantagens competitivas. A sigla VRIO é derivada dos recursos VRIN, porém no lugar do $\mathrm{N}$ de "não-substituíveis" foi adicionado $\mathrm{O}$ de "organização", pois além dos recursos serem valiosos, raros e inimitáveis, é necessário que a empresa seja organizada, ou seja, esteja preparada para explorar ao máximo esses recursos, como ilustrado na Figura 2.

É um recurso ou capacidade:

\begin{tabular}{ccccc}
\hline Valioso? & Raro? & Inimitável? & $\begin{array}{c}\text { Explorado pela } \\
\text { organização? }\end{array}$ & Implicações Competitivas \\
\hline Não & - & - & Não & Desvantagem competitiva \\
Sim & Não & - & $\uparrow$ & Paridade competitiva \\
Sim & Sim & Não & $\downarrow$ & Vantagem competitiva temporária \\
Sim & Sim & Sim & Sim & Vantagem competitiva sustentável \\
\hline
\end{tabular}

Figura 2 - Modelo VRIO. Fonte: adaptado de Barney e Hesterly (2011)

A visão baseada em recursos da empresa ampara muito do pensamento atual sobre estratégia de operações de serviços (Roth e Menor, 2009). Na literatura, diferentes pesquisas utilizam a RBV para analisar o desempenho das organizações e os seus resultados mostram que há uma relação significativa entre recursos, capacidades e desempenho (Nath et al., 2010).

Lin e Wu (2014) evidenciam que os recursos VRIN estão relacionados à vantagem competitiva e que a vantagem competitiva está relacionada ao desempenho, assim, o acumulo desses recursos para o aumento da vantagem competitiva tornou-se um pensamento estratégico essencial tanto para o meio acadêmico quanto gerencial.

Hamid e Ismail (2016), por exemplo, em sua pesquisa sobre fatores de sucesso do Lean Thinking e desempenho operacional no setor de serviços, 
abordaram a teoria RBV para identificar fatores internos que são orientados para os trabalhadores que influenciam o sucesso do Lean Thinking. O resultado mostra que o fator importante que move as práticas de melhoria deve ser iniciado a partir das forças internas da organização. Hong et al. (2017) se baseiam na teoria RBV para estudar a relação entre sistemas de trabalho de alto desempenho para qualidade de serviço e desempenho do serviço no setor de hotelaria.

Predecessor à Barney (1991), Porter em 1979 descreveu as forças de mercado que caracterizam o posicionamento das empresas diante a concorrência. Estas forças são: (i) barreiras para novos entrantes; (ii) ameaça de produtos ou serviços substitutos; (iii) poder de negociação dos compradores; (iv) poder de negociação dos fornecedores; (v) rivalidade entre os atuais concorrentes. A intensidade de cada força é determinada de acordo com a estrutura da indústria e suas características econômicas (Porter, 2008). Essas cinco forças competitivas são descritas a seguir:

- Barreiras para novos entrantes: são vantagens que os operadores possuem em relação aos novos entrantes, havendo seis principais fontes, sendo economias de escala (força a organização a introduzir-se em larga escala, arriscando-se a uma forte reação das empresas existentes, ou em pequena escala, tendo desvantagem de custo), diferenciação do produto (quando as empresas existentes já possuem lealdade dos clientes, necessitando que as empresas entrantes tenham altas despesas afim de superar esse vínculo firmados com os clientes), necessidades de capital (necessidade de alto investimento financeiro para competitividade), custos de mudança (refere-se aos custos que o comprador enfrenta ao mudar de fornecedor), acesso aos canais de distribuição (refere-se a necessidade de garantir a distribuição para seu produto, portanto quanto mais os canais forem limitados e controlados pelos concorrentes mais forte será essa barreira) e desvantagens de custo independentes de escala (independente do seu tamanho ou economias de escalas das empresas entrantes, pode ocorrer das mesmas não conseguirem se igualar às empresas existentes devido terem vantagens de custos);

- Ameaça de produtos ou serviços substitutos: compreende a existência de um substituto que executa a mesma função ou uma função semelhante ao produto ou serviço de uma indústria por diferentes meios; 
- Poder de negociação dos compradores: ocorre quando os clientes detêm mais valor, forçando preços baixos, exigindo melhor qualidade ou mais serviço (gerando aumento nos custos) e fomentando a competitividade para a lucratividade do setor;

- Poder de negociação dos fornecedores: ocorre quando os fornecedores detêm mais valor, fazendo transferência de custos para outros elos da cadeia, cobrando preços mais altos ou limitando a qualidade dos serviços;

- Rivalidade entre os atuais concorrentes: abrange desconto de preço, lançamentos de novos produtos, campanhas publicitárias e melhorias de serviço. Uma alta rivalidade limita a lucratividade e isto depende principalmente da intensidade da competitividade.

\section{3 \\ Pequenos negócios em serviços: definição e desempenho operacional}

Os pequenos negócios podem ser definidos por diferentes parâmetros (Ribeiro Neto, 2008; Reis, 2018). Este estudo considera a definição do SEBRAE, que possui como parâmetro a receita bruta anual da empresa, baseado na Lei Geral das Microempresas e Empresas de Pequeno Porte.

Assim, os pequenos negócios são definidos como: microempreendedor individual se possui uma renda bruta mensal igual ou inferior a $\mathrm{R} \$ 81.000$; microempresa se se possui uma renda bruta mensal igual ou inferior a $\mathrm{R} \$ 360.000$; e empresa de pequeno porte se se possui uma renda bruta mensal superior a $\mathrm{R} \$ 360.000$ e igual ou inferior a $\mathrm{R} \$ 4.800 .000$ (SEBRAE, 2018b).

O desempenho operacional em serviços é um tema que já vem sendo abordado na literatura (Agarwal et al., 2003; Tsiotsou, 2010; Cho et al., 2012). Por exemplo, Heskett (2014) discute indicadores que explicam o desempenho do serviço e mostra que em organizações com pessoas que trabalham na linha de frente, fornecendo serviços de alto valor que exigem relações estreitas e fortes com os clientes, há uma relação relativamente forte entre cultura organizacional e lucro operacional. Em sua revisão sistemática da literatura de estudos em operações de serviço, Victorino et al. (2018) apontam que um dos temas-chave emergentes da pesquisa é a avaliação e medição do desempenho das operações de serviço. 
O desempenho operacional geralmente é representado por diversas dimensões e, mais especificamente na área de serviços, não há um consenso na literatura sobre quais dimensões devem ser utilizadas. Esta pesquisa engloba as quatro dimensões de desempenho clássicas da literatura, como apresentado em Power et al. (2010), a saber: custo, flexibilidade, qualidade e entrega.

Tendo a perspectiva de vantagem competitiva da teoria RBV, a empresa com capacidade de competir em custo, flexibilidade, qualidade e entrega possui investimentos relacionados aos recursos tangíveis e intangíveis disponíveis, sendo que a capacidade competitiva é fortemente determinada por meio da inter-relação entre esses investimentos (Power et al., 2010). Além dessas dimensões, Fitzgerald et al. (1991) também sugeriram a dimensão de inovação. As prioridades competitivas são definidas a seguir:

- Custo: é a base da precificação do serviço, sendo que o preço pode ser um dos critérios para a escolha do serviço, portanto, esse fator pode gerar vantagem competitiva e deve ser medido (Rushton e Carson, 1985);

- Flexibilidade: é a capacidade de modificar e adaptar a operação devido a alterações das necessidades dos clientes no processo ou no suprimento de recursos (Gianesi e Corrêa, 2008). Fitzgerald et al. (1991) dividem a flexibilidade em: flexibilidade de volume (resposta a diferentes níveis de demanda), flexibilidade de velocidade de entrega (rapidez na resposta adaptando-se às diferentes necessidades do cliente) e flexibilidade de especificação (adaptabilidade que o processo pode ter às necessidades individuais do cliente);

- Qualidade: as cinco dimensões da qualidade são um dos principais critérios que os clientes consideram na avaliação do serviço, sendo: confiabilidade (realização do serviço no prazo certo e de maneira correta conforme pré-estabelecido com o consumidor), prontidão (rapidez na prestação do serviço), segurança (funcionários com competência para a realização do serviço, simpatia e boa comunicação), empatia (caracterizado por acessibilidade e esforços que sejam capazes de atender as necessidades dos clientes) e aspectos tangíveis (relacionado aos bens facilitadores do serviço, como infraestrutura, equipamentos, entre outros) (Fitzsimmons e Fitzsimmons, 2010); 
- Entrega: a entrega se refere à confiabilidade e ao valor do tempo de entrega (Gaur et al. 2011).

- Inovação: o desenvolvimento de novos serviços tem potencial capacidade de gerar vantagem competitiva e, portanto, a inovação deve ser considerada no desempenho da empresa (Fitzgerald et al., 1991). A dimensão de inovação pode ser mensurada por vendas relativas a inovação, sucesso da inovação, patentes concedidas, desenvolvimento de novos produtos/serviços, taxa de inovação, entre outros (Reis, 2018).

Várias pesquisas abordaram o desempenho operacional em empresas de grande porte (Brackertz, 2006; Gengo et al., 2011; Ali e Shabir, 2017). Recentemente, devido ao seu potencial crescimento, os pequenos negócios tem sido objeto de estudos acadêmicos (Papadopoulos et al., 2018).

\section{4 \\ Orientação ao mercado}

Empresas que possuem orientação ao mercado, possuem atividades organizacionais que envolvem geração, disseminação e capacidade de resposta à inteligência de mercado, além de doutrinas organizacionais que engajam condutas próprias para a orientação ao mercado (Kirca et al., 2005). Esses autores ainda mostram que a orientação para o mercado gera consequências para o desempenho, pois proporciona capacidades de analisar o mercado e a partir disso ter proatividade para atender às necessidades dos clientes, enfatizando a maior utilização de informações, melhorando a capacidade de inovação e a qualidade dos produtos ou serviços, o que eleva o desempenho organizacional, além de criar um vínculo de lealdade com os clientes.

Narver e Slater (1990) explicam que a orientação ao mercado possui três componentes: orientação ao cliente, orientação ao concorrente e integração interfuncional.

- Orientação ao cliente: compreende os desejos e as necessidades dos clientes com intuito de criar valor nos serviços. Assim, organizações que possuem essa orientação geralmente possuem atividades de inovação bemsucedidas devido ao atendimento das necessidades dos clientes; 
- Orientação ao concorrente: compreende os pontos fracos e fortes tanto da concorrência quanto da própria empresa, além das estratégias e capacidades; - Integração interfuncional: compreende a utilização coordenada dos recursos ao criar valor, pois ao se ter funções organizacionais integradas, os funcionários aprimoram sua capacidade de resolver um problema.

Abordando pequenos negócios com orientação ao mercado na literatura, Rojas-Méndez et al. (2006) examinaram a influência da orientação do mercado sobre o desempenho das pequenas empresas no ambiente varejista chileno e os resultados mostraram uma correlação significativa entre a orientação do mercado e o desempenho das mesmas. Didonet et al. (2016) em sua pesquisa revelam que a orientação para o mercado afeta significativamente as fontes de inovação, fornecendo um foco centrado no mercado para as pequenas empresas. Fahim e Baharun (2017), ao examinarem os determinantes da orientação estratégica para o desempenho agrícola dos pequenos negócios na Malásia, com o efeito de mediação da capacidade de inovação, afirmam que a orientação ao mercado, combinado com orientação de aprendizagem, tem um impacto positivo maior na capacidade de inovação, bem como no desempenho dos pequenos negócios.

\section{5 \\ Orientação à inovação}

As empresas de menor porte quando comparadas às de maior parte mostram alcançar um desempenho organizacional superior quando há esforços de inovação (Augusto et al., 2014). Este trabalho considera a definição de inovação da OECD (2005), a qual diz que a inovação ocorre quando há implantação de novos serviços ou produtos ou processos ou métodos de marketing e organizacionais, ou quando são significativamente melhorados, nas práticas internas ou externas da empresa. Dessa forma, divide-se a inovação em quatro tipos: produto ou serviço, processo, marketing e organizacional.

- Inovação de produto ou serviço: quando se cria bens ou serviços novos ou quando os existentes são melhorados em relação à sua utilização prevista ou características funcionais; 
- Inovação de processo: quando se implanta novos métodos de produção ou distribuição ou quando os existentes são melhorados, em relação à técnicas, equipamentos e/ou softwares;

- Inovação de marketing: quando se cria métodos de marketing novos ou quando os existentes sofrem mudanças significativas em relação à concepção do produto ou serviço, embalagem, posicionamento, promoção ou na fixação de preços;

- Inovação organizacional: quando se implanta novos métodos organizacionais ou quando os existentes sofrem mudanças significativas nas práticas de negócios, na organização do seu local de trabalho ou em suas relações externas.

Jaw et al. (2010) descreveram que uma organização de serviços necessita compreender como desenvolver esforços estratégicos em inovação, tendo um compromisso da alta administração. Assim, esses mesmos autores relatam que para a empresa manter uma cultura orientada à inovação, seus esforços são divididos em (i) recursos de inovação e (ii) recompensas pela inovação, descritos a seguir.

- Recursos de inovação: são os recursos humanos, financeiros, tempo, entre outros, disponibilizados para criar serviços novos ou melhorá-los. Pode-se ter um setor novo voltado à inovação ou uma equipe para tal, introdução de sistemas de tecnologia da informação, por exemplo. Assim, as empresas que aplicam recursos para os processos de pesquisa e desenvolvimento de inovação aumentam a obtenção de sucesso em um novo serviço, o que consequentemente gera melhor desempenho em relação aos concorrentes;

- Recompensas pela inovação: são os incentivos aos funcionários para realizarem atividades inovadoras, criando serviços eficazes. Pode-se ter bônus ou comissões, por exemplo. Essas motivações contribuem com a produtividade e o desempenho da empresa.

Abordando pequenos negócios com orientação à inovação na literatura, Augusto et al. (2014) afirmam que muitas pesquisas na literatura discutem a relação entre inovação e desempenho, entretanto, menos estudos englobam essa relação considerando o tamanho da organização. Esses mesmos autores ainda relatam que os pequenos negócios, devido a geralmente terem uma estrutura flexível, mais práticas de gestão do conhecimento e compartilhamento dos valores 
organizacionais entre gerentes e funcionários, tendem a ter maior capacidade de criar valor agregado inovador para os clientes.

Keizer et al. (2002) realizaram uma pesquisa exploratória para explicar os esforços inovadores das pequenas empresas e sugerem que as pequenas empresas precisam implementar uma política orientada para a inovação para conseguirem um bom desempenho. Ndubisi e Iftikhar (2012) estudaram a relação entre empreendedorismo, inovação e desempenho em pequenas e médias empresas e nos resultados concluíram que a inovação está diretamente relacionada ao desempenho e serve como mediador no vínculo empreendedor-desempenho.

Haase e Franco (2016) em sua pesquisa que objetivava identificar quais fatores influenciam o desempenho das pequenas empresas, sugeriram que pesquisas futuras devem abordar o papel da inovação no desempenho de pequenos negócios de forma mais exaustiva, tendo em conta que a relação inovaçãodesempenho depende do contexto, além de sugerirem a repetição do estudo em outro lugar (ou seja, em outros países), pois isto também pode melhorar a compreensão de quais fatores impulsionam o desempenho empresarial das pequenas empresas.

Considerando os pequenos negócios brasileiros, Gonçalves et al. (2017) relatam que, para a maioria das empresas, a inovação demanda altos custos e altas tecnologias, porém os pequenos negócios que mais inovam são os que conseguem se manter no mercado por mais tempo, demonstrando a necessidade de inovação para competitividade das organizações.

\section{6 \\ Perspectiva integrada}

Tendo uma perspectiva integrada dos conceitos apresentados, a partir de uma compilação dos trabalhos citados ao longo das seções 1 e 2, no Quadro 1 é apresentado uma síntese dos trabalhos mais recentes relacionados ao tema desta pesquisa, evidenciando quais aspectos são abordados nos estudos. 
Quadro 1 - Resumo do referencial teórico

\begin{tabular}{|l|c|c|c|c|c|c|c|}
\hline \multicolumn{1}{|c|}{} & $\mathrm{x}$ & $\mathrm{x}$ & $\mathrm{x}$ & $\mathrm{x}$ & $\mathrm{x}$ & $\mathrm{x}$ \\
\hline Narcizo et al. (2013) & $\mathrm{x}$ & & & $\mathrm{x}$ & & $\mathrm{x}$ & $\mathrm{x}$ \\
\hline $\begin{array}{l}\text { Oly Ndubisi e Agarwal } \\
\text { (2014) }\end{array}$ & $\mathrm{x}$ & $\mathrm{x}$ & $\mathrm{x}$ & $\mathrm{x}$ & $\mathrm{x}$ & $\mathrm{x}$ & \\
\hline Perrons (2014) & $\mathrm{x}$ & & & $\mathrm{x}$ & & $\mathrm{x}$ & $\mathrm{x}$ \\
\hline Meutia e Ismail (2015) & $\mathrm{x}$ & $\mathrm{x}$ & $\mathrm{x}$ & $\mathrm{x}$ & $\mathrm{x}$ & $\mathrm{x}$ & \\
\hline Borba et al. (2016) & $\mathrm{x}$ & & $\mathrm{x}$ & & & $\mathrm{x}$ & $\mathrm{x}$ \\
\hline Haase e Franco (2016) & $\mathrm{x}$ & $\mathrm{x}$ & $\mathrm{x}$ & $\mathrm{x}$ & & & \\
\hline Didonet et al. (2016) & $\mathrm{x}$ & & & $\mathrm{x}$ & $\mathrm{x}$ & $\mathrm{x}$ & \\
\hline Campbell e Park (2017) & $\mathrm{x}$ & $\mathrm{x}$ & $\mathrm{x}$ & $\mathrm{x}$ & $\mathrm{x}$ & & \\
\hline Gonçalves et al. (2017) & $\mathrm{x}$ & & & $\mathrm{x}$ & & $\mathrm{x}$ & \\
\hline Fahim e Baharun (2017) & $\mathrm{x}$ & & $\mathrm{x}$ & $\mathrm{x}$ & $\mathrm{x}$ & & \\
\hline Akinwale et al. (2018) & $\mathrm{x}$ & & & $\mathrm{x}$ & & $\mathrm{x}$ & $\mathrm{x}$ \\
\hline Este estudo & $\mathrm{x}$ & $\mathrm{x}$ & $\mathrm{x}$ & $\mathrm{x}$ & $\mathrm{x}$ & $\mathrm{x}$ & $\mathrm{x}$ \\
\hline
\end{tabular}

Diante do Quadro 1, há poucos estudos que abordem o segmento de serviços no âmbito do setor de óleo e gás, ainda mais referentes aos pequenos negócios, sendo que muitos não fazem a relação dos determinantes com desempenho operacional e sem fundamentação teórica.

Desse modo, devido ao desequilíbrio existente entre a importância econômica do setor de serviços e a falta de pesquisas de gestão de operações em serviços na academia, uma das contribuições deste trabalho é diminuir a lacuna existente na literatura. Além disso, a fundamentação teórica deste estudo usa a teoria RBV para identificar evidências de recursos VRIN no desempenho operacional de pequenos negócios prestadores de serviços. Esta pesquisa também se fundamenta nas cinco forças competitivas de mercado, determinadas por Porter (2008), para verificar fatores externos às pequenas empresas que contribuem para seu desempenho em relação aos concorrentes.

Como observa-se no Quadro 1, os estudos que mais se aproximam com a temática desta pesquisa são Oly Ndubisi e Agarwal (2014), Meutia e Ismail (2015) e Campbell e Park (2017), porém nenhum desses foi realizado no contexto do setor de óleo e gás. Oly Ndubisi e Agarwal (2014) realizaram a pesquisa no contexto de pequenas empresas de Tecnologia da Informação (TI) na Ásia, na qual acrescentaram a teoria do RBV e capacidades dinâmicas na literatura de 
gerenciamento estratégico existente. Indicaram uma relação positiva direta e indireta significativa entre inovação, orientação empreendedora (OE) e desempenho organizacional em qualidade, evidenciando na literatura que uma justaposição de OE com cultura orientada para o mercado contribui significativamente para o sucesso da inovação (Oly Ndubisi e Agarwal, 2014).

Meutia e Ismail (2015) realizaram a pesquisa no contexto de pequenas empresas de Batik na Indonésia, na qual contribuíram para a teoria do RBV ao afirmarem que uma organização é capaz de melhorar o desempenho de marketing por meio da criatividade inovadora de produto e da capacidade de adaptação à mudança do mercado. Já Campbell e Park (2017) realizaram a pesquisa no contexto de pequenas empresas em vários segmentos de negócios nos EUA, na qual combinaram a teoria do RBV com uma abordagem instrumental dos stakeholders e sugeriram que essa junção de gestão estratégica de stakeholders com recursos, como orientação empreendedora que engaja informações sobre o mercado, contribuem para o desempenho dos pequenos negócios. 


\section{3 \\ Método de pesquisa}

Nesta seção são apresentados os métodos e as técnicas utilizados no presente trabalho. A metodologia desta pesquisa é caracterizada como multimetodológica, pois foram aplicados dois diferentes métodos de pesquisa, a saber: revisão sistemática da literatura (RSL) e estudo de caso, com fundamentação das escolhas dos mesmos para demonstrar o caráter científico, bem como suas etapas para a execução do estudo.

A pesquisa multi-metodológica se justifica pela complementaridade das concepções metodológicas, uma vez que essa combinação dos métodos supera as limitações de cada uma das abordagens, além do estudo necessitar de diferentes fontes de dados para validação e aumentar sua confiabilidade.

Dessa forma, os resultados oriundos da revisão sistemática da literatura (identificação dos determinantes, barreiras e facilitadores) embasaram o desenvolvimento do estudo de caso, desde a elaboração do protocolo até a análise dos resultados, sendo possível analisar dados da literatura com dados empíricos.

\section{1 \\ Revisão Sistemática da Literatura (RSL)}

Uma revisão sistemática permite, por meio de procedimentos claros, localizar, avaliar e integrar os resultados de pesquisas especificas, apresentando da melhor forma possível as evidencias disponíveis sobre determinado tema na literatura (Campbell Collaboration, 2014). Thomé et al. (2016) relatam também que a RSL é um método de pesquisa que avalia contribuições, mostrando o que se é conhecido ou não na literatura. Esses mesmos autores descreveram que a RSL possui oito etapas principais, sendo: planejamento e formulação do problema; busca na literatura; coleta de dados; avaliação da qualidade; análise e síntese de dados; interpretação; apresentação dos resultados; e atualização da revisão.

$\mathrm{Na}$ etapa do planejamento e formulação do problema é importante definir o escopo da RSL para desde o início direcionar e estruturar a pesquisa, além de 
explanar aos leitores os objetivos e alcance da revisão, sendo que o escopo descreve o foco de pesquisa (refere-se ao problema de interesse), objetivo (síntese integrativa, revisão crítica ou identificação de problemas em um campo), perspectiva (refere-se ao ponto de vista do revisor, podendo ser uma defesa neutra ou enlevada ou a adoção de uma posição), cobertura (classificada em apresentação exaustiva ou abrangente de trabalhos, exaustiva com citação seletiva baseada em uma pesquisa de artigos selecionados, representativa de um campo de pesquisa e apresentação de trabalhos fundamentais ou tópicos em um determinado campo), organização (histórico, metodológico ou conceitual) e público (estudiosos especializados, acadêmicos gerais, profissionais ou formuladores de políticas e o público em geral) (Thomé et al., 2016). Dessa forma, o escopo da RSL da presente pesquisa é apresentado no Quadro 2.

Quadro 2 - Proposta do escopo da RSL

\begin{tabular}{|c|l|}
\hline \multirow{2}{*}{ Foco de pesquisa } & $\begin{array}{l}\text { Este estudo baseia-se na teoria RBV e na } \\
\text { força de mercado de Porter para identificar e } \\
\text { analisar evidências de recursos VRIN e de } \\
\text { forças de mercado no desempenho } \\
\text { operacional de pequenos negócios } \\
\text { prestadores de serviços. }\end{array}$ \\
\hline Objetivo & Síntese integrativa. \\
\hline Perspectiva & Defesa neutra. \\
\hline Cobertura & Apresentação abrangente de trabalhos. \\
\hline Organização & Metodológica. \\
\hline Público & Acadêmicos gerais. \\
\hline
\end{tabular}

Além da definição do escopo, nesta etapa também é importante realizar a identificação do tema da pesquisa. Assim, na Seção 1 é apresentado o tema deste trabalho, evidenciando as teorias, justificativas e questões de pesquisas, tendo a aplicação do método de RSL para atender ao primeiro objetivo específico. Desse modo, a presente RSL visa identificar na literatura os principais determinantes, facilitadores e barreiras relacionados ao desempenho operacional de pequenas empresas prestadoras de serviços, servindo como base para o método de pesquisa principal, o estudo de caso, para analisar como esses determinantes são abordados pelas empresas afim de melhorar seus desempenhos. A revisão da literatura é focada nos objetivos do estudo, porém utiliza as técnicas da SLR para assegurar objetividade e transparência quanto aos métodos adotados. 
Na etapa da busca na literatura, Thomé et al. (2016) relatam que há sete sub etapas: seleção da base eletrônica de dados, identificação das palavras-chave para a pesquisa, revisão dos resumos dos artigos selecionados, aplicação de critérios para inclusão ou exclusão de artigos, revisão do texto completo dos artigos selecionados, pesquisa para trás e pesquisa para frente em documentos recuperados. Adaptando estas sub etapas para este estudo, foram executadas as cinco primeiras sub etapas citadas, descritas a seguir.

a) Seleção da base eletrônica de dados: foi selecionado o Scopus como base de dados para aplicar a pesquisa. O campo de Ciências Naturais e Engenharia possui maior cobertura na base de dados do Scopus, cobrindo $38 \%$ dos periódicos, e, além disso, o Scopus tem uma proporção maior de periódicos exclusivos em todos os campos de estudos (Mongeon e Paul-Hus, 2016).

b) Identificação das palavras-chave para a pesquisa: foram definidos dois grupos de palavras-chave para a busca ser ampla o suficiente para evitar limitações na quantidade de trabalhos, porém suficientemente especificas capaz de retirar resultados fora do tema de pesquisa (Petticrew e Roberts, 2006; Cooper, 2010; Thomé et al., 2016). As palavras-chave do primeiro grupo foram ("performance" $O R$ "operational performance") AND ("small companie*" OR "small business" OR "small firm" OR "sme") AND ("service*" or "service provider") e as do segundo grupo foram as mesmas do primeiro grupo, mas com a inclusão de AND ("resource based view" OR "rbv"), para poder identificar quais pesquisas se baseavam na teoria RBV. Essas palavras-chave foram aplicadas nos campos do título, resumo e palavraschave dos artigos e a busca foi finalizada em maio de 2018, resultando em 456 pesquisas.

c) Revisão dos resumos dos artigos selecionados e aplicação de critérios para exclusão de artigos: para a leitura dos resumos, aplicou-se como critérios de exclusão os artigos que não identificavam os recursos VRIN abordados no estudo e os que não abordavam pequenos negócios no setor de serviços, resultando em 81 artigos selecionados para a próxima etapa. 
d) Revisão do texto completo dos artigos selecionados: esta etapa consistiu na leitura completa dos 81 artigos selecionados, sendo utilizado como critério de exclusão artigos que não relacionavam os recursos VRIN identificados com o desempenho de pequenos negócios, resultando na exclusão de 33 estudos e tendo como resultado final a seleção de 48 artigos.

$\mathrm{Na}$ etapa da coleta de dados foram identificados os elementos pesquisados nos artigos selecionados, a saber: os principais determinantes que interferem no desempenho de pequenos negócios prestadores de serviços, assim como os facilitadores e barreiras para tal. Na etapa da avaliação da qualidade, que consiste em adequar o objetivo do estudo com a implementação da RSL, o critério de qualidade em relação à validade do estudo aplicado foi a validação externa, pois ao selecionar e usar artigos revisados por pares indexados na base Scopus, foi possível generalizar os resultados da pesquisa. A etapa de análise e síntese de dados foi feita por meio da identificação de características relevantes do estudo, com base nas definições de determinantes, barreiras e facilitadores, e uso de dados contextuais da unidade de análise, como anos de publicação, periódicos e autores para descrever a pesquisa. Já na etapa de interpretação dos dados foi descrito os padrões observados na literatura. A apresentação dos resultados dessa RSL encontra-se na Seção 4.1. A atualização da revisão é apresentada como sugestão de trabalhos futuros.

\section{2}

\section{Estudo de caso}

Para alcançar o objetivo geral desta pesquisa, foi utilizado igualmente como método de pesquisa o estudo de caso. Cauchick Miguel (2012) caracteriza o estudo de caso como um estudo empírico, no qual geralmente não há uma definição clara das fronteiras entre o fenômeno pesquisado e o contexto onde se insere, realizando uma investigação de um fenômeno atual no contexto de uma situação real.

O estudo de caso como estratégia de pesquisa, por poder existir muitas variáveis de interesse, necessita de múltiplas fontes de dados convergindo para 
uma triangulação, e a condução da coleta e análise de dados baseia-se em proposições teóricas (Yin, 2013). Voss et al. (2002) descrevem que esse método pode ser utilizado quando há questões de pesquisas do tipo "por que, o que, qual e como", pois possibilita respostas completas que compreendem a complexidade do fenômeno. Além disso, o estudo de caso pode ser único ou múltiplo. O estudo de caso único aborda apenas um caso e o múltiplo abrange dois ou mais casos, sendo que no caso único há maior aprofundamento na pesquisa e nos múltiplos casos há maior possibilidade de generalização (Cauchick Miguel, 2012). Neste trabalho foi usado o método do estudo de caso múltiplo, uma vez que Yin (2013) indica que a replicação de casos proporciona resultados similares ou contrastantes.

Para a efetiva aplicação do método do estudo de caso, utilizou-se como base as seis etapas de execução apresentadas por Yin (2013), ilustradas na Figura 3 e descritas a seguir.

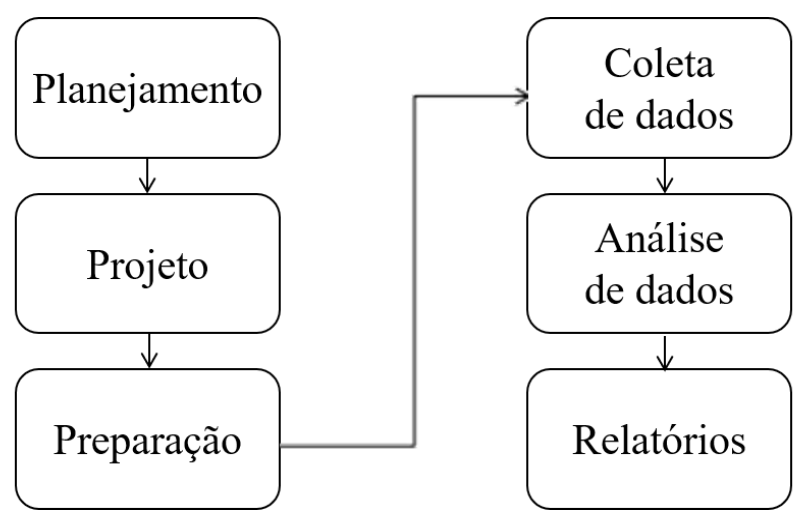

Figura 3 - Etapas do estudo de caso

A primeira etapa, planejamento, consiste na adequação do método com o objetivo do trabalho. Assim, observa-se neste estudo que a utilização desse método é adequada, pois permite pesquisar um fenômeno contemporâneo inserido no seu contexto da vida real, abrangendo múltiplos casos com várias fontes de evidências, nas quais as suas coletas e analises são conduzidas por proposição teórica. Essas diretrizes atendem ao objetivo de analisar os determinantes que impactam o desempenho operacional no contexto real dos pequenos negócios prestadores de serviços do setor de óleo e gás, assim como seus facilitadores e barreiras, com base nos resultados oriundos da RSL.

A etapa do projeto auxilia o planejamento, tendo cinco componentes (questões de pesquisa; proposições, caso haja; unidade(s) de análise; lógica que une os dados às preposições; e critérios para interpretar as constatações). Assim, 
as questões desta pesquisa relacionam-se à verificação da aderência dos determinantes relacionados ao desempenho operacional de pequenos negócios identificados na literatura com o que é observado em situações reais, identificando as suas barreiras e facilitadores. Tem-se a proposição de que os pequenos negócios têm uma maior propensão ao mercado e a inovação dependendo das forças de mercado explicitadas por Porter (1979) e baseadas nos recursos VRIN da empresa postulados pela teoria RBV (Barney, 1991). Em relação às unidades de análises, por ser um estudo de múltiplos casos, foram selecionadas quatro pequenas empresas prestadoras de serviços do setor óleo e gás, localizadas no estado do Rio de Janeiro. A lógica que conecta os dados com a proposição é a lógica de adequação ao padrão (Yin, 2013) e a técnica de linhas de síntese de argumentos (Tranfield et al., 2003). Os critérios para interpretação referem-se a dados reais que reforçam, complementam ou contrastam com o referencial teórico, de maneira que possibilite gerar pontos de discussão novos que contribuam com a literatura.

A etapa da preparação refere-se à elaboração de um protocolo de pesquisa, o qual apresenta a fundamentação teórica do estudo de caso e os procedimentos para aplicar o instrumento de pesquisa, assim como o teste piloto, no intuito de direcionar o pesquisador na coleta e análise dos dados e na condução da pesquisa. O protocolo do estudo de caso completo deste trabalho é apresentado no Apêndice 1.

A partir da elaboração do protocolo do estudo de caso, realizou-se um questionário e um roteiro de observação direta como instrumentos de pesquisa, com base no referencial teórico do estudo, para possibilitar a coleta de dados. Posteriormente, realizou-se um teste piloto para verificar se os mesmos estavam compreensíveis e se o questionário não estava muito cansativo. Yin (2013) afirma que o teste piloto auxilia para a aprimoração do planejamento para coleta de dados, relacionados ao conteúdo dos dados ou aos procedimentos metodológicos.

Assim, a partir dos critérios de seleção (ver seção 3.1. do Apêndice 1), selecionou-se duas pequenas empresas prestadoras de serviço do setor de óleo e gás, que atuam em parceria com o SEBRAE/RJ, para aplicar o teste. No total foram três entrevistados (um pertencente a uma empresa e dois pertencentes a outra empresa), com os seguintes cargos: Sócio-Diretor, Diretor Comercial e Sênior. 
Após a aplicação do teste piloto, verificou-se que o tempo médio das entrevistas era de uma hora, não sendo cansativo para os respondentes. O roteiro de observação estava adequado e o questionário necessitava ser aprimorado. Assim, foram feitas as devidas correções de acordo com as propostas de melhorias sugeridas pelos respondentes, como: mudança textual para melhor compreensão, exclusão de perguntas redundantes, mais objetividade e inclusão de perguntas relacionadas às tecnologias disruptivas. A adição da tecnologia na pesquisa corrobora com a literatura, na qual foi identificada como parte dos principais determinantes do desempenho operacional em pequenos negócios (Reis, 2018).

Tecnologias disruptivas são tecnologias que permitem a mudança em ritmo acelerado (Deloitte, 2018), ocasionando uma ruptura com os padrões vigentes. Representam uma transformação nas estruturas das empresas, na qual a tecnologia é incorporada nas estratégias, e nas ações internas e externas realizadas (FNQ, 2018).

Dessa forma, com base em pesquisas da Confederação Nacional da Industria (CNI), Fundação Nacional da Qualidade (FNQ) e Deloitte, foram identificadas nove principais tecnologias disruptivas abordadas nos estudos, sendo: internet das coisas; inteligência artificial; interface das coisas; machine learning; big data; impressão 3D; materiais avançados; robótica avançada e automação cognitiva; design digital, simulação e integração. (CNI-Indicators, 2016; Deloitte, 2018; FNQ, 2018). Logo, as questões adicionadas no questionário sobre tecnologias envolvem a identificação do uso das mesmas. O questionário modificado após o teste piloto encontra-se no Apêndice 1.

$\mathrm{Na}$ etapa da coleta de dados, as múltiplas fontes primárias de informações de cada caso deste estudo foram: entrevistas semiestruturadas, observações diretas e a verificação de documentos relacionados e websites das empresas, para permitir a triangulação de dados. Desse modo, a coleta dos dados empíricos foi realizada durante dois meses, totalizando 4 empresas, sendo que em cada uma ocorreu uma visitação técnica para observação direta e uma entrevista semiestruturada de aproximadamente $1 \mathrm{~h}$ com 3 diretores e 1 gerente técnico.

$\mathrm{Na}$ etapa da análise de dados, foram realizadas as análises intracaso (consiste em analisar os dados coletados em cada estudo de caso separadamente) e intercaso (consiste em analisar os dados coletados dos estudos de casos em conjunto), utilizando a técnica de adequação ao padrão (verifica a correspondência 
entre padrões empíricos observados com padrões teóricos) e a técnica de linhas de síntese de argumentos (analisa o mesmo fenômeno por diferentes aspectos). $\mathrm{Na}$ análise de conteúdo foi utilizado o software WebQDA de análise qualitativa para codificar e categorizar os textos originados das transcrições, observações, documentos e sites, reduzindo a quantidade de dados e estruturando as ideias temáticas, sendo que a codificação foi feita com base no referencial teórico. Além disso, na análise intercaso foi aplicado o modelo VRIO para identificar as implicações competitivas dos recursos e capacidades dos pequenos negócios.

Por fim, a etapa do relatório se dá por meio do texto completo da dissertação, tendo em vista que o maior objetivo desta etapa é o compartilhamento de informações. 


\section{4 \\ Resultados e discussões}

Nesta seção são abordados os resultados obtidos com o desenvolvimento da pesquisa, divido em duas subseções: primeiro referente à RSL e segundo referente ao estudo de caso.

\section{1 \\ Resultados obtidos com a RSL}

Por meio da RSL, observou-se que a literatura ainda carece de estudos que analisem o desempenho operacional de pequenos negócios do setor de serviços, principalmente com base teórica do RBV. O Quadro 3 evidencia os 48 artigos selecionados na RSL, com dados referentes aos autores, ano e fonte de publicação.

Quadro 3 - Estudos que abordam fatores determinantes para o desempenho dos pequenos negócios do setor de serviços

\begin{tabular}{|l|c|c|}
\hline \multicolumn{1}{|c|}{ Título } & Autor(es) e Ano & Fonte \\
\hline $\begin{array}{l}\text { Investigating the moderating role of education on a } \\
\text { structural model of restaurant performance using multi- } \\
\text { group PLS-SEM analysis }\end{array}$ & Lee e Hallak (2018) & $\begin{array}{c}\text { Journal of Business } \\
\text { Research }\end{array}$ \\
\hline $\begin{array}{l}\text { Critical success factors of small and medium-sized } \\
\text { enterprises in Palestine }\end{array}$ & Alfoqahaa (2018) & $\begin{array}{c}\text { Journal of Research in } \\
\text { Marketing and } \\
\text { Entrepreneurship }\end{array}$ \\
\hline $\begin{array}{l}\text { Innovation and business performance for Spanish SMEs: } \\
\text { New evidence from a multi-dimensional approach }\end{array}$ & $\begin{array}{c}\text { Exposito, Sanchis- } \\
\text { llopis (2018) }\end{array}$ & $\begin{array}{c}\text { International Small } \\
\text { Business Journal: } \\
\text { Researching } \\
\text { Entrepreneurship }\end{array}$ \\
\hline $\begin{array}{l}\text { Open and Closed Innovation and Enhanced Performance } \\
\text { of SME Hospitals-A Conceptual Model }\end{array}$ & $\begin{array}{c}\text { Ahmed, Halim e } \\
\text { Ahmad (2018) }\end{array}$ & $\begin{array}{c}\text { Business Perspectives } \\
\text { and Research }\end{array}$ \\
\hline $\begin{array}{l}\text { The performance effect of micro-innovation in SMEs: } \\
\text { evidence from China }\end{array}$ & Zhou et al. (2017) & $\begin{array}{c}\text { Chinese Management } \\
\text { Studies }\end{array}$ \\
\hline $\begin{array}{l}\text { Is innovation performance measurement beneficial for } \\
\text { performance in services? }\end{array}$ & Saunila (2017a) & $\begin{array}{c}\text { International Journal of } \\
\text { Business and } \\
\text { Globalisation }\end{array}$ \\
\hline $\begin{array}{l}\text { Exploring market orientation among Chinese small and } \\
\text { medium-sized enterprises }\end{array}$ & Zhang et al. (2017) & $\begin{array}{c}\text { Chinese Management } \\
\text { Studies }\end{array}$ \\
\hline $\begin{array}{l}\text { Managing continuous innovation through performance } \\
\text { measurement }\end{array}$ & Saunila (2017b) & Competitiveness \\
\hline $\begin{array}{l}\text { Extending the resource-based view: Effects of strategic } \\
\text { orientation toward community on small business } \\
\text { performance }\end{array}$ & $\begin{array}{c}\text { Campbell e Park } \\
\text { (2017) }\end{array}$ & $\begin{array}{c}\text { Journal of Retailing and } \\
\text { Consumer Services }\end{array}$ \\
\hline $\begin{array}{l}\text { Effect of digital transformation on organisational } \\
\text { performance of SMEs: Evidence from the Taiwanese } \\
\text { textile industry's web portal }\end{array}$ & $\begin{array}{c}\text { Chen, Jaw e Wu } \\
\text { (2016) }\end{array}$ & \begin{tabular}{c} 
Internet Research \\
\hline
\end{tabular} \\
\hline
\end{tabular}




\begin{tabular}{|c|c|c|}
\hline Título & Autor(es) e Ano & Fonte \\
\hline $\begin{array}{l}\text { Role of collaboration in innovation success: differences } \\
\text { for large and small businesses }\end{array}$ & $\begin{array}{l}\text { González-benito et al. } \\
\text { (2016) }\end{array}$ & $\begin{array}{c}\text { Journal of Business } \\
\text { Economics and } \\
\text { Management } \\
\end{array}$ \\
\hline $\begin{array}{l}\text { The Effect of Customer Orientation on Smaller Sized } \\
\text { Service Firms and on the Market: A Multilevel } \\
\text { Application Embracing Firms and Customers }\end{array}$ & $\begin{array}{l}\text { Polo Peña et al. } \\
\qquad(2016)\end{array}$ & $\begin{array}{c}\text { Journal of Small } \\
\text { Business Management }\end{array}$ \\
\hline $\begin{array}{l}\text { The relationship between entrepreneurship social } \\
\text { competence and marketing performance in Indonesian } \\
\text { smes: The role of business networking and product } \\
\text { innovation }\end{array}$ & Meutia (2015) & $\begin{array}{l}\text { International Journal of } \\
\text { Applied Business and } \\
\text { Economic Research }\end{array}$ \\
\hline $\begin{array}{l}\text { The influence of competitive pressure on innovative } \\
\text { creativity }\end{array}$ & $\begin{array}{c}\text { Meutia e Ismail } \\
(2015)\end{array}$ & $\begin{array}{l}\text { Academy of Strategic } \\
\text { Management Journal }\end{array}$ \\
\hline $\begin{array}{l}\text { External accountants' business advice and } \\
\text { performance }\end{array}$ & Carey (2015) & $\begin{array}{l}\text { Pacific Accounting } \\
\text { Review }\end{array}$ \\
\hline $\begin{array}{l}\text { Understanding the drivers of international performance } \\
\text { for born global firms: An integrated perspective }\end{array}$ & $\begin{array}{l}\text { Gerschewski, Rose e } \\
\text { Lindsay (2015) }\end{array}$ & $\begin{array}{c}\text { Journal of World } \\
\text { Business }\end{array}$ \\
\hline $\begin{array}{l}\text { Strategies for superior performance under adverse } \\
\text { conditions: A focus on small and medium-sized high- } \\
\text { growth firms }\end{array}$ & $\begin{array}{c}\text { Bamiatzi e } \\
\text { Kirchmaier (2014) }\end{array}$ & $\begin{array}{l}\text { International Small } \\
\text { Business Journal }\end{array}$ \\
\hline Does location matter to export performance? & $\begin{array}{c}\text { Freeman e Styles } \\
(2014)\end{array}$ & $\begin{array}{c}\text { International Marketing } \\
\text { Review }\end{array}$ \\
\hline $\begin{array}{l}\text { The combined effects of IT and HRM capabilities on } \\
\text { competitive performance: Empirical evidence from } \\
\text { service and manufacturing SMEs }\end{array}$ & $\begin{array}{l}\text { Uwizeyemungu et al. } \\
\text { (2014) }\end{array}$ & $\begin{array}{l}\text { 20th Americas } \\
\text { Conference on } \\
\text { Information Systems }\end{array}$ \\
\hline $\begin{array}{l}\text { Quality performance of SMEs in a developing economy: } \\
\text { Direct and indirect effects of service innovation and } \\
\text { entrepreneurial orientation }\end{array}$ & $\begin{array}{l}\text { Oly Ndubisi e } \\
\text { Agarwal (2014) }\end{array}$ & $\begin{array}{l}\text { Journal of Business and } \\
\text { Industrial Marketing }\end{array}$ \\
\hline $\begin{array}{l}\text { Innovation orientations and their effects on business } \\
\text { performance: Contrasting small- and medium-sized } \\
\text { service firms }\end{array}$ & $\begin{array}{l}\text { Prajogo, McDermott e } \\
\text { McDermott (2013) }\end{array}$ & $\mathrm{R}$ and $\mathrm{D}$ Management \\
\hline Service innovation and performance in SMEs & $\begin{array}{l}\text { McDermott e Prajogo } \\
\text { (2012) }\end{array}$ & $\begin{array}{l}\text { International Journal of } \\
\text { Operations and } \\
\text { Production } \\
\text { Management }\end{array}$ \\
\hline $\begin{array}{l}\text { What are the factors that affect innovation in growing } \\
\text { SMEs? }\end{array}$ & Heimonen (2012) & $\begin{array}{l}\text { European Journal of } \\
\text { Innovation Management }\end{array}$ \\
\hline $\begin{array}{l}\text { Effects of SME collaboration on R\&D in the service } \\
\text { sector in open innovation }\end{array}$ & Suh e Kim (2012) & $\begin{array}{l}\text { Innovation: } \\
\text { Management, Policy } \\
\text { and Practice }\end{array}$ \\
\hline $\begin{array}{l}\text { The impact of advisory services on Iranian SME } \\
\text { performance: An empirical investigation of the role of } \\
\text { professional accountants }\end{array}$ & $\begin{array}{l}\text { Kamyabi e Devi } \\
\quad(2012)\end{array}$ & $\begin{array}{c}\text { South African Journal } \\
\text { of Business } \\
\text { Management }\end{array}$ \\
\hline $\begin{array}{l}\text { Clustering and the internationalisation of high technology } \\
\text { small firms in film and television }\end{array}$ & Cook e Pandit (2012) & $\begin{array}{l}\text { New Technology Based } \\
\text { Firms in the New } \\
\text { Millennium }\end{array}$ \\
\hline $\begin{array}{l}\text { Impact of Market Orientation and ICT on the } \\
\text { Performance of Rural Smaller Service Enterprises }\end{array}$ & $\begin{array}{l}\text { Polo Peña et al. } \\
\text { (2011) }\end{array}$ & $\begin{array}{c}\text { Journal of Small } \\
\text { Business Management }\end{array}$ \\
\hline $\begin{array}{l}\text { The impact of service } \mathrm{R} \& \mathrm{D} \text { on the performance of } \\
\text { Korean information communication technology small } \\
\text { and medium enterprises }\end{array}$ & $\begin{array}{l}\text { Lee, Kim e Lee } \\
\quad(2011)\end{array}$ & $\begin{array}{l}\text { Journal of Engineering } \\
\text { and Technology } \\
\text { Management - JET-M }\end{array}$ \\
\hline $\begin{array}{l}\text { National export-promotion programs as drivers of } \\
\text { organizational resources and capabilities: Effects on } \\
\text { strategy, competitive advantage, and performance }\end{array}$ & $\begin{array}{c}\text { Leonidou, } \\
\text { Palihawadana e } \\
\text { Theodosiou (2011) }\end{array}$ & $\begin{array}{l}\text { Journal of International } \\
\text { Marketing }\end{array}$ \\
\hline $\begin{array}{l}\text { The link between non-technological innovations and } \\
\text { technological innovation }\end{array}$ & Mothe e Thi (2010) & $\begin{array}{l}\text { European Journal of } \\
\text { Innovation Management }\end{array}$ \\
\hline $\begin{array}{l}\text { Measuring TQM implementation: A case study of } \\
\text { Malaysian SMEs }\end{array}$ & Abdullah (2010) & $\begin{array}{l}\text { Measuring Business } \\
\text { Excellence }\end{array}$ \\
\hline Small-business owners' knowledge and rural tourism & Hernández-Maestro, & Journal of Travel \\
\hline
\end{tabular}




\begin{tabular}{|c|c|c|}
\hline Título & Autor(es) e Ano & Fonte \\
\hline establishment performance in Spain & $\begin{array}{l}\text { Muñoz-Gallego e } \\
\text { Santos-Requejo } \\
(2009)\end{array}$ & Research \\
\hline $\begin{array}{l}\text { The role of human and financial capital in the } \\
\text { profitability and growth of women-owned small firms }\end{array}$ & Coleman (2007) & $\begin{array}{c}\text { Journal of Small } \\
\text { Business Management }\end{array}$ \\
\hline $\begin{array}{l}\text { Does innovation lead to performance? An empirical } \\
\text { study of SMEs in Taiwan }\end{array}$ & $\begin{array}{l}\text { Yeh-Yun Lin e Yi- } \\
\text { Ching Chen (2007) }\end{array}$ & $\begin{array}{l}\text { Management Research } \\
\text { News }\end{array}$ \\
\hline $\begin{array}{l}\text { Intellectual capital and corporate performance in } \\
\text { knowledge-intensive SMEs }\end{array}$ & $\begin{array}{l}\text { Cohen e Kaimenakis } \\
\text { (2007) }\end{array}$ & Learning Organization \\
\hline $\begin{array}{l}\text { An analysis of the relationship between TQM } \\
\text { implementation and organizational performance: } \\
\text { Evidence from Turkish SMEs }\end{array}$ & $\begin{array}{l}\text { Demirbag et al. } \\
\quad(2006)\end{array}$ & $\begin{array}{c}\text { Journal of } \\
\text { Manufacturing } \\
\text { Technology } \\
\text { Management }\end{array}$ \\
\hline Trade promotion and SME export performance & $\begin{array}{c}\text { Wilkinson e } \\
\text { Brouthers (2006) }\end{array}$ & $\begin{array}{c}\text { International Business } \\
\text { Review }\end{array}$ \\
\hline $\begin{array}{l}\text { Marketing practices and performance of small service } \\
\text { firms: An examination in the tourism accommodation } \\
\text { sector }\end{array}$ & $\begin{array}{l}\text { Coviello, Winklhofer } \\
\text { e Hamilton (2006) }\end{array}$ & $\begin{array}{l}\text { Journal of Service } \\
\text { Research }\end{array}$ \\
\hline $\begin{array}{l}\text { The role of resource commitment and innovation in } \\
\text { reverse logistics performance }\end{array}$ & $\begin{array}{l}\text { Richey, Genchev e } \\
\text { Daugherty (2005) }\end{array}$ & $\begin{array}{l}\text { International Journal of } \\
\text { Physical Distribution } \\
\text { and Logistics } \\
\text { Management }\end{array}$ \\
\hline $\begin{array}{l}\text { Co-alignment in the resource-performance relationship: } \\
\text { Strategy as mediator }\end{array}$ & $\begin{array}{l}\text { Edelman, Brush e } \\
\text { Manolova (2005) }\end{array}$ & $\begin{array}{c}\text { Journal of Business } \\
\text { Venturing }\end{array}$ \\
\hline $\begin{array}{l}\text { Identifying key determinants for new product } \\
\text { introductions and firm performance in small service firms }\end{array}$ & $\begin{array}{l}\text { Vermeulen, De Jong e } \\
\text { O'shaughnessy (2005) }\end{array}$ & $\begin{array}{l}\text { Service Industries } \\
\text { Journal }\end{array}$ \\
\hline $\begin{array}{l}\text { Small firm innovation, growth and performance: } \\
\text { Evidence from Scotland and Northern England }\end{array}$ & Freel e Robson (2004) & $\begin{array}{c}\text { International Small } \\
\text { Business Journal }\end{array}$ \\
\hline $\begin{array}{l}\text { The internationalization of new and small firms: A } \\
\text { resource-based view }\end{array}$ & $\begin{array}{l}\text { Westhead, Wright e } \\
\text { Ucbasaran (2001) }\end{array}$ & $\begin{array}{c}\text { Journal of Business } \\
\text { Venturing }\end{array}$ \\
\hline $\begin{array}{l}\text { Performance factors of small tourism ventures: The } \\
\text { interface of tourism, entrepreneurship and the } \\
\text { environment }\end{array}$ & Lerner e Haber (2001) & $\begin{array}{l}\text { Journal of Business } \\
\text { Venturing }\end{array}$ \\
\hline Learning orientations and growth in smaller firms & $\begin{array}{c}\text { Sadler-Smith, Spicer e } \\
\text { Chaston (2001) }\end{array}$ & Long Range Planning \\
\hline $\begin{array}{l}\text { Businesses without glamour? An analysis of resources on } \\
\text { performance by size and age in small service and retail } \\
\text { firms }\end{array}$ & $\begin{array}{l}\text { Brush e Chaganti } \\
\text { (1999) }\end{array}$ & $\begin{array}{l}\text { Journal of Business } \\
\text { Venturing }\end{array}$ \\
\hline $\begin{array}{l}\text { Small firms, innovation and regional development in } \\
\text { Britain in the } 1990 \mathrm{~s}\end{array}$ & Keeble (1997) & Regional Studies \\
\hline $\begin{array}{l}\text { Service quality and service productivity management } \\
\text { practices }\end{array}$ & $\begin{array}{l}\text { Filiatrault, Harvey e } \\
\text { Chebat (1996) }\end{array}$ & $\begin{array}{c}\text { Industrial Marketing } \\
\text { Management }\end{array}$ \\
\hline
\end{tabular}

Por meio da Figura 4, é possível observar a distribuição do número de estudos publicados no decorrer dos anos, a qual atingiu picos nos anos de $2012 \mathrm{e}$ 2017, com 5 publicações em cada, considerado um número pequeno que evidencia a lacuna desse tema de pesquisa na literatura. Dentre esses artigos, também foram identificados os mais citados (Tabela 1) e as principais fontes de publicação, ilustradas na Figura 5. 


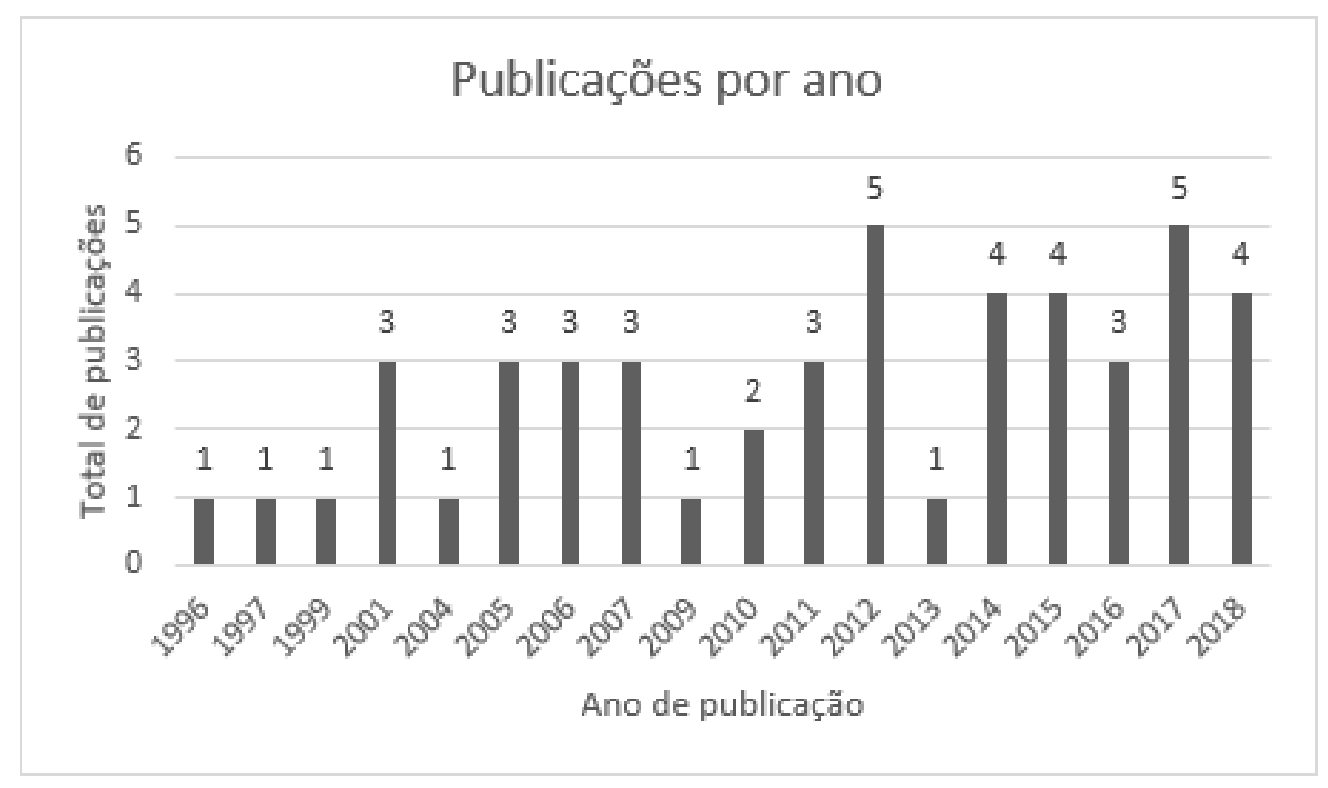

Figura 4 - Relação da quantidade de publicações por ano

Tabela 1 - Trabalhos com mais citações

\begin{tabular}{|c|c|c|}
\hline Autores & Título & Citações \\
\hline $\begin{array}{l}\text { Westhead et al. } \\
\text { (2001) }\end{array}$ & The internationalization of new and small firms: A resource-based view & 465 \\
\hline $\begin{array}{l}\text { Brush e Chaganti } \\
\text { (1999) }\end{array}$ & $\begin{array}{l}\text { Businesses without glamour? An analysis of resources on performance by } \\
\text { size and age in small service and retail firms }\end{array}$ & 129 \\
\hline $\begin{array}{l}\text { Demirbag et al. } \\
\text { (2006) }\end{array}$ & $\begin{array}{l}\text { An analysis of the relationship between TQM implementation and } \\
\text { organizational performance: Evidence from Turkish SMEs }\end{array}$ & 126 \\
\hline Coleman (2007) & $\begin{array}{l}\text { The role of human and financial capital in the profitability and growth of } \\
\text { women-owned small firms }\end{array}$ & 120 \\
\hline Richey et al. (2005) & $\begin{array}{l}\text { The role of resource commitment and innovation in reverse logistics } \\
\text { performance }\end{array}$ & 116 \\
\hline $\begin{array}{l}\text { Freel e Robson } \\
(2004)\end{array}$ & $\begin{array}{l}\text { Small firm innovation, growth and performance: Evidence from Scotland } \\
\text { and Northern England }\end{array}$ & 112 \\
\hline $\begin{array}{l}\text { Wilkinson e } \\
\text { Brouthers (2006) }\end{array}$ & Trade promotion and SME export performance & 112 \\
\hline $\begin{array}{l}\text { Edelman, Brush e } \\
\text { Manolova (2005) }\end{array}$ & $\begin{array}{l}\text { Co-alignment in the resource-performance relationship: Strategy as } \\
\text { mediator }\end{array}$ & 111 \\
\hline $\begin{array}{l}\text { Lerner e Haber } \\
(2001)\end{array}$ & $\begin{array}{l}\text { Performance factors of small tourism ventures: The interface of tourism, } \\
\text { entrepreneurship and the environment }\end{array}$ & 104 \\
\hline $\begin{array}{l}\text { Yeh-Yun Lin e Yi- } \\
\text { Ching Chen (2007) }\end{array}$ & $\begin{array}{l}\text { Does innovation lead to performance? An empirical study of SMEs in } \\
\text { Taiwan }\end{array}$ & 101 \\
\hline Keeble (1997) & Small firms, innovation and regional development in Britain in the 1990s & 95 \\
\hline $\begin{array}{l}\text { Cohen e Kaimenakis } \\
\text { (2007) }\end{array}$ & $\begin{array}{l}\text { Intellectual capital and corporate performance in knowledge-intensive } \\
\text { SMEs }\end{array}$ & 86 \\
\hline $\begin{array}{l}\text { Sadler-Smith et al. } \\
\text { (2001) }\end{array}$ & Learning orientations and growth in smaller firms & 75 \\
\hline
\end{tabular}




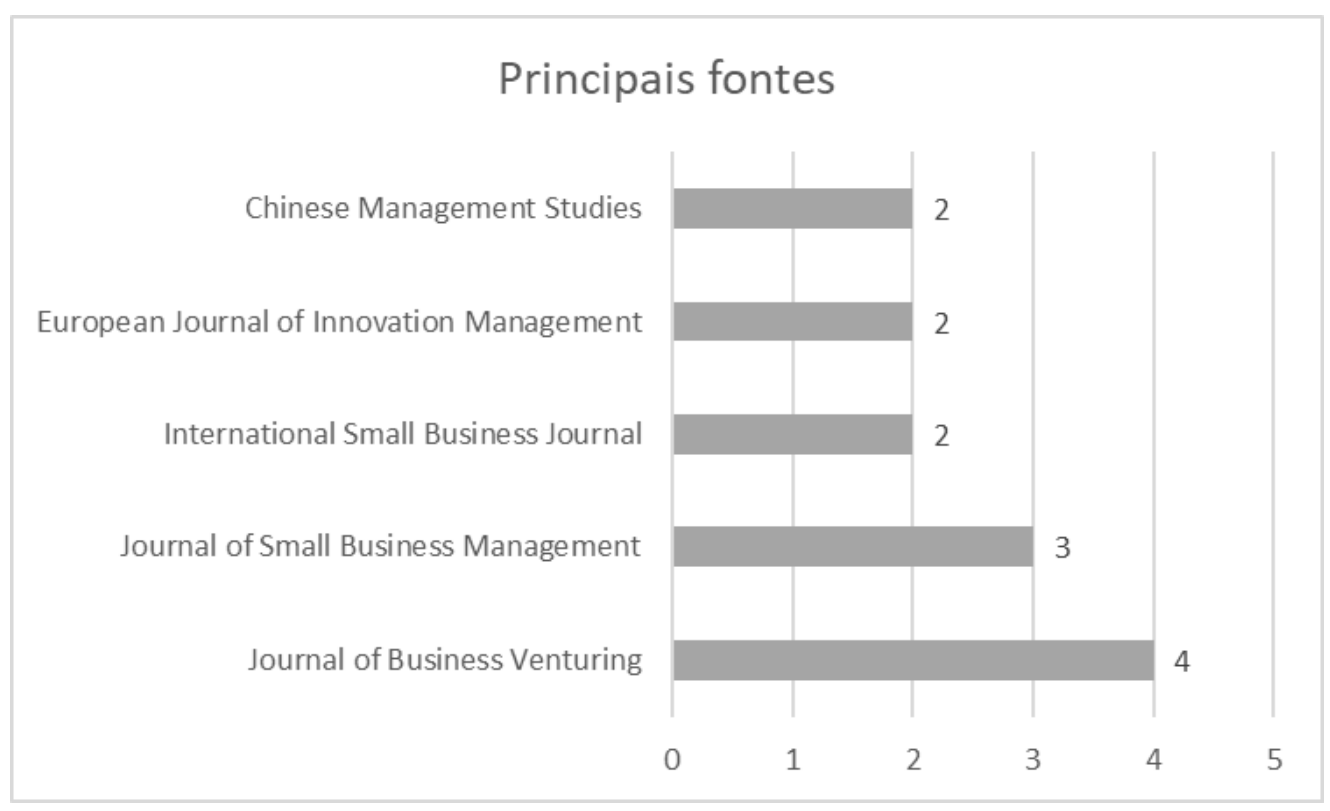

Figura 5 - Principais fontes de publicação

A partir da busca na literatura, dentre os 48 artigos, identificou-se que em 25 os recursos eram voltados à inovação, em 15 eram voltados à orientação ao mercado, sendo que apenas 3 estudos abordavam ambos temas juntos, e os restantes dividiam-se na abordagem de recursos voltados à qualidade, ao $\mathrm{P} \& \mathrm{D}$, marketing e expertise dos gerentes.

Assim, com a RSL identificou-se a inovação e a orientação ao mercado como os principais fatores determinantes frequentemente relacionados ao desempenho em pequenos negócios de serviços, como observa-se no Quadro 4.

Quadro 4 - Principais determinantes do desempenho operacional de serviço em pequenos negócios

\begin{tabular}{|c|c|}
\hline Determinantes & Referências \\
\hline $\begin{array}{l}\text { Inovação } \\
\text { Frequência: } 25 . \\
52 \% \text { da RSL. }\end{array}$ & $\begin{array}{l}\text { Lee e Hallak (2018); Alfoqahaa (2018); Exposito e Sanchis-llopis (2018); Ahmed } \\
\text { et al. (2018); Zhou et al. (2017); Saunila (2017a); Saunila (2017b); González- } \\
\text { Benito et al. (2016); Meutia (2015); Meutia e Ismail (2015); Bamiatzi e } \\
\text { Kirchmaier (2014); Oly Ndubisi e Agarwal (2014); Prajogo et al. (2013); } \\
\text { McDermott e Prajogo (2012); Heimonen (2012); Suh e Kim (2012); Cook e Pandit } \\
\text { (2012); Mothe e Thi (2010); Yeh-Yun Lin e Yi-Ching Chen (2007); Richey et al. } \\
\text { (2005); Edelman, Brush e Manolova (2005); Vermeulen et al. (2005); Freel e } \\
\text { Robson (2004); Keeble (1997). }\end{array}$ \\
\hline $\begin{array}{l}\text { Orientação ao } \\
\text { mercado } \\
\text { Frequência: } 15 . \\
31 \% \text { da RSL. }\end{array}$ & $\begin{array}{l}\text { Zhang et al. (2017); Campbell e Park (2017); Chen et al. (2016); Polo Peña et al. } \\
\text { (2016); Meutia e Ismail (2015); Carey (2015); Gerschewski et al. (2015); Oly } \\
\text { Ndubisi e Agarwal (2014); Kamyabi e Devi (2012); Cook e Pandit (2012); Polo } \\
\text { Peña et al. (2011); Leonidou et al. (2011); Wilkinson e Brouthers (2006); } \\
\text { Westhead et al. (2001). }\end{array}$ \\
\hline $\begin{array}{l}\text { Inovação e Orientação } \\
\text { ao mercado } \\
\text { Frequência: } 3 \text {. } \\
6 \% \text { da RSL. }\end{array}$ & Meutia e Ismail (2015); Oly Ndubisi e Agarwal (2014); Cook e Pandit (2012). \\
\hline
\end{tabular}


O resultado do Quadro 4, corrobora com a literatura ao identificar a inovação e a orientação ao mercado como parte dos principais determinantes para o desempenho operacional em pequenas empresas (Reis, 2018). É válido ressaltar que a inclusão da tecnologia como um dos principais determinantes, a partir do teste piloto do estudo de caso, também corrobora com a literatura (Reis, 2018). Logo, a identificação desses três determinantes responde a questão "Quais são os principais determinantes do desempenho operacional de serviço em pequenos negócios?" desta pesquisa.

Além disso, apenas 23 artigos se baseavam na teoria RBV (48\% da RSL) e nenhum estudo abordava o contexto do segmento de óleo e gás. Com base nos resultados da RSL, percebe-se a relevância do tema e que este estudo irá adicionar à literatura uma visão da relação entre inovação (fatores internos), orientação ao mercado (fatores externos) e desempenho operacional em serviços para pequenos negócios, mais especificamente do segmento de óleo e gás.

Por meio da RSL também foi possível identificar os facilitadores e barreiras ao desempenho em serviços dos pequenos negócios, evidenciados na Tabela 2, respondendo as questões "Quais são os fatores que favorecem um melhor desempenho em serviços de pequenos negócios? E quais são os obstáculos ao desempenho em serviços de pequenos negócios?” desta pesquisa.

Tabela 2 - Facilitadores e barreias ao desempenho de pequenos negócios em serviços

\begin{tabular}{|c|c|c|}
\hline Facilitadores & Frequência & Referências \\
\hline Qualidade & 8 & $\begin{array}{l}\text { Chen et al. (2016); Oly Ndubisi e Agarwal (2014); Polo Peña et al. } \\
\text { (2011); Abdullah (2010); Demirbag et al. (2006); Edelman, Brush e } \\
\text { Manolova (2005); Keeble (1997); Filiatrault et al. (1996). }\end{array}$ \\
\hline Capital humano & 8 & $\begin{array}{l}\text { Bamiatzi e Kirchmaier (2014); Coleman (2007); Lerner e Haber (2001); } \\
\text { Gerschewski et al. (2015); Oly Ndubisi e Agarwal (2014); Hernández- } \\
\text { Maestro (2009); Demirbag et al. (2006); Brush e Chaganti (1999). }\end{array}$ \\
\hline $\begin{array}{l}\text { Inovação de } \\
\text { produto/serviço }\end{array}$ & 7 & $\begin{array}{l}\text { Exposito e Sanchis-Llopis (2018); Meutia (2015); Meutia e Ismail } \\
\text { (2015); Gerschewski et al. (2015); Oly Ndubisi e Agarwal (2014); } \\
\text { McDermott e Prajogo (2012); Heimonen (2012). }\end{array}$ \\
\hline $\begin{array}{l}\text { Bons } \\
\text { relacionamentos } \\
\text { com os } \\
\text { stakeholders }\end{array}$ & 6 & $\begin{array}{l}\text { Zhang et al. (2017); Campbell e Park (2017); González-benito et al. } \\
\text { (2016); Meutia (2015); Freeman e Styles (2014); Leonidou et al. (2011). }\end{array}$ \\
\hline $\begin{array}{l}\text { Gestão estratégica } \\
\text { dos recursos }\end{array}$ & 5 & $\begin{array}{l}\text { Lee e Hallak (2018); Campbell e Park (2017); Wilkinson e Brouthers } \\
\text { (2006); Richey et al. (2005); Brush e Chaganti (1999). }\end{array}$ \\
\hline $\begin{array}{l}\text { Medição de } \\
\text { desempenho }\end{array}$ & 3 & Chen et al. (2016); Meutia (2015); Freeman e Styles (2014). \\
\hline $\begin{array}{l}\text { Capital social } \\
\text { (reputação, rede de } \\
\text { trabalho social etc.) }\end{array}$ & 3 & Alfoqahaa (2018); Meutia (2015); Campbell e Park (2017). \\
\hline $\begin{array}{l}\text { Análise do mercado } \\
\text { externo }\end{array}$ & 3 & $\begin{array}{l}\text { Lee e Hallak (2018); Leonidou et al. (2011); Yeh-Yun Lin e Yi-Ching } \\
\text { Chen (2007). }\end{array}$ \\
\hline
\end{tabular}




\begin{tabular}{|c|c|c|}
\hline Facilitadores & Frequência & Referências \\
\hline $\begin{array}{l}\text { Atender as } \\
\text { necessidades dos } \\
\text { clientes }\end{array}$ & 3 & Alfoqahaa (2018); Vermeulen et al. (2005); Brush e Chaganti (1999). \\
\hline Entrega & 3 & Alfoqahaa (2018); Polo Peña et al. (2016); Wilkinson e Brouthers (2006). \\
\hline $\mathrm{P} \& \mathrm{D}$ & 3 & Heimonen (2012); Suh e Kim (2012); Lee et al. (2011). \\
\hline Rede de negócios & 2 & Meutia (2015); Bamiatzi e Kirchmaier (2014). \\
\hline Informações (TI) & 2 & Chen et al. (2016); Uwizeyemungu et al. (2014). \\
\hline Flexibilidade & 2 & Richey et al. (2005); Vermeulen et al. (2005). \\
\hline Marketing & 2 & Leonidou et al. (2011); Coviello et al. (2006). \\
\hline Potenciais parceiros & 2 & González-benito et al. (2016); Wilkinson e Brouthers (2006). \\
\hline $\begin{array}{l}\text { Aspectos } \\
\text { comportamentais }\end{array}$ & 2 & Gerschewski et al. (2015); Oly Ndubisi e Agarwal (2014). \\
\hline $\begin{array}{l}\text { Responsabilidade } \\
\text { social corporativa }\end{array}$ & 1 & Campbell e Park (2017). \\
\hline Barreiras & Frequência & Referências \\
\hline Recursos limitados & 7 & $\begin{array}{l}\text { Campbell e Park (2017); Chen et al. (2016); Prajogo et al. (2013); } \\
\text { Heimonen (2012); Coleman (2007); Richey et al. (2005); Westhead et al. } \\
\text { (2001). }\end{array}$ \\
\hline $\begin{array}{l}\text { Funcionários } \\
\text { desqualificados }\end{array}$ & 6 & $\begin{array}{l}\text { Campbell e Park (2017); Meutia e Ismail (2015); Polo Peña et al. (2011); } \\
\text { Leonidou et al. (2011); Wilkinson e Brouthers (2006); Lerner e Haber } \\
\text { (2001). }\end{array}$ \\
\hline $\begin{array}{l}\text { Fraco } \\
\text { conhecimento / } \\
\text { força do mercado }\end{array}$ & 2 & Meutia e Ismail (2015); Wilkinson e Brouthers (2006). \\
\hline Forte concorrência & 1 & Wilkinson e Brouthers (2006). \\
\hline Baixa qualidade & 1 & Demirbag et al. (2006). \\
\hline Falta de informação & 1 & Westhead et al. (2001). \\
\hline Falta de cooperação & 1 & Campbell e Park (2017). \\
\hline $\begin{array}{l}\text { Ambiente de } \\
\text { negócio }\end{array}$ & 1 & Meutia e Ismail (2015). \\
\hline $\begin{array}{l}\text { Capitalização } \\
\text { inadequada }\end{array}$ & 1 & Coleman (2007). \\
\hline
\end{tabular}

Portanto, com os resultados da RSL, foi possível alcançar o primeiro objetivo específico desta pesquisa "identificar na literatura científica os principais determinantes, facilitadores e barreiras para o desempenho operacional de serviços dos pequenos negócios”.

\section{2 \\ Resultados obtidos com o estudo de caso}

$\mathrm{Na}$ análise dos resultados do estudo de caso múltiplo, primeiro foram feitas as análises intracasos, focada em cada empresa de forma individual, e posteriormente a análise intercasos, atingindo o segundo objetivo especifico da pesquisa "realizar a pesquisa de campo em diferentes organizações para observar 
e analisar os determinantes, facilitadores e barreiras no contexto operacional das empresas do estudo de caso".

Ressalta-se que em todas as análises foram utilizadas as técnicas descritas no método do estudo de caso, o que permitiu alcançar o terceiro objetivo especifico da pesquisa "identificar as similaridades, contrastes e lacunas sobre determinantes, facilitadores e barreiras existentes entre a literatura acadêmica com as práticas empresariais, a partir dos dados da pesquisa de campo".

É válido ressaltar também que com a análise de conteúdo, foi feito a codificação de dados e o Quadro 5 ilustra as informações gerais correspondentes às empresas e seus respectivos códigos para facilitar a compreensão ao longo do texto. A lista completa dos códigos utilizados na análise de conteúdo está no Apêndice 3.

Quadro 5 - Códigos das informações das empresas

\begin{tabular}{|l|l|}
\hline \multicolumn{1}{|c|}{ Informações gerais } & \multicolumn{1}{c|}{ Códigos } \\
\hline Empresa & organizaçãoA; organizaçãoB; organizaçãoC; organizaçãoD. \\
\hline Entrevista semiestruturada & entrevistadoA; entrevistadoB; entrevistadoC; entrevistadoD. \\
\hline Observação direta & obsA; obsB; obsC; obsD. \\
\hline Documentos e site & doc/siteA; doc/siteB; doc/siteC; doc/siteD. \\
\hline
\end{tabular}

\subsection{1}

Estudo de caso A

A organizaçãoA tem como principal atividade o desenvolvimento de soluções, e realiza também treinamentos e consultorias. A sua especialização em soluções ocorre em todas as etapas do processo (end-to-end), utilizando veículos não tripulados, como por exemplo drones, multirotores, entre outros. Dessa forma, a empresa atua em diferentes áreas do mercado, por exemplo em agronegócio, indústria, construção civil etc.

De acordo com as definições do Sebrae, é classificada como microempresa, sendo relatada como uma startup pelo entrevistado. Em relação ao segmento de petróleo, atua diretamente com o Sebrae há dois anos e os principais eventos que já participou do ou com Sebrae foram: Rio Oil \& Gas, Pitch para startups, Programas do Sebrae junto com Instituto Brasileiro do Petróleo (IBP), além de palestras. 
A entrevista foi realizada com o diretor da organização, no qual atua nesse cargo há três anos. O painel de dados da organizaçãoA é apresentado no Quadro 6. De acordo com o entrevistadoA e com doc/siteA da empresa, o tema inovação está presente nas suas operações, sendo um dos valores da organização. O tipo de inovação desenvolvido pela organizaçãoA é a inovação de processo, por incorporar novos equipamentos, melhorando significativamente os métodos para realizar os processos.

Um caso significativo de inovação da empresa no segmento de óleo e gás está em progresso, no qual melhora o processo de medição de espessura de tanques, incluindo drones para a automação da coleta de dados, que hoje é feita manualmente. Essa inovação foi fruto de uma necessidade de um cliente.

As principais fontes de informação para desenvolver essa inovação foram os clientes, concorrentes e parcerias, tendo uma interação com os mesmos do tipo de fontes abertas de informação. Além disso, na empresa há esforços de inovação, mas focados apenas nos seus recursos de inovação, não havendo esforços de recompensas pela inovação. Assim, o entrevistadoA relata que há recursos financeiros, humanos e materiais suficientes para desenvolver atividades de inovação, sendo que a empresa busca diversas fontes de financiamento além do capital próprio.

No que tange à orientação ao mercado, também apresentado no Quadro 6, a empresa considera as necessidades dos clientes na intenção de criar valor nos serviços, pois, de acordo com o entrevistadoA, primeiro é descoberto qual a necessidade do cliente para posteriormente desenvolver a solução. Em doc/siteA há também que um dos seus valores é o conhecimento das necessidades dos clientes, tendo assim uma orientação ao cliente. A organizaçãoA não tem muitos concorrentes, mas conhece os pontos fortes, fracos, capacidade e as estratégias tanto da concorrência quanto da própria empresa, tendo uma orientação ao concorrente. 
Quadro 6 - Painel de dados do estudo de caso A

\begin{tabular}{|c|c|c|c|c|}
\hline Fon $ळ$ de dados & Inovação & Orientação ao mercado & Desempenho operacional & Tecnologias disruptivas \\
\hline 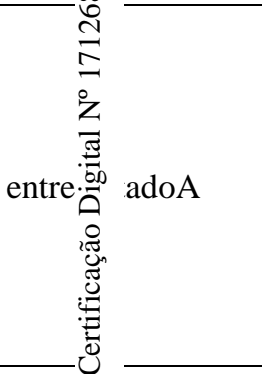 & $\begin{array}{l}\text { Realiza inovação de processo, implementado devido } \\
\text { à fatores externos (necessidades dos clientes). } \\
\text { Possui como principais fontes de informação para } \\
\text { inovar os clientes, concorrentes e organizações } \\
\text { parceiras. Há recursos financeiros, humanos e } \\
\text { materiais suficientes para o desenvolvimento de } \\
\text { atividades de inovação. Apesar de existir uma } \\
\text { cultura voltada à inovação, não há formalidade para } \\
\text { incentivo dos funcionários. }\end{array}$ & $\begin{array}{l}\text { Cria valor nos serviços atendendo as } \\
\text { necessidades do cliente e conhece os } \\
\text { pontos fracos, fortes, capacidades e } \\
\text { estratégias tanto da concorrência } \\
\text { quanto da própria empresa. Tem como } \\
\text { principal estratégia a diferenciação } \\
\text { para obter vantagem competitiva. Atua } \\
\text { como serviço substituto e não tem } \\
\text { força nas negociações. } \\
\end{array}$ & $\begin{array}{l}\text { Não há um sistema de medição } \\
\text { de desempenho. O desempenho } \\
\text { da empresa é medido por } \\
\text { captação de recurso versus } \\
\text { capital próprio. Tem as } \\
\text { dimensões de qualidade e de } \\
\text { inovação como as principais } \\
\text { para vantagem competitiva. }\end{array}$ & $\begin{array}{l}\text { O uso das tecnologias se dá por } \\
\text { necessidades externas (clientes) e internas } \\
\text { (investimento). Há integração das } \\
\text { mesmas, consideradas relevantes para o } \\
\text { desempenho. É um atrativo para grandes } \\
\text { empresas e investidores, são escaláveis e } \\
\text { tem potencial de redução de custo. Porém, } \\
\text { no Brasil o imposto é alto, são poucas } \\
\text { difundidas e há poucos profissionais. }\end{array}$ \\
\hline obsA过 & $\begin{array}{l}\text { Fornece inovação de processo, sendo inovação } \\
\text { própria ainda em progresso. Possui um } \\
\text { comportamento reativo, já que a inovação é voltada } \\
\text { para não perder mercado. Utiliza as fontes abertas } \\
\text { de informação. }\end{array}$ & & & \\
\hline doc/siteA & $\begin{array}{l}\text { Um dos valores da empresa é inovação como } \\
\text { diferencial competitivo. Utilizam tecnologia para } \\
\text { equipamentos inovadores. }\end{array}$ & $\begin{array}{l}\text { Um dos valores da empresa é o } \\
\text { conhecimento das necessidades dos } \\
\text { clientes. Assim, a empresa adequa } \\
\text { diferentes soluções de acordo com os } \\
\text { desejos do cliente. }\end{array}$ & & $\begin{array}{l}\text { A tecnologia é incorporada nas soluções } \\
\text { para gerar valor nos serviços. }\end{array}$ \\
\hline Síntese & $\begin{array}{l}\text { Apesar da inovação estar incorporada na visão } \\
\text { estratégica da empresa, o mercado é que gera a } \\
\text { necessidade de inovar. Com a inovação, procura } \\
\text { criar um diferencial competitivo, utilizando } \\
\text { tecnologias e equipamentos que agregam valor nos } \\
\text { seus serviços. Há esforços de inovação, com foco } \\
\text { maior nos recursos de inovação do que recompensas } \\
\text { pela inovação. }\end{array}$ & $\begin{array}{l}\text { Possui conhecimento voltado ao } \\
\text { mercado, tanto dos clientes quanto dos } \\
\text { concorrentes. A orientação ao cliente } \\
\text { está incorporada na visão estratégica } \\
\text { da empresa e é a que mais impulsiona } \\
\text { a inovação, e a orientação ao } \\
\text { concorrente tem a diferenciação como } \\
\text { principal estratégia para obter } \\
\text { vantagens. }\end{array}$ & $\begin{array}{l}\text { É usado um indicador } \\
\text { financeiro para obter o } \\
\text { desempenho da empresa, mas } \\
\text { não há indicadores } \\
\text { operacionais referentes às cinco } \\
\text { dimensões. Para a vantagem } \\
\text { competitiva, qualidade e } \\
\text { inovação são considerados } \\
\text { muito importantes, enquanto o } \\
\text { custo como não importante. }\end{array}$ & $\begin{array}{l}\text { Utiliza-se a tecnologia para inovação, o } \\
\text { que agrega valor no serviço, oriunda de } \\
\text { necessidades internas ou do mercado. }\end{array}$ \\
\hline
\end{tabular}


A vantagem que a empresa possui tanto em relação aos novos entrantes quanto à rivalidade entre os concorrentes é a diferenciação, principalmente diferenciação por qualidade. No mercado, a organizaçãoA atua como serviços substitutos, oferecendo um serviço que executa a mesma função dos concorrentes, porém por meios diferentes. Tanto no poder de negociação dos compradores quanto que no poder de negociação dos fornecedores, a empresa não possui força para negociar, são os clientes e os fornecedores que detêm mais valor.

Em relação às tecnologias disruptivas, também apresentado no Quadro 6, dentre as 9 principais identificadas na literatura, a organizaçãoA utiliza todas elas, algumas com mais ênfase que outras. De acordo com o entrevistadoA, os principais motivos para implementar essas tecnologias foram as necessidades dos clientes e dos investidores, no caso a própria empresa.

A organizaçãoA procura utilizar a tecnologia mais moderna em soluções. Assim, enquanto a maioria das empresas trabalham com uma ou outra, poucas empresas como a organizaçãoA realizam a integração delas. Com essas tecnologias, os clientes recebem as informações em uma plataforma online e estas informações, organizadas, passam a gerar valor para os seus negócios.

Algumas barreiras para a adoção dessas tecnologias foram citadas pelo entrevistadoA, como: são poucas difundidas no Brasil, especificamente; não tem profissionais ou são muito caros; o imposto é muito alto. Além disso, alguns facilitadores para adoção dessas tecnologias também foram relatados: são muito atrativas para grandes empresas e investidores, pois são altamente escaláveis e tem potencial de redução de custo enorme.

Em relação ao desempenho operacional, a organizaçãoA não possui um sistema de medição de desempenho, portanto, de acordo com o entrevistadoA, o seu desempenho é medido por captação de recurso versus capital próprio, tendo que ter uma proporção acima de 3 para 1. Apesar de não ser realizado medições, o entrevistadoA apontou que dentre as cincos principais dimensões de desempenho operacional em serviços, apenas o custo não é importante para vantagem competitiva da empresa, enquanto ressalta duas como principais: qualidade e inovação.

Sobre dimensão da qualidade, o entrevistadoA afirma: "apesar de não termos parâmetros, em relação ao status quo do mercado, a qualidade dos nossos serviços definitivamente melhorou, porque é mais rápido e mais fácil”. A empresa 
utiliza um formulário pós-venda como ferramenta para medir o nível de satisfação dos clientes em relação à qualidade do atendimento.

Em relação à dimensão da inovação, a empresa consegue aumentar a sua capacidade em desenvolver novos serviços. Além disso, o entrevistadoA relatou que a empresa também se preocupa com a dimensão da flexibilidade em termos de entrega, já que não personalizam por cliente e eles recebem praticamente os mesmos serviços.

Por fim, no Quadro 7 é apresentado quais dos facilitadores e barreiras ao desempenho de pequenos negócios em serviços, presentes na literatura, a empresa enfrenta na prática, identificados pelo entrevistadoA, no qual não sugeriu inclusão de outros facilitadores ou barreiras na pesquisa.

Quadro 7 - Facilitadores e barreiras ao desempenho do estudo de caso A

\begin{tabular}{|c|}
\hline Facilitadores \\
\hline Informações (TI) \\
Qualidade \\
\hline Inovação de produto/serviço \\
\hline $\begin{array}{c}\text { Aspectos comportamentais (posturas inovadoras, proatividade, comprometimento, } \\
\text { perspectiva de longo prazo, autonomia, experiência, liderança) }\end{array}$ \\
\hline Rede de negócios \\
\hline Flexibilidade \\
\hline Bons relacionamentos com os stakeholders \\
\hline Atender as necessidades dos clientes \\
\hline Barreiras \\
\hline Recurso limitado (financeiro) \\
\hline Funcionários desqualificados \\
\hline Capitalização inadequada \\
\hline Ambiente de negócio \\
\hline Fraco conhecimento / força do mercado \\
\hline
\end{tabular}

\subsection{2}

\section{Estudo de caso B}

A organização B é especializada em monitoramento ocupacional e ambiental com alto grau de complexidade, atuando principalmente na área de saúde, segurança do trabalho e meio ambiente. É uma empresa de consultoria, medição, pericia, auditoria e treinamento, tendo a consultoria como uma das suas principais atividades. Classificada pelo SEBRAE como empresa de pequeno porte, desde 1999 oferece estudos e soluções de tecnologia da informação, instrumentação e automação. 
Em relação ao segmento de petróleo e gás, atua diretamente com o Sebrae desde 2005 e os principais eventos que já participou do ou com Sebrae recentemente foram: Offshore Technology Conference (OTC) e Feira Macaé Offshore. Além disso, a empresa está entre os fundadores e membros da Rede Petro Rio, assim, participam continuamente tanto em programas de capacitação de fornecedores do Sebrae quanto da Rede Petro Rio.

A entrevista foi realizada com o diretor executivo da organização, no qual atua nesse cargo desde 1999. O painel de dados da organizaçãoB é apresentado no Quadro 8. De acordo com o entrevistadoB e com doc/siteB da empresa, o tema inovação está presente nas suas operações, tendo publicado livros nesse tema no setor de petróleo e gás sobre instrumentação, automação, segurança do trabalho e meio ambiente. Além disso, em 2017 a empresa destacou-se por uma solução inovadora referente à poluição sonora.

O tipo de inovação desenvolvido pela organizaçãoB é a inovação de serviço, por melhorá-los significativamente em relação à sua funcionalidade. O entrevistadoB relata que a empresa consegue oferecer um serviço diferenciado com garantia técnica e garantia legal. Atender uma área que demanda uma necessidade de serviços especiais é o que motiva a empresa para implementar as inovações.

Assim, com as inovações, a organizaçãoB consegue manter e conquistar mais mercado, aumentando sua capacidade competitiva e adição de valor nos serviços. As principais fontes de informação para desenvolver inovações são organizações parceiras, SEBRAE e internet. Os trabalhos com as parcerias ocorrem de forma formal e não-formal, sendo que há uma troca de conhecimento maior com as parcerias não-formais. E com o SEBRAE, a empresa consegue entender o que as empresas âncoras do setor de óleo e gás desejam.

Na empresa há esforços de inovação, mas focados apenas nos seus recursos de inovação, não havendo esforços de recompensas pela inovação. Assim, o entrevistadoB relata que há recursos financeiros suficiente para desenvolver novos serviços, o capital próprio é a sua principal fonte de financiamento para inovação, possuindo diversas marcas e patentes no setor de óleo e gás, além de participar da Rede Petro Rio, também há recursos humanos e materiais suficientes para desenvolver atividades de inovação. 
Quadro 8 - Painel de dados do estudo de caso B

\begin{tabular}{|c|c|c|c|c|}
\hline $\begin{array}{c}\text { Fon } \\
\text { da }\end{array}$ & Inovação & Orientação ao mercado & Desempenho operacional & Tecnologias disruptivas \\
\hline 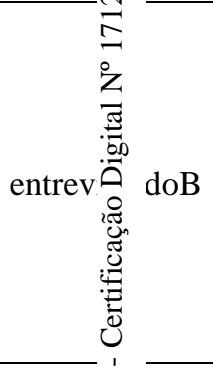 & $\begin{array}{l}\text { Realiza inovação de serviço, implementado } \\
\text { devido à fatores externos (desejo do mercado), } \\
\text { gerando a manutenção e conquista de mercado. } \\
\text { Possui como principais fontes de informação } \\
\text { para inovar a internet, SEBRAE e } \\
\text { organizações parceiras. Há recursos } \\
\text { financeiros, humanos e materiais suficientes } \\
\text { para o desenvolvimento de atividades de } \\
\text { inovação. }\end{array}$ & $\begin{array}{l}\text { Realiza pesquisa de mercado antes de lançar um } \\
\text { serviço novo. Tem uma adaptação e dinâmica de } \\
\text { trabalho rápidos para mudanças das necessidades } \\
\text { do mercado. Considera as necessidades dos } \\
\text { clientes na prestação ou criação de serviços. Não } \\
\text { há muitos concorrentes por motivos de preço e } \\
\text { inovação. Usa parcerias, diferenciação e criação de } \\
\text { valor como estratégias para obter vantagens } \\
\text { competitivas. }\end{array}$ & $\begin{array}{l}\text { Não há um sistema de medição de } \\
\text { desempenho. O desempenho da empresa é } \\
\text { medido pela rentabilidade. Maior ênfase } \\
\text { nas dimensões de qualidade e de inovação } \\
\text { para vantagem competitiva. Devido à } \\
\text { inovação e tecnologia houve redução nos } \\
\text { custos, aumento da qualidade dos serviços } \\
\text { e aumento da capacidade de personalizar } \\
\text { e desenvolver novos serviços. } \\
\end{array}$ & $\begin{array}{l}\text { Desde sua origem a empresa } \\
\text { utiliza e desenvolve tecnologia } \\
\text { com o objetivo de agregar valor } \\
\text { ao serviço (necessidade } \\
\text { interna). Considera o governo } \\
\text { como uma barreira para sua } \\
\text { utilização e os órgãos de } \\
\text { fomento, como SEBRAE, } \\
\text { como facilitadores. }\end{array}$ \\
\hline obsB & $\begin{array}{l}\text { Fornece inovações de serviços, sendo } \\
\text { inovações próprias e bem-sucedidas. Possui } \\
\text { um comportamento proativo, já que a inovação } \\
\text { é voltada para ganhar mercado. Utiliza as } \\
\text { fontes abertas de informação, aquisição de } \\
\text { conhecimentos e tecnologia, e inovação } \\
\text { cooperativa. }\end{array}$ & & $\begin{array}{l}\text { Ambiente integrado com disponibilização } \\
\text { de diversos materiais para os clientes. }\end{array}$ & \\
\hline doc/siteB & $\begin{array}{l}\text { Detentora de diversas marcas e patentes. } \\
\text { Participante em Programas de Capacitação de } \\
\text { Fornecedores do SEBRAE e da Rede Petro } \\
\text { Rio. Inova com os cursos prestados e nos } \\
\text { serviços periciais, atendendo as novas } \\
\text { tendências. Destaque 2017: solução inovadora } \\
\text { referente à poluição sonora. Modelo de } \\
\text { trabalho com três pilares no processo inovador: } \\
\text { empresa, fornecedores/laboratórios e clientes. } \\
\text { Mantem parcerias de desenvolvimento com } \\
\text { universidades e empresas internacionais. }\end{array}$ & A missão da empresa é a satisfação dos clientes. & $\begin{array}{l}\text { Satisfação dos clientes como missão. } \\
\text { Motivação para a busca contínua da } \\
\text { excelência nos relacionamentos } \\
\text { comerciais, qualidade do serviço, } \\
\text { melhoria da eficácia dos serviços e do } \\
\text { sistema de gestão de qualidade. }\end{array}$ & $\begin{array}{l}\text { Desde sua origem desenvolve } \\
\text { tecnologias que hoje são } \\
\text { referências nas áreas de } \\
\text { atuação. Pioneira no uso de } \\
\text { drones na área de SST, com } \\
\text { tecnologia e automação. }\end{array}$ \\
\hline
\end{tabular}




\begin{tabular}{|c|c|c|c|c|}
\hline $\begin{array}{r}\text { Fon } \\
\text { da }\end{array}$ & Inovação & Orientação ao mercado & Desempenho operacional & Tecnologias disruptivas \\
\hline Sintesi⿺ & $\begin{array}{l}\text { A inovação está incorporada no modelo de } \\
\text { trabalho da empresa, mas o mercado é que gera } \\
\text { a necessidade de inovar. Com a inovação, } \\
\text { procura manter e ganhar mercado, utilizando } \\
\text { tecnologias e equipamentos que agregam valor } \\
\text { nos seus serviços. Na empresa há esforços de } \\
\text { inovação, mas focados apenas nos seus } \\
\text { recusos de inovação, não havendo esforços de } \\
\text { recompensas pela inovação. }\end{array}$ & $\begin{array}{l}\text { Possui conhecimento voltado ao mercado, tanto } \\
\text { que faz pesquisa de mercado para implementar } \\
\text { novos serviços. Tem foco maior na orientação ao } \\
\text { cliente, que está incorporada na visão estratégica } \\
\text { da empresa, e não há uma orientação ao } \\
\text { concorrente, uma vez que não tem muita } \\
\text { concorrência no mercado. Apesar disso, usa } \\
\text { parcerias, diferenciação e criação de valor como } \\
\text { estratégias para obter vantagens. }\end{array}$ & $\begin{array}{l}\text { É usado um indicador financeiro para } \\
\text { obter o desempenho da empresa, mas não } \\
\text { há indicadores operacionais referentes às } \\
\text { cinco dimensões. Mas há uma ênfase na } \\
\text { dimensão da qualidade, que está } \\
\text { incorporada na visão estratégica da } \\
\text { empresa, para vantagem competitiva. }\end{array}$ & $\begin{array}{l}\text { A empresa utiliza a tecnologia } \\
\text { por necessidades internas, afim } \\
\text { de agregar valor no serviço. }\end{array}$ \\
\hline
\end{tabular}


Em relação à orientação ao mercado, a organizaçãoB procura atender as necessidades que o mercado demanda, com uma dinâmica de trabalho e adaptação rápidas às necessidades do nicho que atua. $\mathrm{O}$ entrevistadoB relatou: "nós fazemos pesquisa de mercado antes de lançarmos um produto ou serviço novo, portanto só lançamos quando sabemos que dará certo".

Segundo o entrevistadoB, a empresa considera as necessidades dos clientes na prestação ou criação de serviços, e em doc/siteB uma das missões da companhia é a satisfação dos clientes, tendo uma orientação voltada ao cliente. A empresa não tem muitos concorrentes e, assim, usam as parcerias com grandes e pequenas empresas como estratégia para obter vantagens competitivas.

As vantagens que a empresa possui tanto em relação aos novos entrantes quanto à rivalidade entre os concorrentes são em relação ao custo e à inovação. No mercado, a organizaçãoB utiliza a agregação de valor como estratégia para superar os serviços substitutos aos seus existentes no mercado. A empresa que detém maior poder de negociação na venda e um dos principais fatores levados em consideração na hora de negociar é a diferenciação. Já em relação ao poder de negociação dos fornecedores, não há uma relação muito forte com fornecedores, pois o entrevistadoB é representante da maioria dos materiais que a empresa utiliza.

No que tange às tecnologias disruptivas, dentre as 9 principais identificadas na literatura, a organizaçãoB utiliza 5, sendo: internet das coisas, inteligência artificial, interface das coisas, big data e design digital, simulação e integração. De acordo com o entrevistadoB, o principal motivo para implementar essas tecnologias foi para agregar valor ao serviço. A organizaçãoB desde sua origem utiliza e desenvolve tecnologia em suas soluções. Uma barreira citada pelo entrevistadoB para a adoção dessas tecnologias foi o governo e um facilitador são os órgãos de fomento, como o SEBRAE.

Em relação ao desempenho operacional, a organizaçãoB não possui um sistema de medição de desempenho, o entrevistadoB afirma: "trabalhamos com uma visão macro do desempenho, então para sabermos o desempenho da empresa avaliamos a rentabilidade". Apesar de não ser realizado medições, o entrevistadoB apontou que todas as cincos dimensões de desempenho operacional em serviços são consideradas importantes para a vantagem competitiva da empresa, ressaltando duas com maior ênfase: qualidade e inovação. 
Na dimensão de qualidade, o entrevistadoB relata que devido à inovação e tecnologia houve um aumento da qualidade dos serviços, porém não usa nenhuma ferramenta para medir o nível de satisfação dos clientes em relação à qualidade do atendimento e do ambiente físico da empresa. Em inovação, também foi dito que houve aumento da capacidade da empresa para personalizar e/ou desenvolver novos serviços devido à inovação e tecnologia, além de ganhar e criar conhecimentos.

Já sobre as demais dimensões, na entrega geralmente ocorrem atrasos por parte da empresa, não atendendo o prazo. Entretanto, o entrevistadoB ressalta que esses atrasos não ocorrem para todos os clientes, alguns são priorizados. Sobre flexibilidade, a empresa necessita tratar os clientes de forma individualizada. E em custos, há o conhecimento de quanto custa realizar um serviço e esse custo está igual ao esperado, além de ter ocorrido redução de custos devido aos esforços de inovação e uso de tecnologias.

Por fim, no Quadro 9 é apresentado quais dos facilitadores e barreiras ao desempenho de pequenos negócios em serviços, presentes na literatura, a empresa enfrenta na prática, identificados pelo entrevistadoB, que sugeriu a inclusão da “área de compras das empresas” como uma barreira.

Quadro 9 - Facilitadores e barreiras ao desempenho do estudo de caso B

\begin{tabular}{|c|}
\hline Facilitadores \\
\hline Gestão estratégica dos recursos \\
\hline Capital humano \\
\hline Responsabilidade social corporativa \\
\hline Informações (TI) \\
\hline Qualidade \\
\hline Atender as necessidades dos clientes \\
\hline Inovação de produto/serviço \\
\hline Flexibilidade \\
\hline Potenciais parceiros \\
\hline Rede de negócios \\
\hline Barreiras \\
\hline Funcionários desqualificados \\
\hline Falta de cooperação \\
\hline Área de compras das empresas \\
\hline
\end{tabular}

\subsection{3}

\section{Estudo de caso C}


A organizaçãoC é focada em soluções industriais, atuando em diferentes áreas como óleo e gás, energia, construção civil, entre outros. É uma empresa especializada em prestação de serviços de altura, como inspeções, pinturas, manutenções etc., e, de acordo com as definições do SEBRAE, é classificada como empresa de pequeno porte.

Além disso, possui um sistema de gestão integrado, em conformidade com as normas ISO 9001:2008 (Qualidade), ISO 14001:2004 (Meio Ambiente) e OHSAS 18001:2007 (Segurança e Saúde Ocupacional), certificado pela Associação Brasileira de Normas Técnicas (ABNT).

Em relação ao segmento de petróleo e gás, atua diretamente com o SEBRAE/RJ há mais de quatro anos, participando de vários eventos, sendo um dos principais o programa Sebraetec.

A entrevista foi realizada com o diretor comercial, no qual atua nesse cargo há mais de seis anos. O painel de dados da organizaçãoC é apresentado no Quadro 10. De acordo com o entrevistadoC e com doc/siteC da empresa, o tema inovação está presente nas suas operações, sendo parte da missão da organização. Os tipos de inovações desenvolvidos pela organizaçãoC são inovações de serviços e processos. O entrevistadoC relata: "estamos buscando inovações e tecnologias, mas estamos no início".

A organizaçãoC participa de um projeto de inovação, que ainda está em progresso, atuando como parceiro comercial, sendo o representante comercial no Rio de Janeiro, que consiste no desenvolvimento de uma tecnologia que processa resíduos sólidos transformando-os em biogás. $\mathrm{O}$ entrevistadoC relata que apesar do projeto não ter sido desenvolvido pela empresa, há um grande envolvimento e engajamento na sua parceria, pois engloba inovação, tecnologia e sustentabilidade, fatores que estão presentes na visão estratégica da empresa. Além disso, o entrevistadoC afirma: "um dos motivos por estarmos envolvidos nesse projeto é que enxergamos muito potencial de crescimento em escala". 
Quadro 10 - Painel de dados do estudo de caso C

\begin{tabular}{|c|c|c|c|c|c|}
\hline $\begin{array}{r}\text { Fol } \\
\text { d }\end{array}$ & $\begin{array}{l}\text {; de } \\
\text { os }\end{array}$ & Inovação & Orientação ao mercado & Desempenho operacional & Tecnologias disruptivas \\
\hline entre & 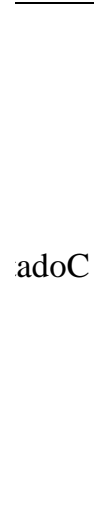 & $\begin{array}{l}\text { O desenvolvimento de inovações ainda está no } \\
\text { início e a sua busca possui o objetivo de } \\
\text { crescimento no mercado. Realiza inovação de } \\
\text { processo em parceria. As principais fontes de } \\
\text { informações para inovar são as organizações } \\
\text { parceiras e SEBRAE. Considera que há recursos } \\
\text { humanos e materiais para desenvolver } \\
\text { atividades de inovação, mas que poderia ser } \\
\text { melhor, e que há recursos financeiros } \\
\text { suficientes. Incentiva os funcionários a trazerem } \\
\text { novidades e desenvolverem inovações, mas de } \\
\text { forma não-oficializada. Desenvolve novos } \\
\text { serviços com inovações focado em qualidade. }\end{array}$ & $\begin{array}{l}\text { A empresa sempre considera as necessidades } \\
\text { dos clientes na prestação ou criação de } \\
\text { serviços. Existem muitos concorrentes, mas a } \\
\text { empresa não conhece os pontos fortes e } \\
\text { fracos, capacidade e estratégias da sua } \\
\text { concorrência para usá-los na obtenção de } \\
\text { vantagens. As estratégias utilizadas para } \\
\text { obter vantagens competitivas no mercado são } \\
\text { preço enxuto, flexibilidade e diferenciação no } \\
\text { atendimento, com segurança, qualidade e } \\
\text { cumprimento dos requisitos das normas. }\end{array}$ & $\begin{array}{l}\text { Existe um sistema de medição de desempenho, } \\
\text { tendo indicadores financeiros, de recursos } \\
\text { humanos, de performance e logística, e } \\
\text { relacionados ao meio ambiente. Dentre as cinco } \\
\text { principais dimensões, não há indicadores de } \\
\text { inovação e o foco maior é dado para qualidade, } \\
\text { custo e entrega. Com inovações, parte de } \\
\text { processos foram agilizados, o que aumentou a } \\
\text { velocidade de entrega e permitiu rastreabilidade, } \\
\text { também ocorreu uma pequena redução interna de } \\
\text { gastos com materiais e distribuição e aumentou a } \\
\text { qualidade dos serviços. }\end{array}$ & $\begin{array}{l}\text { A empresa ainda está no } \\
\text { início do uso de } \\
\text { tecnologias disruptivas. } \\
\text { Todas com as quais } \\
\text { trabalham no momento } \\
\text { são de parceiros. É feita a } \\
\text { integração com esses } \\
\text { parceiros com objetivo de } \\
\text { ser diferenciado no } \\
\text { mercado (necessidade } \\
\text { externa), oferecendo } \\
\text { soluções mais completas. }\end{array}$ \\
\hline obsC & & $\begin{array}{l}\text { Realiza inovação de serviços, com as atividades } \\
\text { de inovação ainda em progresso. As inovações } \\
\text { implementadas são adotadas, que foram geradas } \\
\text { por outras organizações. Possui um } \\
\text { comportamento proativo, buscando ganhar } \\
\text { mercado. Interage com stakeholders para } \\
\text { inovação cooperativa. }\end{array}$ & & $\begin{array}{l}\text { Possui um sistema de gestão integrado, em } \\
\text { conformidade com as normas ISO 9001:2008, } \\
\text { ISO 14001:2004 e OHSAS 18001:2007. } \\
\text { Ambiente integrado. Equipamentos evidentes, } \\
\text { com preocupação pela segurança do trabalho. }\end{array}$ & \\
\hline
\end{tabular}


(continua)

\begin{tabular}{|c|c|c|c|c|}
\hline $\begin{array}{c}\text { Folల ; de } \\
\text { dळo is }\end{array}$ & Inovação & Orientação ao mercado & Desempenho operacional & Tecnologias disruptivas \\
\hline doc/s: & $\begin{array}{l}\text { Oferece um atendimento diferenciado. Tem } \\
\text { como missão atuar de forma inovadora nos } \\
\text { setores em que está inserida, oferecendo } \\
\text { soluções objetivas e superando as expectativas } \\
\text { do mercado, gerando valor para os clientes, } \\
\text { acionistas, equipes e sociedade. }\end{array}$ & $\begin{array}{l}\text { Tem como visão ser referência global nos } \\
\text { mercados de atuação. Se compromete a ter } \\
\text { uma equipe atenta às necessidades do cliente, } \\
\text { estabelecer canal direto de relacionamento } \\
\text { estreito com cliente e equipe. Tem como } \\
\text { valores que o relacionamento com cliente e } \\
\text { colaboradores tenha transparência e } \\
\text { responsabilidade baseadas na confiança entre } \\
\text { as partes. Possui um setor específico para o } \\
\text { desenvolvimento de estratégias de mudança } \\
\text { para os mercados em que atua, frente a } \\
\text { evolução constante e contínua dos ambientes, } \\
\text { tecnologias e relações de trabalho. }\end{array}$ & $\begin{array}{l}\text { Com a sua política do sistema de gestão } \\
\text { integrada, há o comprometimento de fortalecer e } \\
\text { capacitar os funcionários e estabelecer canal } \\
\text { direto de relacionamento com cliente. Em todas } \\
\text { as atividades da empresa existe a preocupação } \\
\text { com a qualidade dos serviços, garantindo o } \\
\text { cumprimento dos prazos estabelecidos com } \\
\text { segurança e qualidade. Tem como foco a redução } \\
\text { de prazos, juntamente com a segurança, } \\
\text { qualidade e responsabilidade no cumprimento de } \\
\text { contratos. }\end{array}$ & $\begin{array}{l}\text { Devido a evolução } \\
\text { constante e } \\
\text { tecnologias }\end{array}$ \\
\hline Síntese & $\begin{array}{l}\text { Apesar da inovação estar incorporada na visão } \\
\text { estratégica da empresa, o mercado é que gera a } \\
\text { necessidade de inovar. Com a inovação, procura } \\
\text { ganhar mercado e criar um diferencial } \\
\text { competitivo, agregando valor nos seus serviços. } \\
\text { Os esforços de inovação são feitos com maior } \\
\text { foco nos recursos de inovação, mas os esforços } \\
\text { de recompensa pela inovação não são } \\
\text { oficializados pela empresa, por mais que haja } \\
\text { incentivo para tal. }\end{array}$ & $\begin{array}{l}\text { Possui conhecimento voltado ao mercado, } \\
\text { que é o que impulsiona a inovação. Tem uma } \\
\text { orientação ao cliente, está incorporada na } \\
\text { visão estratégica da empresa. Mas não há } \\
\text { uma orientação ao concorrente, apesar de } \\
\text { haver grande concorrência no mercado. } \\
\text { Apesar disso, utiliza preço enxuto, } \\
\text { flexibilidade e diferenciação no atendimento, } \\
\text { para obter vantagens. }\end{array}$ & $\begin{array}{l}\text { Devido ao sistema de gestão integrado que a } \\
\text { empresa possui, existem indicadores para obter o } \\
\text { desempenho operacional. A principal dimensão } \\
\text { de desempenho para a empresa é a qualidade, } \\
\text { que está incorporada na sua visão estratégica. E } \\
\text { não há indicadores do desempenho de inovação. }\end{array}$ & $\begin{array}{l}\text { Devido às necessidades } \\
\text { do mercado, a empresa } \\
\text { procura utilizar } \\
\text { tecnologias disruptivas, } \\
\text { mas ainda está no início } \\
\text { dessa implementação, } \\
\text { portanto, usufrui de } \\
\text { tecnologias de empresas } \\
\text { parceiras para conseguir } \\
\text { diferenciação no mercado. }\end{array}$ \\
\hline
\end{tabular}


A principal fonte de informação para desenvolver esse projeto de inovação foi direto com o proprietário. O entrevistadoC relata: "foi apresentado um relatório de caracterização do petróleo que se enquadra nas normas, hoje em dia fazem biocombustível da soja, isso é um custo muito alto, então essa tecnologia permite você chegar a um diesel mais barato, além de ser sustentável”.

Outra fonte de informação citada foi o SEBRAE, considerada pela empresa como uma das instituições que mais funcionam em apoio aos pequenos negócios, pois através do SEBRAE que a organizaçãoC implementou o sistema de gestão e a partir disso começou a entender o negócio com estratégia.

$\mathrm{Na}$ empresa há esforços de inovação, mas com foco maior nos seus recursos de inovação. Assim, o entrevistadoC relata que há recursos humanos e materiais para desenvolver atividades de inovação, mas que poderia ser melhor. Sobre os recursos financeiros, o investimento próprio da empresa é a sua principal fonte de financiamento para implementar inovação, havendo orçamento suficiente para tal, o entrevistadoC afirma: "estamos até desenvolvendo novos serviços com inovações focado em qualidade". Em relação aos esforços de recompensas pela inovação, apesar da empresa incentivar e estimular seus funcionários a trazerem novidades e desenvolverem inovações, não há recompensa oficializada para esses esforços.

No que tange à orientação ao mercado, a organizaçãoC tem como visão ser referência global nos mercados de atuação. Assim, busca desenvolver estratégias de mudança para os mercados em que atua, devido às transformações continuas do ambiente, tecnologias e relações de trabalho.

A empresa sempre considera as necessidades dos clientes na prestação ou criação de serviços, o entrevistadoC citou como exemplo o fato da empresa oferecer o atendimento com urgência. Além disso, foi verificado em doc/siteC que a empresa conta com uma equipe voltada às necessidades dos clientes, estabelecendo um canal direto de relacionamento com clientes. E tem como um de seus valores que esse relacionamento com clientes seja baseado na confiança entre as partes, tendo assim uma orientação ao cliente.

A organizaçãoC tem muitos concorrentes, porém não há conhecimento dos pontos fortes, capacidade e as estratégias dos seus concorrentes para usá-lo na obtenção de vantagens, não tendo assim uma orientação ao concorrente. Apesar de não existir essa discussão referentes aos seus concorrentes, a empresa conhece 
seus próprios pontos fortes e fracos, capacidade e estratégias. O entrevistadoC cita alguns pontos fortes como: possuir o sistema de gestão integrado, flexibilidade de estrutura enxuta, análise da satisfação tanto dos funcionários quanto dos clientes. E alguns pontos fracos: carteira de clientes muito voltada a óleo e gás e não ter contrato de longo prazo, o que origina uma insegurança.

A estratégia que a empresa usa para obter vantagens tanto em relação aos novos entrantes quanto à rivalidade entre os concorrentes é o preço enxuto, sendo muito flexível com clientes para ser realmente diferenciado do mercado. No mercado, onde há vários serviços substitutos aos da organizaçãoC, a estratégia utilizada para superá-los é um atendimento diferenciado, com segurança, qualidade e atendendo a todos os requisitos das normas. Os clientes detêm maior poder na negociação da venda, prezando pelo custo. Já no poder de negociação dos fornecedores, a organizaçãoC tem maior força, prezando pelo prazo, preço e entrega.

Em relação às tecnologias, dentre as 9 principais identificadas na literatura, a organizaçãoC utiliza 3, sendo: internet das coisas, big data e design digital, simulação e integração. De acordo com o entrevistadoC, todas essas tecnologias são de parceiros. A empresa integra com parceiros estratégicos que detêm esse know-how com o principal objetivo de ser diferenciado no mercado, apresentando para o cliente uma solução sempre mais completa.

No que tange ao desempenho operacional, a organizaçãoC possui um sistema de medição de desempenho. O entrevistadoC relata que há poucos indicadores, mas que são os mais importantes para empresa, tendo 2 indicadores financeiros, 2 indicadores de recursos humanos, 2 indicadores de performance comercial e logística, também há indicadores relacionados ao meio ambiente devido à norma ISO 14001:2004.

$\mathrm{O}$ entrevistadoC apontou que dentre as cincos principais dimensões de desempenho operacional em serviços, todas são importantes para vantagem competitiva da empresa. Na dimensão da entrega, a empresa tem como foco a redução de prazos, juntamente com a segurança, qualidade e responsabilidade no cumprimento de contratos, assim, os pedidos sempre são atendidos no prazo, o entrevistadoC afirma: "não ocorre atrasos, temos um grau de satisfação dos clientes muito alto e se perdemos cliente é por causa do preço". E houve um 
aumento da velocidade de entrega devido à inovação, mas só em parte do processo agilizou e deu rastreabilidade.

$\mathrm{Na}$ dimensão de custo, a empresa conhece quanto custa realizar um serviço e o valor está igual ao esperado. O entrevistadoC relata que ainda não houve uma redução significativa nos custos devido à inovação, ocorreu apenas uma pequena redução interna de gastos com materiais e na distribuição. Na dimensão de flexibilidade, a empresa possui capacidade de adaptar seus serviços, com foco maior na flexibilidade de velocidade de entrega, tendo rapidez na resposta a diferentes necessidades dos clientes. Já no desempenho de inovação, apesar da empresa não possuir indicadores para tal, afirma que consegue aumentar a sua capacidade de desenvolver novos serviços.

Sobre a dimensão da qualidade, a organizaçãoC usa ferramenta para medir o nível de satisfação tanto dos clientes quanto dos funcionários. Há a confiabilidade do serviço, pois a empresa garante o cumprimento dos prazos estabelecidos de acordo com as normas, prontidão para atender os clientes e também segurança, pois são feitos treinamentos e capacitações para seus funcionários. O entrevistadoC argumenta: "apesar de muitas vezes os clientes priorizarem custo, a qualidade permite um trabalho diferenciado, além de gerar confiança".

Por fim, no Quadro 11 é apresentado quais dos facilitadores e barreiras ao desempenho de pequenos negócios em serviços, presentes na literatura, a empresa enfrenta na prática, identificados pelo entrevistadoC, no qual sugeriu a inclusão de "corrupção" como barreira na pesquisa, pois segundo o entrevistadoC; "a corrupção na política atrapalha a economia, principalmente nesse mercado que atuamos de óleo e gás”.

Quadro 11 - Facilitadores e barreiras ao desempenho do estudo de caso C

\begin{tabular}{|c|}
\hline Facilitadores \\
\hline Gestão estratégica dos recursos \\
\hline Responsabilidade social corporativa \\
\hline Informações (TI) \\
\hline Qualidade \\
\hline Medição de desempenho \\
\hline Inovação de produto/serviço \\
\hline Rede de negócios \\
\hline $\begin{array}{c}\text { Aspectos comportamentais (posturas inovadoras, proatividade, comprometimento, } \\
\text { perspectiva de longo prazo, autonomia, experiência, liderança) }\end{array}$ \\
\hline Capital humano \\
\hline
\end{tabular}




\begin{tabular}{|c|}
\hline Facilitadores \\
\hline Potenciais parceiros \\
\hline Flexibilidade \\
\hline Bons relacionamentos com os stakeholders \\
\hline Atender as necessidades dos clientes \\
\hline Barreiras \\
\hline Falta de cooperação \\
\hline Corrupção \\
\hline
\end{tabular}

\subsection{4}

\section{Estudo de caso D}

A organização D tem como principal atividade o desenvolvimento de soluções integradas em sistemas de controle e supervisão de maquinas e de geração de energia, tanto para a área civil quanto para área militar, com atuação em diversas áreas como indústria naval, óleo e gás, entre outros.

Classificada pelo Sebrae como empresa de pequeno porte, desde 1992 é uma empresa de engenharia que acumulou expertise em desenvolvimento de projetos (elétricos, software e instrumentação), produção de quadros elétricos e painéis de distribuição, e serviços de manutenções, montagens, automação etc. Além disso, é certificada pela ISO 9001 (Qualidade).

Em relação ao segmento de petróleo e gás, atua diretamente com o Sebrae há mais de dois anos, participando de vários eventos do ou com Sebrae, sendo um dos principais o Rio Oil \& Gas.

A entrevista foi realizada com o gerente técnico, o qual atua nesse cargo há sete anos. O painel de dados da organização é apresentado no Quadro 12. De acordo com o entrevistadoD e com doc/siteD da empresa, o tema inovação está presente nas suas operações, sendo parte tanto da missão da organização quanto de seus valores. Os tipos de inovações no setor de óleo e gás desenvolvidas pela organizaçãoD são inovações de serviços e processo, tendo feito alguns retrofits, adicionando tecnologias que não tinham antes nos sistemas originais, também é fornecido quadros elétricos e sistemas de automação. 
Quadro 12 - Painel de dados do estudo de caso D

\begin{tabular}{|c|c|c|c|c|c|}
\hline Font & le & Inovação & Orientação ao mercado & Desempenho operacional & Tecnologias disruptivas \\
\hline entrevis & & $\begin{array}{l}\text { Desenvolve inovações de serviços e processo. Inova } \\
\text { devido a fatores externos (atender a necessidade do } \\
\text { cliente). As principais fontes de informações para } \\
\text { desenvolver inovações são clientes, material de } \\
\text { fabricante e práticas de projeto próprios da empresa. Há } \\
\text { recursos humanos e materiais suficientes para } \\
\text { desenvolver atividades de inovação, e em recursos } \\
\text { financeiros, dependendo do tipo de inovação, pode ser } \\
\text { necessário verba de pesquisa. Os funcionários de } \\
\text { pesquisa são incentivados a buscar novas soluções e } \\
\text { novas tecnologias, mas não há alguma recompensa } \\
\text { oficializada para esses esforços. }\end{array}$ & $\begin{array}{l}\text { Está na natureza do negócio considerar as } \\
\text { necessidades dos clientes na prestação ou } \\
\text { criação de serviços, uma vez que os projetos são } \\
\text { personalizados, feitos de acordo com as } \\
\text { especificações dos clientes. Tem muitos } \\
\text { concorrentes e conhece os pontos fortes, fracos, } \\
\text { capacidade e as estratégias tanto da } \\
\text { concorrência quanto da própria empresa. Usa a } \\
\text { diferenciação do serviço como estratégia para } \\
\text { obter vantagem competitiva. }\end{array}$ & $\begin{array}{l}\text { Existe um sistema de medição de } \\
\text { desempenho, tendo indicadores } \\
\text { relacionados ao faturamento versus } \\
\text { despesas, utilização de recursos, avaliação } \\
\text { do cliente e quantas solicitações de } \\
\text { serviços foram aprovadas. Considera que } \\
\text { todas as dimensões de desempenho } \\
\text { operacional são importantes para } \\
\text { vantagem competitiva da empresa, mas a } \\
\text { principal é a qualidade. Devido à } \\
\text { inovação houve redução de custos e } \\
\text { aumento da qualidade dos serviços. }\end{array}$ & $\begin{array}{l}\text { A empresa utiliza a } \\
\text { tecnologia internet das } \\
\text { coisas. O principal } \\
\text { motivo para implementar } \\
\text { essa tecnologia é a } \\
\text { necessidade para } \\
\text { executar os processos de } \\
\text { serviços (necessidade } \\
\text { interna). }\end{array}$ \\
\hline obsD & & $\begin{array}{l}\text { Realiza inovações de serviços e processo, tanto próprias, } \\
\text { criadas pelas empresas ou em cooperação, quanto } \\
\text { adotadas, desenvolvidas por outras empresas. Suas } \\
\text { atividades de inovação são bem-sucedidas. A empresa } \\
\text { tem um comportamento reativo ao inovar, ou seja, para } \\
\text { evitar perda de mercado. E as suas interações são do tipo } \\
\text { fontes abertas de informação. }\end{array}$ & & & \\
\hline
\end{tabular}




\begin{tabular}{|c|c|c|c|c|}
\hline $\begin{aligned} \text { Font } & \text { ô } \\
\text { dac } & \text { le }\end{aligned}$ & Inovação & Orientação ao mercado & Desempenho operacional & Tecnologias disruptivas \\
\hline doc/site & $\begin{array}{l}\text { Tem como missão promover soluções competitivas e } \\
\text { inovadoras em projetos, fabricação, serviços de } \\
\text { comissionamento e assistência técnica, investindo em } \\
\text { pesquisa e desenvolvimento. E tem como um de seus } \\
\text { valores a inovação, além de obter fontes de informações } \\
\text { com o SEBRAE e organizações parceiras. }\end{array}$ & $\begin{array}{l}\text { Existe o compromisso com os clientes externos } \\
\text { e internos. Assim, devido a política de qualidade } \\
\text { da empresa, há o comprometimento de fornecer } \\
\text { serviços confiáveis que atendam as } \\
\text { especificações e os requisitos acordados, } \\
\text { visualizando as necessidades de mercado e } \\
\text { buscando a satisfação de seus clientes. }\end{array}$ & $\begin{array}{l}\text { A dimensão da qualidade está presente na } \\
\text { missão da empresa ao citar investimento } \\
\text { na qualidade do atendimento aos seus } \\
\text { clientes e na capacitação dos seus } \\
\text { colaboradores. Existe também uma } \\
\text { política de qualidade, assim há a } \\
\text { confiabilidade, ao oferecer serviços } \\
\text { confiáveis que atendam as especificações } \\
\text { e os requisitos acordados, segurança, } \\
\text { mediante a capacitação de seus } \\
\text { colaboradores, e a melhoria contínua dos } \\
\text { processos. }\end{array}$ & $\begin{array}{l}\text { A empresa busca a } \\
\text { atualização tecnológica, } \\
\text { aliando o conhecimento } \\
\text { (know-How), com } \\
\text { pesquisa, } \\
\text { desenvolvimento } \\
\text { parceiras com empresas, } \\
\text { fornecedores } \\
\text { institutos de tecnologia. }\end{array}$ \\
\hline Síntese & $\begin{array}{l}\text { Apesar da inovação estar incorporada na visão } \\
\text { estratégica da empresa, o mercado é que gera a } \\
\text { necessidade de inovar. Com a inovação, procura criar um } \\
\text { diferencial competitivo. Os esforços de inovação são } \\
\text { feitos com maior foco nos recursos de inovação, mas os } \\
\text { esforços de recompensa pela inovação não são } \\
\text { oficializados pela empresa. }\end{array}$ & $\begin{array}{l}\text { Possui conhecimento voltado ao mercado, tanto } \\
\text { dos clientes quanto dos concorrentes. A } \\
\text { orientação ao cliente está incorporada na visão } \\
\text { estratégica da empresa e é a que mais } \\
\text { impulsiona a inovação, e a orientação ao } \\
\text { concorrente tem a diferenciação como principal } \\
\text { estratégia para obter vantagens. }\end{array}$ & $\begin{array}{l}\text { A empresa é certificada pela ISO 9001, } \\
\text { fazendo com que haja algumas medidas } \\
\text { de desempenho operacional. A dimensão } \\
\text { mais importante para a empresa é a } \\
\text { qualidade, que está incorporada na sua } \\
\text { visão estratégica. }\end{array}$ & $\begin{array}{l}\text { Na empresa, desde sua } \\
\text { origem, há o uso de } \\
\text { tecnologia e preocupação } \\
\text { em acompanhar a sua } \\
\text { evolução. Assim, utiliza- } \\
\text { se a tecnologia por } \\
\text { necessidades internas. }\end{array}$ \\
\hline
\end{tabular}


Um dos objetivos para empresa inovar é atender a necessidade do cliente. O entrevistadoD relata que o cliente chega com a necessidade de algo novo que precisa ser projetado, seja um sistema, uma distribuição elétrica ou automação de integração de sistemas, e a empresa faz todo o conjunto, desde o projeto, o desenvolvimento, a instalação, até o pós-venda, e também faz de forma separada, caso o cliente queira só uma consultoria ou só o projeto.

As principais fontes de informações para desenvolver inovações citadas pelo entrevistadoD são documentação do cliente, material de fabricante e práticas de projeto próprios da empresa, e em doc/siteD constata-se a existência de parcerias com outras organizações e com o SEBRAE. Além disso, na empresa há esforços de inovação, mas com foco maior nos seus recursos de inovação. Assim, o entrevistadoD relata que há recursos humanos e materiais suficientes para desenvolver atividades de inovação.

Em relação aos recursos financeiros, a principal fonte de financiamento da empresa para implementar inovações é o capital próprio, mas, dependendo da inovação, pode ser necessário verba de pesquisa. Dessa forma, o entrevistadoD considera que, dependendo da inovação, a empresa tem orçamento suficiente para desenvolver inovações. Além disso, a empresa não protege suas inovações, com patentes por exemplo, pois realiza transferência tecnológica para os clientes, o entrevistadoD afirma: "trabalhamos com material padronizado de mercado, com programação aberta, não trabalhamos com nada proprietário".

No caso dos esforços de recompensas pela inovação, a maioria dos funcionários não são de pesquisas e sim de execução, assim os colaboradores de projetos são incentivados a buscar novas soluções e novas tecnologias, mas não há recompensa oficializada para esses esforços.

No que tange à orientação ao mercado, as necessidades dos clientes são levadas em consideração na prestação ou criação de serviços, o entrevistadoD diz que isso está na natureza do negócio, os projetos são personalizados, feitos de acordo com as especificações dos clientes, e em doc/siteD pode-se verificar que a política de qualidade da empresa faz com que haja o comprometimento de fornecer serviços confiáveis que atendam as especificações e os requisitos acordados, visualizando as necessidades de mercado e buscando a satisfação de seus clientes, e o compromisso com os clientes externos e internos, tendo assim uma orientação ao cliente. 
A organizaçãoD tem muitos concorrentes e conhece os pontos fortes, fracos, capacidade e as estratégias tanto da concorrência quanto da própria empresa, tendo uma orientação ao concorrente. $\mathrm{O}$ entrevistadoD cita como ponto forte a integração na comunicação e como ponto fraco haver um monopólio no setor de óleo e gás, então se o monopólio entra em crise, o setor inteiro também entra em crise.

A vantagem que a empresa possui tanto em relação aos novos entrantes quanto à rivalidade entre os concorrentes é a diferenciação do serviço. Uma barreira que a empresa impôs contra a entrada do novo serviço ou processo no mercado foi alavancar alto investimento, assim a concorrência teria a necessidade de alto investimento financeiro para competitividade. Os clientes detêm maior poder na negociação da compra, prezando pelo custo e qualidade. Já no poder de negociação dos fornecedores, a organizaçãoD que tem maior força, dependendo do fornecedor, pois alguns são flexíveis na negociação, prezando pelo preço e entrega.

Em relação às tecnologias disruptivas, dentre as 9 principais identificadas na literatura, a organizaçãoD utiliza apenas uma: internet das coisas. De acordo com o entrevistadoD, o principal motivo para implementar essa tecnologia é a necessidade para executar os processos de serviços.

A organizaçãoD busca a atualização tecnológica, aliando o conhecimento (know-How), com pesquisa, desenvolvimento e parceiras com empresas, fornecedores e institutos de tecnologia, e essas parcerias foram relatadas pelo entrevistadoD, como facilitador para adoção de tecnologias.

No que tange ao desempenho operacional, a organizaçãoD possui um sistema de medição de desempenho. Assim, os principais indicadores são relacionados ao faturamento versus despesas, utilização de recursos, avaliação do cliente e quantas solicitações de serviços foram aprovadas.

$\mathrm{O}$ entrevistadoD aponta que dentre as cincos principais dimensões de desempenho operacional em serviços, todas são importantes para vantagem competitiva da empresa. Na dimensão da entrega, dependendo do tipo de serviço pode ocorrer atrasos. Sobre custo, a empresa conhece quanto custa realizar um serviço e o valor está igual ao esperado, e houve redução nos custos devido à inovação. Em flexibilidade, a empresa possui capacidade de ser flexível no atendimento aos clientes, com foco maior na flexibilidade de velocidade de 
entrega, havendo aumento na rapidez de resposta a diferentes necessidades dos clientes.

A dimensão da qualidade é a principal para a organizaçãoD. Em doc/siteD é evidenciado que o investimento na qualidade do atendimento aos clientes faz parte da missão da empresa, e existe uma política de qualidade, na qual a empresa possui comprometimento em fornecer serviços confiáveis que atendam as especificações e os requisitos acordados, buscando a satisfação dos clientes. O entrevistadoD relata que houve um aumento da qualidade dos serviços devido à inovação, e que é usado ferramenta para medir o nível de satisfação dos clientes em relação à qualidade do atendimento e do ambiente físico da empresa. Assim há a confiabilidade, com serviços atendendo as especificações e os requisitos acordados, e segurança, com capacitação de seus colaboradores.

Já com a inovação, a empresa consegue aumentar a sua capacidade de desenvolver novos serviços. Além disso, o entrevistadoD relatou que existem clientes receptivos aos novos, assim como existem clientes que só aceitam os serviços padronizados.

Por fim, no Quadro 13 é apresentado quais são os facilitadores e barreiras ao desempenho de pequenos negócios em serviços, presentes na literatura, que a empresa enfrenta na prática, identificados pelo entrevistadoD, o qual não sugeriu nenhuma inclusão de facilitador ou barreira na pesquisa.

\begin{tabular}{l} 
Quadro 13 - Facilitadores e barreiras ao desempenho do estud \\
$\qquad$\begin{tabular}{c|}
\hline Facilitadores \\
\hline Questão estratégica dos recursos \\
\hline Medição de desempenho \\
\hline Inovação de produto/serviço \\
\hline Informações (TI) \\
\hline Capital humano \\
\hline Potenciais parceiros \\
\hline Bons relacionamentos com os stakeholders \\
\hline Atender as necessidades dos clientes \\
\hline Barreiras \\
\hline Recurso limitado (financeiro e técnico) \\
\hline Funcionários desqualificados \\
\hline Forte concorrência \\
\hline Fraco conhecimento / força do mercado $)$ \\
\hline
\end{tabular} \\
\hline
\end{tabular}




\subsection{5 \\ Análise intercasos}

$\mathrm{Na}$ análise intercasos realizou-se uma comparação entre todos os casos de forma simultânea. Dessa forma, são analisadas as semelhanças e diferenças entre os estudos de caso para cada determinante, assim como para os elementos de desempenho operacional, facilitadores e barreiras, tanto das práticas gerenciais quanto da literatura.

Com base na teoria do RBV, é apresentado no Quadro 14 a classificação dos recursos VRIN dos estudos de caso. Observa-se que muitos dos recursos destacados são diferentes para cada empresa, por exemplo, enquanto o recurso físico "equipamentos" gera uma vantagem competitiva sustentável no estudo de caso A, nos outros casos esse mesmo recurso gera paridade competitiva. $\mathrm{Na}$ organizaçãoA também se destaca como recurso VRIN seus serviços substitutos, na organizaçãoB as patentes, marca, e garantia técnica e legal, e na organizaçãoC o sistema de gestão integrada.

Barney (1991) relata que uma das suposições fundamentais da RBV é a heterogeneidade de recursos das organizações, ou seja, mesmo que diversas empresas sejam competidoras em um mesmo setor, pode haver diferenças de recursos entre elas, evidenciando que há empresas mais competitivas que outras por usarem diferentes recursos.

Já os recursos voltados à orientação ao mercado e esforços de inovação são destacados em comum entre os estudos de caso, porém os recursos voltados à orientação ao mercado geram apenas paridade competitiva por serem considerados apenas como valiosos, enquanto que os recursos de esforços de inovação geram vantagens competitivas para todos os casos, uma vez que são considerados valiosos, raros e inimitáveis. Além disso, o recurso físico "tecnologia" também é identificado em comum na maioria das empresas, só não é destacado na organizaçãoC, pois a busca pelo seu uso na empresa ainda está na fase inicial e os que tem são de parceiros.

Assim, postula-se a seguinte proposição: quanto maior a capacidade do pequeno negócio de serviços em tornar seus esforços de inovação em recursos 
VRIN, maior o seu desempenho operacional, gerando vantagem competitiva no setor de óleo e gás.

Quadro 14 - Classificação dos recursos VRIN dos estudos de caso

\begin{tabular}{|c|c|c|c|c|c|c|}
\hline $\begin{array}{l}\text { Estudo } \\
\text { de caso }\end{array}$ & Recursos da empresa & Valioso & Raro & Inimitável & $\begin{array}{c}\text { Explorado } \\
\text { pela empresa }\end{array}$ & Implicações competitivas \\
\hline \multirow{8}{*}{ A } & $\begin{array}{l}\text { Equipamentos (veículos não } \\
\text { tripulados) }\end{array}$ & $\mathrm{x}$ & $\mathrm{x}$ & $\mathrm{x}$ & $\mathrm{x}$ & Vantagem competitiva sustentável \\
\hline & Esforços em inovações & $\mathrm{X}$ & $\mathrm{X}$ & $\mathrm{X}$ & $\mathrm{x}$ & Vantagem competitiva sustentável \\
\hline & Softwares & $\mathrm{x}$ & & & $\mathrm{x}$ & Paridade competitiva \\
\hline & $\begin{array}{l}\text { Conhecimento das } \\
\text { necessidades dos clientes }\end{array}$ & $\mathrm{x}$ & & & $\mathrm{x}$ & Paridade competitiva \\
\hline & Conhecimento do mercado & $\mathrm{x}$ & & & $\mathrm{x}$ & Paridade competitiva \\
\hline & Tecnologia & $\mathrm{x}$ & $\mathrm{x}$ & $\mathrm{x}$ & $\mathrm{x}$ & Vantagem competitiva sustentável \\
\hline & Qualidade do serviço & $\mathrm{x}$ & & & $\mathrm{x}$ & Paridade competitiva \\
\hline & Serviços substitutos & $\mathrm{x}$ & $\mathrm{x}$ & $\mathrm{x}$ & $\mathrm{x}$ & Vantagem competitiva sustentável \\
\hline \multirow{13}{*}{ 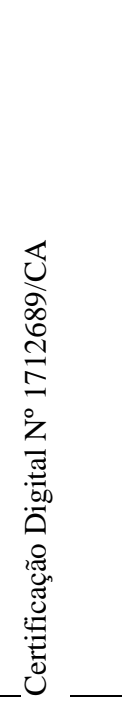 } & Patentes & $\mathrm{x}$ & $\mathrm{x}$ & $\mathrm{x}$ & $\mathrm{x}$ & Vantagem competitiva sustentável \\
\hline & Marca & $\mathrm{x}$ & $\mathrm{x}$ & $\mathrm{x}$ & $\mathrm{x}$ & Vantagem competitiva sustentável \\
\hline & Experiencia no mercado & $\mathrm{x}$ & & & $\mathrm{x}$ & Paridade competitiva \\
\hline & Profissionais qualificados & $\mathrm{x}$ & $\mathrm{x}$ & & $\mathrm{x}$ & Vantagem competitiva temporária \\
\hline & Softwares & $\mathrm{x}$ & & & $\mathrm{x}$ & Paridade competitiva \\
\hline & Equipamentos & $\mathrm{x}$ & & & $\mathrm{x}$ & Paridade competitiva \\
\hline & Tecnologia & $\mathrm{x}$ & $\mathrm{x}$ & $\mathrm{x}$ & $\mathrm{x}$ & Vantagem competitiva sustentável \\
\hline & Esforços em inovações & $\mathrm{x}$ & $\mathrm{x}$ & & $\mathrm{x}$ & Vantagem competitiva temporária \\
\hline & Pesquisa de mercado & $\mathrm{x}$ & & & $\mathrm{x}$ & Paridade competitiva \\
\hline & Parcerias & $\mathrm{x}$ & & & $\mathrm{x}$ & Paridade competitiva \\
\hline & Serviços diferenciados & $\mathrm{x}$ & $\mathrm{x}$ & & $\mathrm{x}$ & Vantagem competitiva temporária \\
\hline & Qualidade do serviço & $\mathrm{x}$ & & & $\mathrm{x}$ & Paridade competitiva \\
\hline & Garantia técnica e legal & $\mathrm{x}$ & $\mathrm{x}$ & $\mathrm{x}$ & $\mathrm{x}$ & Vantagem competitiva sustentável \\
\hline \multirow{5}{*}{ 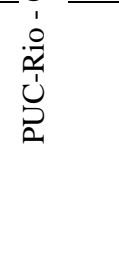 } & Treinamentos & $\mathrm{x}$ & & & $\mathrm{x}$ & Paridade competitiva \\
\hline & Parcerias & $\mathrm{x}$ & & & $\mathrm{x}$ & Paridade competitiva \\
\hline & Sustentabilidade & $\mathrm{x}$ & $\mathrm{x}$ & & $\mathrm{x}$ & Vantagem competitiva temporária \\
\hline & Velocidade de entrega & $\mathrm{x}$ & & & $\mathrm{x}$ & Paridade competitiva \\
\hline & Relacionamento com cliente & $\mathrm{x}$ & & & $\mathrm{x}$ & Paridade competitiva \\
\hline \multirow[t]{6}{*}{$\mathrm{C}$} & Qualidade do serviço & $\mathrm{x}$ & & & $\mathrm{x}$ & Paridade competitiva \\
\hline & Equipe qualificada & $\mathrm{x}$ & & & $\mathrm{x}$ & Paridade competitiva \\
\hline & $\begin{array}{l}\text { Flexibilidade de estrutura } \\
\text { enxuta }\end{array}$ & $\mathrm{x}$ & & & $\mathrm{x}$ & Paridade competitiva \\
\hline & Certificações & $\mathrm{x}$ & $\mathrm{x}$ & & $\mathrm{x}$ & Vantagem competitiva temporária \\
\hline & Sistema de gestão integrada & $\mathrm{x}$ & $\mathrm{x}$ & $\mathrm{x}$ & $\mathrm{x}$ & Vantagem competitiva sustentável \\
\hline & Esforços em inovações & $\mathrm{x}$ & $\mathrm{x}$ & & $\mathrm{x}$ & Vantagem competitiva temporária \\
\hline \multirow{5}{*}{$\mathrm{D}$} & Softwares & $\mathrm{x}$ & & & $\mathrm{x}$ & Paridade competitiva \\
\hline & Equipamentos & $\mathrm{x}$ & & & $\mathrm{x}$ & Paridade competitiva \\
\hline & Tecnologia & $\mathrm{x}$ & $\mathrm{x}$ & $\mathrm{x}$ & $\mathrm{x}$ & Vantagem competitiva sustentável \\
\hline & Experiencia no mercado & $\mathrm{x}$ & & & $\mathrm{x}$ & Paridade competitiva \\
\hline & $\begin{array}{l}\text { Conhecimento das } \\
\text { necessidades dos clientes }\end{array}$ & $\mathrm{x}$ & & & $\mathrm{x}$ & Paridade competitiva \\
\hline
\end{tabular}




\begin{tabular}{|l|l|c|c|c|c|c|}
\hline $\begin{array}{c}\text { Estudo } \\
\text { de caso }\end{array}$ & \multicolumn{1}{|c|}{ Recursos da empresa } & Valioso & Raro & Inimitável & $\begin{array}{c}\text { Explorado } \\
\text { pela empresa }\end{array}$ & Implicações competitivas \\
\hline \multirow{5}{*}{} & Qualidade do serviço & $\mathrm{x}$ & & & $\mathrm{x}$ & Paridade competitiva \\
\cline { 2 - 7 } & Certificações & $\mathrm{x}$ & $\mathrm{x}$ & & $\mathrm{x}$ & Vantagem competitiva temporária \\
\cline { 2 - 7 } & Integração na comunicação & $\mathrm{x}$ & & & $\mathrm{x}$ & Paridade competitiva \\
\cline { 2 - 7 } & Esforços em inovações & $\mathrm{x}$ & $\mathrm{x}$ & $\mathrm{x}$ & $\mathrm{x}$ & Vantagem competitiva sustentável \\
\cline { 2 - 7 } & Conhecimento do mercado & $\mathrm{x}$ & & & $\mathrm{x}$ & Paridade competitiva \\
\cline { 2 - 7 } & Profissionais qualificados & $\mathrm{X}$ & $\mathrm{x}$ & & $\mathrm{x}$ & Vantagem competitiva temporária \\
\cline { 2 - 7 } & Treinamentos & $\mathrm{X}$ & & & $\mathrm{x}$ & Paridade competitiva \\
\hline
\end{tabular}

No que tange às cinco forças competitivas de Porter, na Figura 6 é ilustrada a análise das forças de mercado que caracterizam o posicionamento dos estudos de caso diante da concorrência. Observa-se que os estudos de caso B e C apresentam algumas estratégias importantes como a liderança de custo, ao oferecer preços enxutos, e parcerias, que também é considerado como um recurso valioso pelas empresas. González-Benito et al. (2016) afirmam que as pequenas empresas possuem maior probabilidade de sucesso quando usam a colaboração para apoiar sua inovação.

Contudo, a principal estratégia utilizada para lidar com a concorrência, presente em todos os estudos de caso, é a diferenciação, o que corrobora com a literatura. Por exemplo, Campbell e Park (2017) relatam que nas pequenas empresas a diferenciação é importante e pode ocorrer por meio da tomada de decisões estratégicas. Já Porter (2008) diz que um dos posicionamentos estratégicos para obter vantagens é realizar atividades diferentes dos concorrentes ou atividades semelhantes, mas de formas diferentes, e que investir na diferenciação pode moderar a competição de preços no mercado. 


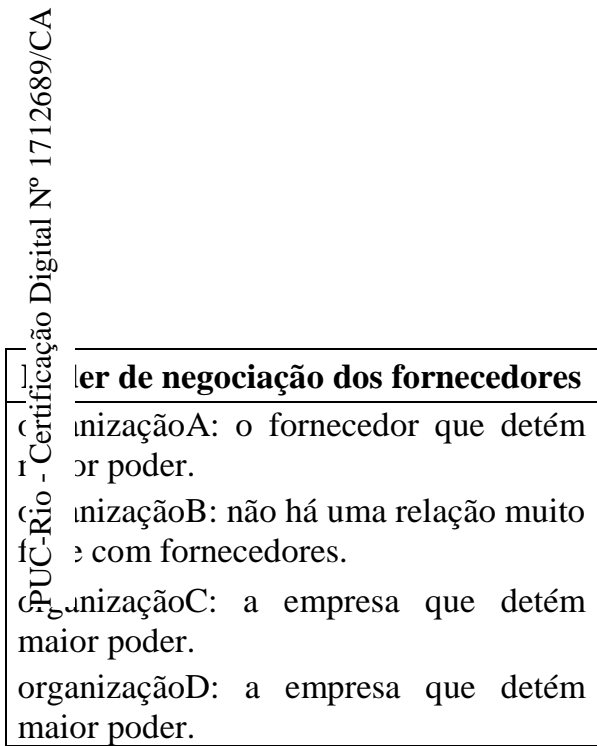

\section{Barreiras para novos entrantes}

organizaçãoA: utiliza a diferenciação por qualidade para obter vantagens.

organizaçãoB: possui vantagens referentes a custo e inovação.

organizaçãoC: tem vantagens em relação ao preço enxuto.

organizaçãoD: utiliza a diferenciação do serviço para ter vantagens.

\section{$\widehat{ }$}

\begin{tabular}{|l|}
\hline Rivalidade entre os atuais concorrentes \\
\hline \\
Os estudos de caso A e B não possuem muitos concorrentes enquanto os \\
estudos de caso C e D têm vários concorrentes. Todas as empresas \\
utilizam em comum a diferenciação como estratégia para obterem \\
vantagens competitivas. As organizações B e C, além da diferenciação, \\
também competem por preço e buscam parcerias.
\end{tabular}

\section{爪1}

\section{Ameaça de produtos ou serviços substitutos}

organizaçãoA: atua como serviços substitutos, oferecendo um serviço que executa a mesma função dos concorrentes, porém por meios diferentes.

organizaçãoB: utiliza a agregação de valor como estratégia para superar os serviços substitutos aos seus existentes no mercado.

organizaçãoC: utiliza como estratégia o atendimento diferenciado, com segurança, qualidade e atendendo todos os requisitos das normas.

organizaçãoD: introduziu como barreira a necessidade de alto investimento financeiro para competitividade.

Figura 6 - Forças competitivas de mercado dos estudos de caso
Poder de negociação dos compradores organizaçãoA: o cliente que detém maior poder.

organizaçãoB: a empresa que detém maior poder.

organizaçãoC: o cliente que detém maior poder.

organizaçãoD: o cliente que detém maior poder. 
A organizaçãoA foca na diferenciação, principalmente no quesito qualidade, nos seus processos e a organizaçãoD foca na diferenciação dos seus serviços. $\mathrm{Na}$ organizaçãoB, a diferenciação é um dos principais fatores levados em consideração pela empresa no momento de negociação da venda dos seus serviços, e na organizaçãoC a flexibilidade permite um atendimento ao cliente diferenciado no mercado. Nos estudos de caso A, C e D a inovação é usada como um meio para conseguir criar esse diferencial competitivo nas empresas.

Devido à heterogeneidade dos clientes, as organizações possuem o desafio de adequar seus serviços à demanda, o que significa que a diferenciação é tão importante quanto o desenvolvimento de novos serviços (OECD, 2005).

Desse modo, postula-se a seguinte proposição: quanto mais diferenciado for o serviço prestado, maior força competitiva os pequenos negócios terão no mercado de óleo e gás.

Quanto aos facilitadores e barreiras ao desempenho operacional em serviços, na Figura 7 são ilustrados os mapas de palavras referentes aos facilitadores e às barreiras citados com mais frequência e no Quadro 15 é apresentado mais detalhadamente os principais facilitadores e barreiras identificados nos estudos de caso.
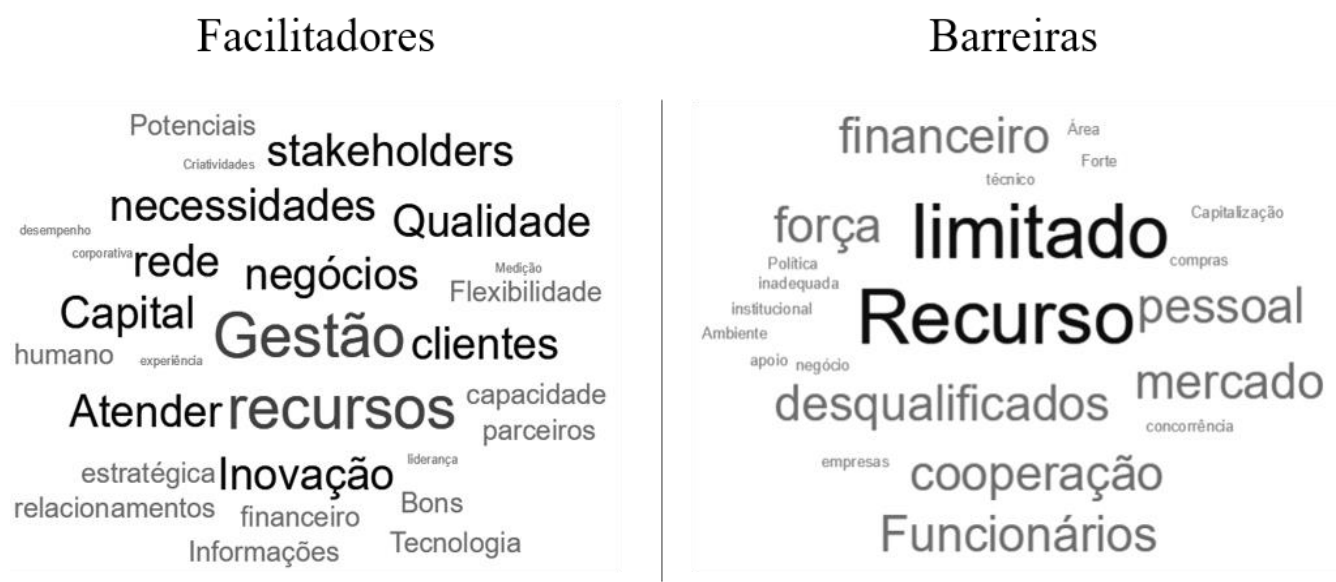

Figura 7- Mapa de facilitadores e barreiras dos estudos de caso

Dentre todos os facilitadores identificados na literatura, quatro foram semelhantes em todos os estudos de caso: qualidade, inovação de produto/serviço, atender as necessidades dos clientes e informações (TI).

Essa semelhança entre os estudos de caso corrobora com a literatura, uma vez que "qualidade" e "inovação de produto/serviço" também foram os facilitadores identificados com maior frequência na RSL. Alfoqahaa (2018) 
afirma que em sua pesquisa a excelência no atendimento ao cliente foi o principal fator ligado ao sucesso das pequenas empresas. Além disso, qualidade, inovação de produto/serviço e atender as necessidades dos clientes são tratados como recursos VRIN em todos os estudos de caso.

Nos estudos de caso B e C o facilitador "potenciais parceiros" também é tratado como um recurso valioso para as empresas, e a organizaçãoC também inclui o facilitador "flexibilidade" em seus recursos valiosos. Já os facilitadores "análise do mercado externo", "marketing", "P\&D" e "entrega" foram os únicos que não foram identificados por nenhuma organização.

É válido ressaltar que em nenhum estudo de caso houve indicação de inclusão de algum facilitador além dos que foram identificados na literatura.

Quadro 15 - Principais facilitadores e barreiras dos estudos de caso

\begin{tabular}{|c|c|c|c|c|}
\hline \multirow{2}{*}{ Facilitadores } & \multicolumn{4}{|c|}{ Estudos de caso } \\
\hline & $\mathbf{A}$ & B & $\mathbf{C}$ & $\mathbf{D}$ \\
\hline Qualidade & $\mathrm{x}$ & $\mathrm{x}$ & $\mathrm{x}$ & $\mathrm{x}$ \\
\hline Inovação de produto/serviço & $\mathrm{x}$ & $\mathrm{x}$ & $\mathrm{x}$ & $\mathrm{x}$ \\
\hline Atender as necessidades dos clientes & $\mathrm{x}$ & $\mathrm{x}$ & $\mathrm{x}$ & $\mathrm{x}$ \\
\hline Informações (TI) & $\mathrm{x}$ & $\mathrm{x}$ & $\mathrm{x}$ & $\mathrm{x}$ \\
\hline Gestão estratégica dos recursos & & $\mathrm{x}$ & $\mathrm{X}$ & $\mathrm{x}$ \\
\hline Rede de negócios & $\mathrm{x}$ & $\mathrm{x}$ & $\mathrm{x}$ & \\
\hline Capital humano & & $\mathrm{x}$ & $\mathrm{x}$ & $\mathrm{x}$ \\
\hline Potenciais parceiros & & $\mathrm{x}$ & $\mathrm{X}$ & $\mathrm{x}$ \\
\hline Flexibilidade & $\mathrm{x}$ & $\mathrm{x}$ & $\mathrm{x}$ & \\
\hline Bons relacionamentos com os stakeholders & $\mathrm{x}$ & & $\mathrm{x}$ & $\mathrm{x}$ \\
\hline Responsabilidade social corporativa & & $\mathrm{x}$ & $\mathrm{x}$ & \\
\hline Medição de desempenho & & & $\mathrm{x}$ & $\mathrm{x}$ \\
\hline $\begin{array}{l}\text { Aspectos comportamentais (posturas inovadoras, proatividade, } \\
\text { comprometimento, perspectiva de longo prazo, autonomia, } \\
\text { experiência, liderança) }\end{array}$ & $\mathrm{x}$ & & $\mathrm{x}$ & \\
\hline Capital social (reputação, rede de trabalho social etc.) & & & & $\mathrm{x}$ \\
\hline \multicolumn{5}{|l|}{ Análise do mercado externo } \\
\hline \multicolumn{5}{|l|}{ Marketing } \\
\hline \multicolumn{5}{|l|}{$\mathrm{P} \& \mathrm{D}$} \\
\hline \multicolumn{5}{|l|}{ Entrega } \\
\hline \multirow{2}{*}{ Barreiras } & \multicolumn{4}{|c|}{ Estudos de caso } \\
\hline & $\mathbf{A}$ & B & $\mathbf{C}$ & $\mathbf{D}$ \\
\hline Funcionários desqualificados & $\mathrm{x}$ & $\mathrm{x}$ & & $\mathrm{x}$ \\
\hline Recursos limitados & $\mathrm{x}$ & & & $\mathrm{X}$ \\
\hline Falta de cooperação & & $\mathrm{x}$ & $\mathrm{x}$ & \\
\hline Fraco conhecimento / força do mercado & $\mathrm{x}$ & & & $\mathrm{X}$ \\
\hline Ambiente de negócio & $\mathrm{x}$ & & & \\
\hline Capitalização inadequada & $\mathrm{x}$ & & & \\
\hline
\end{tabular}




\begin{tabular}{|l|l|l|l|l|} 
Forte concorrência & & & & $\mathrm{x}$ \\
\hline Baixa qualidade & & & & \\
\hline Falta de informação & & & & \\
\hline
\end{tabular}

Dentre todas as barreiras identificadas na literatura, nenhuma foi semelhante em todos os estudos de caso. Na prática empresarial, a identificação das barreiras "funcionários desqualificados" e "recursos limitados", corrobora com a literatura, já que também foram as principais identificadas na RSL desta pesquisa.

É válido ressaltar que em dois estudos de caso houve indicação de inclusão de barreiras, a organizaçãoB incluiu "área de compras das empresas" e a organizaçãoC incluiu "corrupção", sendo uma contribuição desta pesquisa para literatura. Além disso, a barreira "recursos limitados" referem-se a recursos financeiros nos casos A e D, e recursos técnicos no caso $\mathrm{D}$.

A barreira "fraca força do mercado" identificado no estudo de caso A, condiz com a análise das forças competitivas da empresa, na qual mostra que a organizaçãoA não possui força no poder de negociação com clientes e fornecedores. Funcionários qualificados são considerados recursos valiosos e raros para os estudos de caso B e D, portanto "funcionários desqualificados" é uma barreira para essas empresas melhorarem seu desempenho. O desenvolvimento de parcerias estratégicas é um recurso valioso para a organizaçãoC, pois, como já mencionado, é por meio de parcerias que a empresa está começando a incorporar inovações e tecnologias, portanto "falta de cooperação" é uma barreira para o desempenho da mesma.

Em relação aos determinantes identificados na literatura (inovação e orientação ao mercado) que estão relacionados à proposição de pesquisa (as pequenas empresas têm uma maior propensão ao mercado e à inovação dependendo das forças de mercado e baseadas nos recursos VRIN da empresa), enquanto na RSL apenas $6 \%$ das pesquisas identificavam esses dois determinantes em conjunto, na prática todas as organizações dos estudos de caso lidam com ambos. Isso ressalta a relevância da pesquisa na literatura. O painel de dados dos estudos de caso é apresentado no Quadro 16. A Figura 8 mostra uma visão geral dos temas que cada estudo de caso aborda. 


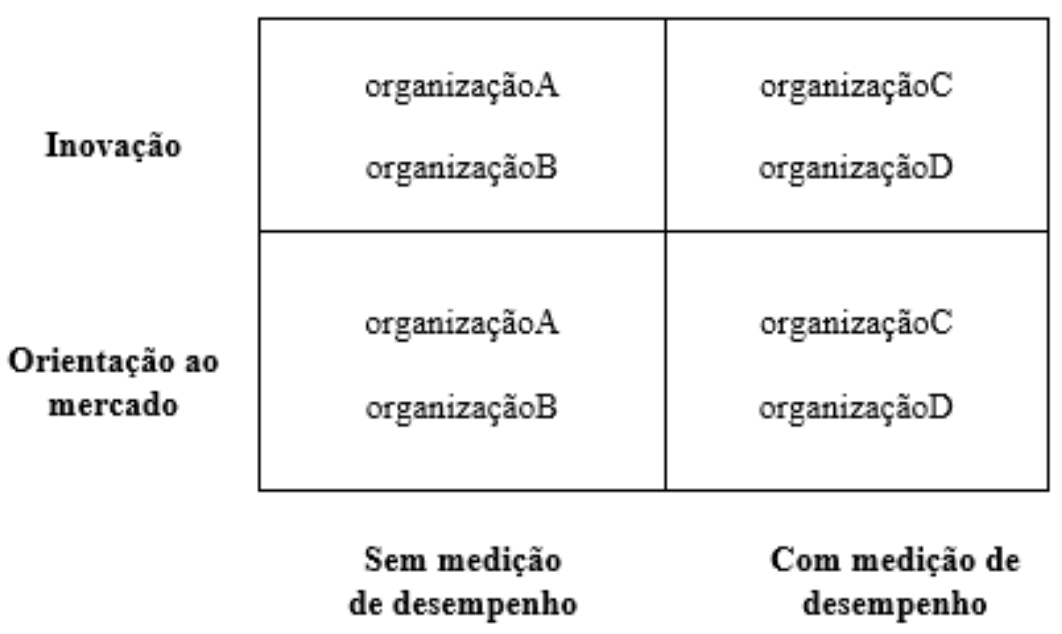

Figura 8 - Matriz dos temas abordados nos estudos de caso

Quadro 16 - Painel de dados dos estudos de caso

\begin{tabular}{|c|c|}
\hline Inovação & $\begin{array}{l}\text { Em todos os estudos de caso a inovação está incorporada na visão } \\
\text { estratégica da empresa e o mercado é que gera a necessidade de } \\
\text { inovar. Enquanto os estudos de caso A e D procuram criar um } \\
\text { diferencial competitivo por meio da inovação, tendo um } \\
\text { comportamento reativo (não perder mercado), os estudos de caso B e } \\
\text { C, além de procurar criar um diferencial, também procuram ganhar } \\
\text { mercado por meio da inovação, tendo um comportamento proativo. } \\
\text { Assim, os esforços de inovação são tratados como um recurso VRIN } \\
\text { em todos os casos, porém não há esforços de recompensa pelo } \\
\text { mesmo, e a inovação também foi identificada como um dos principais } \\
\text { facilitadores para o desempenho por todas as organizações. }\end{array}$ \\
\hline Orientação ao mercado & $\begin{array}{l}\text { Enquanto os casos A e B possuem pouca concorrência, C e D têm } \\
\text { muita concorrência. Todos os estudos de caso possuem orientação ao } \\
\text { mercado, tendo a orientação ao cliente incorporada na visão } \\
\text { estratégica de todas as empresas, sendo que "atender as necessidades } \\
\text { dos clientes" foi um dos principais facilitadores identificados nas } \\
\text { organizações. Apenas os estudos de caso A e D têm orientação ao } \\
\text { concorrente e tratam o conhecimento do mercado como um recurso } \\
\text { valioso. A principal estratégia para lidar com a concorrência, utilizada } \\
\text { por todas as empresas para obter vantagens competitivas, é a } \\
\text { diferenciação, obtida por meio da inovação. Outras importantes } \\
\text { estratégias são usadas, como custo e parcerias nas organizações B e C. }\end{array}$ \\
\hline $\begin{array}{l}\text { Desempenho } \\
\text { operacional }\end{array}$ & $\begin{array}{l}\text { Os estudos de caso A e B não possuem medições de desempenho } \\
\text { operacional referentes às cinco dimensões e conhecem o desempenho } \\
\text { geral das empresas por meio de indicador financeiro. Já os estudos de } \\
\text { caso C e D possuem indicadores de desempenho operacionais e } \\
\text { consideram "medição de desempenho" como um facilitador, porém } \\
\text { não há indicadores referentes à dimensão de inovação. Em todos os } \\
\text { estudos de caso a dimensão da qualidade é considerada a principal } \\
\text { para o desempenho, é tratada como um recurso valioso e apontada } \\
\text { como um dos principais facilitadores em todas as empresas. Além } \\
\text { disso, a qualidade está incorporada na visão estratégica das } \\
\text { organizações B, C e D. }\end{array}$ \\
\hline
\end{tabular}




\begin{tabular}{|l|l|}
\hline Tecnologias disruptivas & $\begin{array}{l}\text { Os estudos de caso A, B e D utilizam as tecnologias por necessidades } \\
\text { internas e os estudos de caso A e C utilizam tecnologias por } \\
\text { necessidades externas (mercado). As organizações A e B buscam } \\
\text { principalmente com as tecnologias agregar valor aos seus serviços. A } \\
\text { organizaçãoD usa tecnologias desde a sua origem e vem } \\
\text { acompanhando sua evolução, enquanto que a organizaçãoC está na } \\
\text { fase inicial de seu uso. Assim, os estudos de caso A, B e D tratam as } \\
\text { tecnologias como um recurso VRIN para seus desempenhos. }\end{array}$ \\
\hline
\end{tabular}

Quanto à inovação, em todas as organizações a inovação está presente na missão, visão ou valores da empresa. O motivo que levou todas as empresas a inovarem foi um fator externo: mercado. As organizações A e D inovam com objetivo de atender as necessidades dos clientes e as organizações B e C inovam com objetivo de ganhar mercado. Assim, a competitividade e o crescimento no mercado são as forças que direcionam as atividades de inovação.

González-Benito et al. (2016) confirmam que as empresas se beneficiam com a implementação de inovação, uma vez que usam recursos e conseguem responder às mudanças do mercado, e portanto, os esforços de inovação são fundamentais para promover o sucesso dos negócios.

É válido ressaltar que, apesar de algumas empresas terem identificado "recursos limitados (financeiro)" em suas barreiras, em nenhum estudo de caso as restrições financeiras afetam a capacidade de inovar, sendo que todos relataram terem recursos suficientes para atividades de inovação.

Quanto a orientação ao mercado, em todas as organizações isso se dá principalmente por meio da orientação ao cliente. Assim, devido às necessidades dos clientes é que as empresas procuram inovar para criar valor nos seus serviços. E apenas em dois estudos de caso (A e D) há uma orientação ao concorrente com o intuito de conhecer as estratégias, os pontos fortes e fracos da concorrência para obter vantagens através desse conhecimento. Na literatura, Zhang et al. (2017) indicam que a orientação ao mercado agrega valor para as organizações, já que gera vantagens ao direcionar ações para competição, atendimento das necessidades dos clientes e desenvolvimento de novas inovações.

Assim, postula-se a seguinte proposição: quanto maior a orientação ao mercado de óleo e gás, mais esforços de inovações os pequenos negócios de serviços terão.

Em relação ao desempenho operacional, em dois estudos de caso (A e B) não há uma cultura de implementar medidas de desempenho. Já na organizaçãoC 
existem indicadores de desempenho devido à implementação do sistema de gestão integrado, em conformidade com normas da ISO, e na organizaçãoD também há indicadores de desempenho devido à certificação da norma ISO 9001.

Dessa forma, as empresas que possuem medidas de desempenho focam principalmente na dimensão da qualidade, e as outras empresas também focam na qualidade dos serviços apesar de não medirem esse desempenho. Assim, em todos os casos a qualidade é considerada um recurso valioso e identificada como um facilitador para o desempenho.

Polo Peña et al. (2011) relatam que a qualidade é uma estratégia de sucesso para empresas de serviços e que o aumento da qualidade do mercado se dá por meio da adoção de orientação ao mercado.

A principal tecnologia disruptiva utilizada por todas as empresas é a internet das coisas, na qual envolve conectar diversos dispositivos à rede para permitir a integração entre eles digitalmente (Deloitte, 2018; FNQ, 2018). Outras tecnologias importantes citadas nos estudos de caso são big data, que permite a mineração e análise de dados, e design digital, simulação e integração (DDSI), que permite desenvolver modelos de simulação. Essas tecnologias são utilizadas pelas organizações principalmente para agregar valor nos seus serviços devido exigências do mercado ou necessidades internas.

Portanto, os pequenos negócios do setor de óleo e gás visam, com a inovação, melhorar seus desempenhos gerando vantagens competitivas, o que ocasiona mudança nas suas curvas de demanda, mantendo ou ganhando novos mercados ao oferecer novos serviços e aumentando a qualidade dos seus serviços.

Entretanto, falta as pequenas empresas aprimorarem suas capacidades de desenvolvimento de inovação, por exemplo, em nenhum estudo de caso há medidas de desempenho referentes à dimensão de inovação e também não há esforços de recompensas pela inovação para contribuir na existência de uma cultura organizacional voltada à inovação.

Saunila (2017a) diz que "medidas adequadas de desempenho da inovação podem contribuir para uma compreensão significativamente melhor da inovação". Complementando, Exposito e Sanchis-Llopis (2018) argumentam que o impacto da inovação no desempenho do negócio pode ser consideravelmente diferente dependendo do tipo de inovação e da dimensão de desempenho considerada, assim é necessário a empresa determinar quais medidas de desempenho e tipos de 
inovações são usadas para direcionar as políticas de inovação de forma mais eficiente.

Os principais motivos que levam as organizações dos estudos de caso a terem atividades de inovação são competição, demanda e mercados. Todos são fatores externos às empresas e a importância desses motivos gera esforços para evitar uma queda ou aumentar a parcela de mercado captada pelas organizações. Logo, a orientação ao mercado se torna necessária paras as empresas direcionarem suas ações de maneira estrategicamente assertiva.

Todavia, nenhum dos estudos de caso possui uma orientação ao mercado de forma abrangente. Há empresas que têm orientação somente voltada aos clientes e não voltada aos concorrentes, e apesar de algumas empresas terem ambas orientações, nenhuma organização mostrou ter uma integração interfuncional, que iria proporcionar o uso coordenado dos seus recursos e o aprimoramento da capacidade de resposta ao mercado.

Zhang et al. (2017) ratificam que as empresas com orientação ao mercado devem ter práticas gerenciais que garantam a implementação dos seus elementos de forma eficaz, podendo ocasionar a necessidade de uma coordenação interfuncional, mudanças estruturais e de recursos humanos para ter inteligência de mercado, uma vez que a orientação ao mercado afeta a estratégia e o desempenho do negócio. 


\section{5 \\ Conclusão}

Nesta seção são abordadas as principais conclusões obtidas com as análises dos resultados da RSL e do estudo de caso múltiplo, dividida em duas subseções: considerações finais, abrangendo os objetivos alcançados, implicações da pesquisa e limitações, e por fim, sugestões para trabalhos futuros.

\section{1 \\ Considerações finais}

A pesquisa identificou e explorou os principais determinantes, facilitadores e barreiras para o desempenho operacional de pequenos negócios prestadores de serviços do segmento de óleo e gás, respondendo às questões de pesquisa apresentadas.

O referencial teórico elucidou que a inovação e a orientação ao mercado são determinantes relevantes para o desempenho de pequenas empresas prestadoras de serviços, além de evidenciar que na literatura existem lacunas sobre a relação desses determinantes com o desempenho em pequenos negócios, principalmente no segmento de serviços de óleo e gás.

A pesquisa multi-metodológica foi complementar e permitiu o melhor entendimento dos fenômenos em estudo. Ressalta-se que as coletas e análises dos dados foram conduzidas por proposição teórica. A RSL permitiu identificar os principais fatores determinantes, facilitadores e barreiras para o desempenho de pequenos negócios do setor de serviços, que serviram de base para as proposições teóricas do estudo de caso, alcançando assim o primeiro objetivo especifico do estudo, descrito na seção 4.1 .

Além disso, a RSL comprovou que a literatura ainda carece de estudos relacionados ao tema desta pesquisa, sendo que em muitas das pesquisas existentes não há a base teórica do RBV e das forças de mercado de Porter. Dessa forma, com o estudo de caso múltiplo, quatro organizações foram selecionadas para realizar a pesquisa de campo e analisar o que foi encontrado na revisão 
sistemática da literatura no contexto operacional das empresas, permitindo o alcance do segundo e terceiro objetivos específicos, além do objetivo geral da pesquisa, descritos na seção 4.2.

Por conseguinte, como resultados da RSL, identificou-se que a inovação e a orientação ao mercado são os principais fatores determinantes para o desempenho de pequenos negócios, e que qualidade, capital humano e inovação de produto/serviços são os principais facilitadores para o desempenho, enquanto que recursos limitados e funcionários desqualificados são as principais barreiras.

Nas análises dos resultados do estudo de caso, identificou-se que há uma heterogeneidade dos principais recursos VRIN das empresas e que os recursos de tecnologia e esforços de inovação são os mais frequentes entre os estudos de caso. Também foram analisadas as forças competitivas de mercado e a principal estratégia utilizada por todas as organizações para lidar com a concorrência é a diferenciação.

Observou-se que o mercado é o principal fator que motiva as empresas na implementação de inovações. Enquanto os estudos de caso A e D procuram criar um diferencial competitivo, atendendo as necessidades dos clientes por meio da inovação, os estudos de caso B e C, além de procurar criar um diferencial, também objetivam ganhar mercado com a inovação. Assim, percebeu-se que a orientação ao mercado é necessária para que as empresas direcionem esforços de forma estratégica para evitar uma queda ou aumentar a parcela de mercado captada por elas.

Também foi identificado que qualidade, inovação de produto/serviço, atender as necessidades dos clientes e informações (TI) foram os quatros facilitadores semelhantes em todos os estudos de caso, sendo que os três primeiros são tratados como recursos VRIN em todas as empresas. Já recursos limitados e funcionários desqualificados foram algumas das principais barreiras identificadas pelas empresas, corroborando com a literatura.

A qualidade também foi identificada como a principal dimensão de desempenho dos estudos de caso, uma vez que todas as organizações focam na melhoria da qualidade dos seus serviços, tanto as que possuem um sistema de medição de desempenho quanto as que não tem essas medidas.

Além disso, nas análises dos resultados dos estudos de caso também foi identificado que a internet das coisas é a principal tecnologia disruptiva utilizada 
por todas as empresas, seguida por big data e design digital, simulação e integração (DDSI), sendo utilizadas principalmente para agregar valor nos serviços devido exigências do mercado ou necessidades internas e tratadas como um recurso VRIN pelos estudos de caso A, B e D.

\subsection{1 \\ Limitações}

Dentre as limitações presentes no decorrer da pesquisa, pode-se citar que na RSL não foi aplicada a técnica de snowball, que consiste nas buscas backward e forward de citações feitas aos artigos selecionados. Além disso, é válido ressaltar que não foi objetivo do trabalho mensurar o nível ou grau de impacto dos determinantes no desempenho operacional das empresas, portanto a abordagem quantitativa não está presente no estudo por definição de escopo da pesquisa.

\section{1 .2 Implicações e contribuições}

Apesar das limitações, o presente estudo apresenta diferentes contribuições de forma efetiva com implicações teóricas e práticas, alcançando assim o quarto objetivo especifico da pesquisa, descrito nas seções 5.1.2 e 5.2. Em relação às implicações teóricas, há uma contribuição para a literatura de gestão de operações de serviços, tendo como base vertentes teóricas da visão baseada em recursos e das forças competitivas de mercado. Mais especificamente, foi discutido a relação entre inovação, orientação ao mercado e desempenho operacional nos pequenos negócios, no qual foi evidenciado na RSL que apenas $6 \%$ das pesquisas identificavam inovação e orientação ao mercado em conjunto, o que ressalta a relevância desta pesquisa para a literatura. Também foi demonstrado que há poucas pesquisas sobre esse tema, realizadas em pequenos negócios nos países em desenvolvimento, principalmente no segmento de óleo e gás, e este estudo aborda essas lacunas.

Quanto às implicações práticas, esta pesquisa contribui para a prática gerencial ressaltando a necessidade de os pequenos negócios buscarem estratégias focadas em orientação ao mercado e de aprimoramento da inovação de forma integrada, para assim poderem gerenciar seus recursos e capacidades organizacionais com intuito de melhorar seus desempenhos. Ressalta igualmente a 
necessidade de desenvolver e aplicar sistemas de medição de desempenho da inovação e operacional nas empresas.

A importância desses determinantes para o desempenho mostra que nas pequenas empresas a diferenciação é uma estratégia que gera vantagens competitivas na rivalidade com os concorrentes, sendo que essa diferenciação pode ocorrer por meio da inovação, melhoria da qualidade, utilização de tecnologias ou oferecendo novos serviços. As parcerias entre as empresas também é uma estratégia que continua importante. Os pequenos negócios podem encontrar oportunidades para aprimorar seus desempenhos através de parcerias que podem afetar a manutenção ou conquista de mercado (cocriação ou esforços colaborativos em inovação e tecnologia).

\section{2 \\ Sugestões de trabalhos futuros}

Devido às limitações referentes aos métodos de pesquisa, sugere-se como trabalhos futuros que na RSL seja realizada a busca em outras bases além do Scopus, o uso da técnica de snowball para seleção de artigos e a aplicação da última etapa da RSL, detalhado por Thomé et al. (2016), que é a atualização da revisão.

Sugere-se também que seja aplicado outros métodos de pesquisa, com abordagem quantitativa, que possam mensurar o impacto e consequências de cada determinante e em como o desempenho operacional dos pequenos negócios é afetado diretamente.

Já que nos estudos de caso não foram observadas medidas de desempenho referentes à dimensão de inovação, outro trabalho sugerido é a investigação de como são desenvolvidas medidas do desempenho da inovação em pequenas empresas de serviços do segmento de óleo e gás, de modo que as relações causais entre essas medidas e o gerenciamento de desempenho operacional possam ser identificadas em maior detalhe.

Além disso, propostas para pesquisas futuras também incluem verificar o efeito dos facilitadores e barreiras ao desempenho de pequenos negócios em serviços na consolidação de sucesso, o que forneceria uma visão mais profunda do 
porquê e como algumas pequenas empresas são mais bem-sucedidas do que outras.

\section{Agradecimento}

O presente trabalho foi realizado com apoio da Coordenação de Aperfeiçoamento de Pessoal de Nível Superior - Brasil (CAPES) - Código de Financiamento 001. 
6

\section{Referências bibliográficas}

ABDULLAH, A. Measuring TQM implementation: A case study of Malaysian SMEs. Measuring Business Excellence, v. 14, n. 3, p. 3-15, 2010.

AGARWAL, S.; KRISHNA ERRAMILLI, M.; DEV, C. S. Market orientation and performance in service firms: role of innovation. Journal of Services Marketing, v. 17, n. 1, p. 68-82, fev. 2003.

AHMED, S.; HALIM, H. A.; AHMAD, N. H. Open and Closed Innovation and Enhanced Performance of SME Hospitals - A Conceptual Model. Business Perspectives and Research, v. 6, n. 1, p. 1-12, 2018.

AKINWALE, Y. O. The nexus between R\&D, innovation and profitability of indigenous oil firms: A structural equilibrium model approach. 5th International Symposium on Computational and Business Intelligence (ISCBI). 2017.

AKINWALE, Y. O.; AKINBAMI, J. F. K.; AKARAKIRI, J. B. Factors influencing technology and innovation capability in the Nigerian indigenous oil firms. International Journal of Business Innovation and Research, v. 15, n. 2, p. 247, 2018.

ALFOQAHAA, S. Critical success factors of small and medium-sized enterprises in Palestine. Journal of Research in Marketing and Entrepreneurship, v. 20, n. 2, p. 170-188, 2018.

ALI, J.; SHABIR, S. Does gender make a difference in business performance? Gender in Management: An International Journal, v. 32, n. 3, p. 218-233, 2 maio 2017.

AUGUSTO, M. G.; LISBOA, J. V.; YASIN, M. M. Organisational performance and innovation in the context of a total quality management philosophy: an empirical investigation. Total Quality Management \& Business Excellence, v. 25, n. 9-10, p. 1141-1155, 7 ago. 2014.

BAMIATZI, V. C.; KIRCHMAIER, T. Strategies for superior performance under adverse conditions: A focus on small and medium-sized high-growth firms. International Small Business Journal, v. 32, n. 3, p. 259-284, 2014.

BARNEY, J. Firm Resources and Sustained Competitive Advantage. Journal of Management, v. 17, n. 1, p. 99-120, 1991.

BARNEY, J. B.; HESTERLY, W. S. Strategic management and competitive advantage: concepts. Prentice Hall PTR, 4ed., 377p., 2011.

BORBA, M.; NETO, C. G.; FIGUEIREDO, O. Open Innovation in the Oil and Gas Industry in Brazil. International Association for Management of 
Technology. IAMOT Conference Proceedings. 2016.

BRACKERTZ, N. Relating physical and service performance in local government community facilities. Facilities, v. 24, n. 7/8, p. 280-291, jun. 2006.

BRUSH, C. G.; CHAGANTI, R. Businesses without glamour? An analysis of resources on performance by size and age in small service and retail firms. Journal of Business Venturing, v. 14, n. 3, p. 233-257, 1999.

CAMPBELL COLLABORATION. Campbell Systematic Reviews: Policies and Guidelines. Campbell Policies and Guidelines Series No. 1. 2014. DOI: $10.4073 /$ cpg.2016.1.

CAMPBELL, J. M.; PARK, J. Extending the resource-based view: Effects of strategic orientation toward community on small business performance. Journal of Retailing and Consumer Services, v. 34, p. 302-308, jan. 2017.

CAREY, P. J. External accountants' business advice and SME performance. Pacific Accounting Review, v. 27, n. 2, p. 166-188, 7 abr. 2015.

CARVALHO, G. D. G.; SILVA, E. D.; CARVALHO, H. G.; CAVALCANTE, M. B.; CRUZ, J. A. W. Brazilian SMEs' innovation strategies: agro-industry, construction and retail industries. International Journal of Business Innovation and Research, v. 14, n. 3, p. 397, 2017.

CAUCHICK MIGUEL, P. A. O método do estudo de caso na Engenharia de Produção. In: Metodologia de Pesquisa em Engenharia de Produção e Gestão de Operações. 2. ed. Rio de Janeiro: Elsevier, 2012.

CHEN, Y.-Y. K.; JAW, Y.-L.; WU, B.-L. Effect of digital transformation on organisational performance of SMEs. Internet Research, v. 26, n. 1, p. 186-212, 12 fev. 2016.

CHO, D. W.; LEE, Y. H.; AHN, S. H.; HWANG, M. K. A framework for measuring the performance of service supply chain management. Computers \& Industrial Engineering, v. 62, n. 3, p. 801-818, abr. 2012.

CNI-INDICATORS. Special survey - Industry 4.0: a new challenge for Brazilian industry. Brazil, National Conference of Industry, n. April, p. 13, 2016.

COHEN, S.; KAIMENAKIS, N. Intellectual capital and corporate performance in knowledge-intensive SMEs. Learning Organization, v. 14, n. 3, p. 241-262, 2007.

COLEMAN, S. the Profitability and Growth of Women-Owned. Journal of Small Business Management, v. 45, n. 3, p. 303-319, 2007.

COOK, G.; PANDIT, N. Chapter 5 Clustering and the Internationalisation of High Technology Small Firms in Film and Television. In: New Technology Based Firms in the New Millennium. [s.l: s.n.]. v. 9p. 49-70. 2012.

COOPER, H. M. Research Synthesis and Meta-Analysis: A Step-by-Step Approach. 4th ed. ed. [s.1.] Thousand Oaks, CA: Sage., 2010.

CORRÊA, H. L.; ELLRAM, L. M.; SCAVARDA, A. J.; COOPER, M. C. 
An operations management view of the services and goods offering mix. International Journal of Operations \& Production Management, v. 27, n. 5, p. 444-463, 2007.

COVIELLO, N.; WINKLHOFER, H.; HAMILTON, K. Marketing practices and performance of small service firms: An examination in the tourism accommodation sector. Journal of Service Research, v. 9, n. 1, p. 38-58, 2006.

COWELL, D. W. New service development. Journal of Marketing Management, v. 3, p. 296-312, 1988.

DELOITTE. Exponential technologies in manufacturing. Singularity University. [s.l: s.n.]. 2018.

DEMIRBAG, M.; TATOGLU, E.; TEKINKUS, M.; ZAIM, S. An analysis of the relationship between TQM implementation and organizational performance: Evidence from Turkish SMEs. Journal of Manufacturing Technology Management, v. 17, n. 6, p. 829-847, 2006.

DIDONET, S. R.; SIMMONS, G.; DÍAZ-VILLAVICENCIO, G.; PALMER, M. Market Orientation's Boundary-Spanning Role to Support Innovation in SMEs. Journal of Small Business Management, v. 54, p. 216-233, 2016.

DOUGHERTY, D.; HARDY, C. Sustained product innovation in large, mature organizations: Overcoming innovation-to-organization problems. Academy of Management Journal, v. 39, n. 5, p. 1120-1153, 1996.

EDELMAN, L. F.; BRUSH, C. G.; MANOLOVA, T. Co-alignment in the resource-performance relationship: Strategy as mediator. Journal of Business Venturing, v. 20, n. 3, p. 359-383, 2005.

EXPOSITO, A.; SANCHIS-LLOPIS, J. A. Innovation and business performance for Spanish SMEs: New evidence from a multi-dimensional approach. International Small Business Journal: Researching Entrepreneurship, p. 026624261878259, 2018.

FAHIM, N. A.; BAHARUN, R. Analyzing the Mediating Effect of Innovation Capability on Strategic Orientations in Agricultural Malaysia. WSEAS Transactions on Business and Economics, v. 14, p. 253-262, 2017.

FERDOWS, K.; DE MEYER, A. Lasting Improvements in Manufacturing Performance: In Search of a New Theory. Journal of Operations Management, v. 9, n. 2, 1990.

FIELD, J. M.; VICTORINO, L.; BUELL, R. W.; DIXON, M. J.; GOLDSTEIN, S. M.; MENOR, L. J.; PULLMAN, M. E.; ROTH, A. V.; SECCHI, E.; ZHANG, J. J. Service operations: what's next? Journal of Service Management, v. 29, n. 1, p. 55-97, 2017.

FILIATRAULT, P.; HARVEY, J.; CHEBAT, J.-C. Service quality and service productivity management practices. Industrial Marketing Management, v. 25, p. 243-255, 1996.

FITZGERALD, L.; BRIGNALL, T. J.; JOHNSTON, R.; SILVESTRO, R. Performance measurement in service businesses. Management 
Accounting. London: CIMA. 1991.

FITZSIMMONS, J. A.; FITZSIMMONS, M. J. Administração de serviços: operações, estratégia e tecnologia da informação. 6. ed. Porto Alegre: Bookman, 2010.

FNQ - Fundação Nacional da Qualidade. Guia completo sobre a transformação digital nas empresas. [s.l: s.n.]. 2018.

FORD, R. C.; STURMAN, M. C.; HEATON, C. P. Managing Quality Service in Hospitality: How Organizations Achieve Excellence in the Guest Experience. [s.1.] Cengage Learning, 2011.

FREEL, M. S.; ROBSON, P. J. A. Small firm innovation, growth and performance: Evidence from Scotland and Northern England. International Small Business Journal, v. 22, n. 6, p. 561-575, 2004.

FREEMAN, J.; STYLES, C. Does location matter to export performance? International Marketing Review, v. 31, n. 2, p. 181-208, 8 abr. 2014.

GAUR, S. S.; VASUDEVAN, H.; GAUR, A. S. Market orientation and manufacturing performance of Indian SMEs: Moderating role of firm resources and environmental factors. European Journal of Marketing, v. 45, n. 7, p. 1172-1193, 2011.

GENGO, T.; FURUTA, K.; KANNO, T.; FUKUMOTO, K. Development of Service Performance Indicators for Operations Management in Airline. In: ONADA, T.; BEKKI, D.; MCCREADY, E. (Eds.). New Frontiers in Artificial Intelligence. Lecture Notes in Computer Science. Berlin, Heidelberg: Springer Berlin Heidelberg, v. 6797, 2011.

GERSCHEWSKI, S.; ROSE, E. L.; LINDSAY, V. J. Understanding the drivers of international performance for born global firms: An integrated perspective. Journal of World Business, v. 50, n. 3, p. 558-575, jul. 2015.

GIANESI, I. G. N.; CORRÊA, H. L. Administração Estratégica de Serviços: operações para a satisfação do cliente. São Paulo: Atlas, 2008.

GONÇALVES, A. D.; CARDOSO, H. H. R.; CARVALHO, H. G.; CARVALHO, G. D. G.; STANKOWITZ, R. F. Panorama view of Innovation in Brazilian Small Businesses. International Journal of Innovation, v. 5, n. 3, p. 325-334, 1 dez. 2017.

GONZÁlEZ-BENITO, Ó.; MUÑOZ-GALLEGO, P. A.; GARCÍAZAMORA, E. Role of collaboration in innovation success: differences for large and small businesses. Journal of Business Economics and Management, v. 17, n. 4, p. 645-662, 2016.

HAASE, H.; FRANCO, M. What factors drive performance of small and Medium-Sized Enterprises? European Journal of International Management, v. 10, n. 6, p. 678-697, 2016.

HALLGREN, M.; OLHAGER, J. Lean and agile manufacturing: External and internal drivers and performance outcomes. International Journal of Operations and Production Management, v. 29, n. 10, p. 976-999, 2009.

HAMID, R. A.; ISMAIL, I. R. Success factors of lean thinking and operational performance in service sector. Journal Pengurusan, v. 47, 
2016.

HASSANI, H.; SILVA, E. S.; AL KAABI, A. M. The role of innovation and technology in sustaining the petroleum and petrochemical industry. Technological Forecasting and Social Change, v. 119, p. 1-17, jun. 2017.

HEIMONEN, T. What are the factors that affect innovation in growing SMEs? European Journal of Innovation Management, v. 15, n. 1, p. 122-144, 2012.

HENARD, D. H.; SZYMANSKI, D. M. Why Some New Products Are More Successful Than Others. Journal of Marketing Research, v. 38, n. 3, p. $362-375,2001$.

HERNÁNDEZ-MAESTRO, R. M.; MUÑOZ-GALLEGO, P. A.; SANTOSREQUEJO, L. Small-business owners' knowledge and rural tourism establishment performance in Spain. Journal of Travel Research, v. 48, n. 1, p. 58-77, 2009.

HESKETT, J. L. Notes from the search for deep indicators in services. Journal of Service Management, v. 25, n. 3, p. 298-309, 10 jun. 2014.

HONG, Y.; JIANG, Y.; LIAO, H.; STURMAN, M. C. High Performance Work Systems for Service Quality: Boundary Conditions and Influence Processes. Human Resource Management, v. 56, n. 5, p. 747-767, set. 2017.

JAW, C.; LO, J.-Y.; LIN, Y.-H. The determinants of new service development: Service characteristics, market orientation, and actualizing innovation effort. Technovation, v. 30, n. 4, p. 265-277, abr. 2010.

KAMYABI, Y.; DEVI, S. The impact of advisory services on Iranian SME performance: An empirical investigation of the role of professional accountants. South African Journal of Business Management, v. 43, n. 2, p. 61-72, 29 jun. 2012.

KEEBLE, D. Small firms, innovation and regional development in Britain in the 1990s. Regional Studies, v. 31, n. 3, p. 281-293, 1997.

KEIZER, J. A.; DIJKSTRA, L.; HALMAN, J. I. M. Explaining innovative efforts of SMEs. An exploratory survey among SMEs in the mechanical and electrical engineering sector in The Netherlands. Technovation, v. 22, n. 1, p. 1-13, jan. 2002.

KIM, J. S.; ARNOLD, P. Manufacturing Competence and Business Performance: A Framework and Empirical Analysis. International Journal of Operations \& Production Management, v. 13, n. 10, p. 4-25, 1993.

KIRCA, A. H.; JAYACHANDRAN, S.; BEARDEN, W. O. Market Orientation: A Meta-Analytic Review and Assessment of Its Antecedents and Impact on Performance. Journal of Marketing, v. 69, n. 2, p. 24-41, abr. 2005.

LEE, C.; HALLAK, R. Investigating the moderating role of education on a structural model of restaurant performance using multi-group PLS-SEM analysis. Journal of Business Research, v. 88, n. June, p. 298-305, 2018.

LEE, Y.; KIM, S.; LEE, H. The impact of service R\&D on the performance 
of Korean information communication technology small and medium enterprises. Journal of Engineering and Technology Management - JETM, v. 28, n. 1-2, p. 77-92, 2011.

LEONIDOU, L. C.; PALIHAWADANA, D.; THEODOSIOU, M. National Export-Promotion Programs as Drivers of Organizational Resources and Capabilities: Effects on Strategy, Competitive Advantage, and Performance. Journal of International Marketing, v. 19, n. 2, p. 1-29, jun. 2011.

LERNER, M.; HABER, S. Performance factors of small tourism ventures: The interface of tourism, entrepreneurship and the environment. Journal of Business Venturing, v. 16, n. 1, p. 77-100, 2001.

LIN, Y.; WU, L. Y. Exploring the role of dynamic capabilities in firm performance under the resource-based view framework. Journal of Business Research, v. 67, n. 3, p. 407-413, 2014.

MACHUCA, J. A. D.; GONZÁLEZ-ZAMORA, M. DEL M.; AGUILARESCOBAR, V. G. Service Operations Management research. Journal of Operations Management, v. 25, n. 3, p. 585-603, 2007.

MCDERMOTT, C. M.; PRAJOGO, D. I. Service innovation and performance in SMEs. International Journal of Operations \& Production Management, v. 32, n. 2, p. 216-237, 2012.

MDIC - Ministério do Desenvolvimento, Indústria e Comércio Exterior. Atlas Nacional de Comércio e Serviços. Brasília: [s.n.]. 2013.

MDIC - Ministério do Desenvolvimento, Indústria e Comércio Exterior. A importância do Setor Terciário. Disponível em: $<$ http://www.mdic.gov.br/index.php/comercio-servicos/a-secretaria-decomercio-e-servicos-scs/402-a-importancia-do-setor-terciario>. Acesso em: 20 mai. 2018.

MEUTIA. The relationship between entrepreneurship social competence and marketing performance in Indonesian smes: The role of business networking and product innovation. International Journal of Applied Business and Economic Research, v. 13, n. 7, p. 5357-5373, 2015.

MEUTIA; ISMAIL, T. The influence of competitive pressure on innovative creativity. In: Academy of Strategic Management Journal. [s.l: s.n.]. v. 10. 2015 .

MONGEON, P.; PAUL-HUS, A. The journal coverage of Web of Science and Scopus: a comparative analysis. Scientometrics, v. 106, n. 1, p. 213 228, 19 jan. 2016.

MOTHE, C.; THI, T. U. N. The link between non-technological innovations and technological innovation. European Journal of Innovation Management, v. 13, n. 3, p. 313-332, 2010.

NARCIZO, R. B.; CANEN, A. G.; TAMMELA, I. SME's innovation capability as a resource to meet future logistical demands of brazilian oil industry. Annals of Faculty Engineering Hunedoara - International Journal Of Engineering, p. 431-438, 2013.

NARVER, J. C.; SLATER, S. F. The Effect of a Market Orientation on a Business Profitability. Journal of marketing, v. 54, n. 4, p. 20-35, 1990. 
NATH, P.; NACHIAPPAN, S.; RAMANATHAN, R. The impact of marketing capability, operations capability and diversification strategy on performance: A resource-based view. Industrial Marketing Management, v. 39, n. 2, p. 317-329, 2010.

NDUBISI, N. O.; IFTIKHAR, K. Relationship between entrepreneurship, innovation and performance. Journal of Research in Marketing and Entrepreneurship, v. 14, n. 2, p. 214-236, 12 out. 2012.

NIKOLIĆ, I.; DHAMO, Zh.; SCHULTE, P.; MIHAJLOVIĆ, I.; KUME, V. An analysis of factors affecting failure of SMEs. Proceedings of 11th International May Conference on Strategic Management-IMKSM2015, 29-31. May 2015, Bor, Serbia, pp. 160-180.

NOGUEIRA, J. F. Gestão estratégica de serviços: teoria e prática. 1. ed. São Paulo: Atlas, 2008.

OECD - Organisation for Economic Co-operation and Development. Oslo manual: proposed guidelines for collecting and interpreting technological innovation data. [s.l: s.n.]. 2005.

OLY NDUBISI, N.; AGARWAL, J. Quality performance of SMEs in a developing economy: direct and indirect effects of service innovation and entrepreneurial orientation. Journal of Business \& Industrial Marketing, v. 29, n. 6, p. 454-468, 30 jun. 2014.

PALADINI, E. P. Gestão de serviços: casos brasileiros. 1. ed. São Paulo: Atlas, 2013.

PAPADOPOULOS, G.; RIKAMA, S.; ALAJÄÄSKÖ, P.; SALAHEDDINE, Z.; AIRAKSINEN, A.; LUOMARANTA, H. Statistics on small and medium-sized enterprises - Statistics Explained. Disponível em: $<$ http://ec.europa.eu/eurostat/statistics-

explained/index.php/Statistics_on_small_and_medium-

sized_enterprises\#General_overview>. Acesso em: 20 mai. 2018.

PARASURAMAN, A.; ZEITHAML, V. A.; BERRY, L. L. SERVQUAL: A multiple-itemscale for measuring consumer perceptions of service quality. Journal of Retailing, v. 64, n. 1, p. 12-40, 1988.

PERRONS, R. K. How innovation and R\&amp;D happen in the upstream oil \&amp; gas industry: Insights from a global survey. Journal of Petroleum Science and Engineering, v. 124, p. 301-312, dez. 2014.

PETTICREW, R.; ROBERTS, H. Systematic Reviews in the Social Sciences. A Pratical Guide. [s.1.] Malden, MA: Blackwell, 2006.

POLO PEÑA, A. I.; FRÍAS JAMILENA, D. M.; RODRÍGUEZ MOLINA, M. Á. Impact of Market Orientation and ICT on the Performance of Rural Smaller Service Enterprises. Journal of Small Business Management, v. 49, n. 3, p. 331-360, 2011.

POLO PEÑA, A. I.; FRÍAS JAMILENA, D. M.; RODRÍGUEZ MOLINA, M. Á. The Effect of Customer Orientation on Smaller Sized Service Firms and on the Market: A Multilevel Application Embracing Firms and Customers. Journal of Small Business Management, v. 54, n. 2, p. 566$581,2016$. 
PORTER, M. The five competitive forces that shape strategy. Harvard business review, v. 86, n. 1, p. 78-93, 137, 2008.

POWER, D.; SCHOENHERR, T.; SAMSON, D. The cultural characteristic of individualism/collectivism: A comparative study of implications for investment in operations between emerging Asian and industrialized Western countries. Journal of Operations Management, v. 28, n. 3, p. 206-222, 2010.

PRAJOGO, D. I.; MCDERMOTT, C. M.; MCDERMOTT, M. A. Innovation orientations and their effects on business performance: Contrasting small- and medium-sized service firms. R and D Management, v. 43, n. 5, p. 486-500, 2013.

REIS, K. A. Desempenho Operacional em Pequenas Empresas : Revisão sistemática da literatura e uma proposta de estudo empírico. [s.l.] Pontifícia Universidade Católica do Rio de Janeiro, 2018.

RIBEIRO NETO, A. B. Fatores que impactam o desempenho de pequenas empresas. Tese (doutorado) - UFRJ/ COPPE/ Programa de Engenharia de Produção, Universidade Federeal do Rio de Janeiro - UFRJ, 2008.

RICHEY, R. G.; GENCHEV, S. E.; DAUGHERTY, P. J. The role of resource commitment and innovation in reverse logistics performance. International Journal of Physical Distribution and Logistics Management, v. 35, n. 4, p. 233-257, 2005.

ROJAS-MÉNDEZ, J. I.; KARA, A.; SPILLAN, J. E. Market Orientation in the Chilean Small Business Context. Journal of Global Marketing, v. 19, n. 3-4, p. 93-132, 2 out. 2006.

ROTH, A. V.; MENOR, L. J. Insights Into Service Operations Management: a Research Agenda. Production and Operations Management, v. 12, n. 2, p. 145-164, 2009.

RUSHTON, A. M.; CARSON, D. J. The Marketing of Services: Managing the Intangibles. European Journal of Marketing, v. 19, p. 19-40, 1985.

SADLER-SMITH, E.; SPICER, D. P.; CHASTON, I. Learning orientations and growth in smaller firms. Long Range Planning, v. 34, n. 2, p. 139-158, 2001.

SAUNILA, M. Is innovation performance measurement beneficial for performance in services? International Journal of Business and Globalisation, v. 18, n. 1, p. 27, 2017a.

SAUNILA, M. Managing continuous innovation through performance measurement. Competitiveness Review, v. 27, n. 2, p. 179-190, 20 mar. $2017 b$.

SEBRAE. As Pequenas Empresas do Simples Nacional. Bibioteca do SEBRAE, p. 1-636, 2011.

SEBRAE. Pequenos negócios em números. Disponível em: $<$ http://www.sebrae.com.br/sites/PortalSebrae/ufs/sp/sebraeaz/pequenosnegocios-em-

numeros, 12e8794363447510VgnVCM1000004c00210aRCRD>. Acesso 
em: 20 mai. 2018a.

SEBRAE. Lei Geral das Micro e Pequenas Empresas. Disponível em: <http://www.sebrae.com.br/sites/PortalSebrae/artigos/entenda-as-

diferencas-entre-microempresa-pequena-empresa-emei,03f5438af1c92410VgnVCM100000b272010aRCRD>. Acesso em: 02 jun. 2018b.

SIGALA, M.; CHRISTOU, E. Global trends and challenges in services. Managing Service Quality: An International Journal, v. 16, n. 4, p. 345348, 2006.

SITKIN, S. B. Learning Through Failure: the strategy of small losses. Research In Organizational Behavior, v. 14, p. 231-266, 1992.

SPRING, M.; ARAUJO, L. Service, services and products: rethinking operations strategy. International Journal of Operations \& Production Management, v. 29, n. 5, p. 444-467, 2009.

SUBRAMONY, M.; DOUGLAS PUGH, S. Services Management Research: Review, Integration, and Future Directions. Journal of Management, v. 41, n. 1, p. 349-373, 2015.

SUH, Y.; KIM, M. S. Effects of SME collaboration on R\&D in the service sector in open innovation. Innovation: Management, Policy and Practice, v. 14, n. 3, p. 349-362, 2012.

TAMMELA, I.; CANEN, A. G.; PAGANELLI, F. Green supply chain management performance: a study in brazilian oil and gas companies. International Conference on Industrial Logistics. ICIL Conference Proceedings. 2014.

THOMÉ, A. M. T.; SCAVARDA, L. F.; SCAVARDA, A. J. Conducting systematic literature review in operations management. Production Planning \& Control, v. 27, n. 5, p. 408-420, 2016.

THOMÉ, A. M. T.; SCAVARDA, L. F.; PIRES, S. R. I.; CERYNO, P.; KLINGEBIEL, K. A multi-tier study on supply chain fl exibility in the automotive industry. Intern. Journal of Production Economics, v. 158, p. 91-105, 2014.

TRANFIELD, D.; DENYER, D.; SMART, P. Towards a Methodology for Developing Evidence-Informed Management Knowledge by Means of Systematic Review. British Journal of Management 14: 207-222. 2003.

TSIOTSOU, R. H. Delineating the effect of market orientation on services performance: a component-wise approach. The Service Industries Journal, v. 30, n. 3, p. 375-403, 16 mar. 2010.

UWIZEYEMUNGU, S.; POBA-NZAOU, P.; RAYMOND, L.; STPIERRE, J. The combined effects of IT and HRM capabilities on competitive performance: Empirical evidence from service and manufacturing SMEs. 20th Americas Conference on Information Systems, AMCIS. 2014.

VERMEULEN, P. A. M.; DE JONG, J. P. J.; O’SHAUGHNESSY, K. C. Identifying key determinants for new product introductions and firm performance in small service firms. The Service Industries Journal, v. 25, 
n. 5, p. 625-640, 2005.

VICTORINO, L. FIELD, J. M.; BUELL, R. W.; DIXON, M. J.; GOLDSTEIN, S. M.; MENOR, L. J.; PULLMAN, M. E.; ROTH, A. V.; SECCHI, E.; ZHANG, J. J. Service operations: what have we learned? Journal of Service Management, v. 29, n. 1, p. 39-54, 8 jan. 2018.

VOSS, C.; TSIKRIKTSIS, N.; FROHLICH, M. Case research in operations management. International Journal of Operations \& Production Management, v. 22, n. 2, p. 195-219, fev. 2002.

WESTHEAD, P.; WRIGHT, M.; UCBASARAN, D. The internationalization of new and small firms: A RESOURCE-BASED VIEW PAUL. Journal of Business Venturing, v. 16, n. 4, p. 333-358, jul. 2001.

WILKINSON, T.; BROUTHERS, L. E. Trade promotion and SME export performance. International Business Review, v. 15, n. 3, p. 233-252, jun. 2006.

WOO, Y. Y.; HSU, S.-L.; WU, S. An integrated inventorymodel for a single vendor and multiple buyers with ordering cost reduction. International Journal of Production Economics, p. 103-2015, 2001.

WORLD BANK. Services, etc., value added | Data. Disponível em: <http://data.worldbank.org/indicator/NV.SRV.TETC.ZS>. Acesso em: 20 mai. 2018.

YEH-YUN LIN, C.; YI-CHING CHEN, M. Does innovation lead to performance? An empirical study of SMEs in Taiwan. Management Research News, v. 30, n. 2, p. 115-132, 2007.

YIN, R. K. Case Study Research: Design and Methods. 5. ed. Los Angeles: Sage Publications, 2013.

ZEITHAML, V.; PARASURAMAN, A.; BERRY, L. L. Problems and Services Strategies in Marketing. Journal of Marketing, v. 49, p. 33-46, 1985.

ZHANG, L.; KARA, A.; SPILLAN, J. E.; MINTU-WIMSATT, A. Exploring market orientation among Chinese small and medium-sized enterprises. Chinese Management Studies, v. 11, n. 4, p. 617-636, 6 nov. 2017.

ZHOU, Q.; FANG, G.; YANG, W.; WU, Y.; REN, L. The performance effect of micro-innovation in SMEs: evidence from China. Chinese Management Studies, v. 11, n. 1, p. 123-138, 2017. 


\section{APÊNDICE 1 - Protocolo do estudo de caso}

\section{1}

\section{Introdução}

Este protocolo de estudo de caso serve como auxilio à pesquisa empírica da dissertação de mestrado intitulada "Fatores determinantes para o desempenho operacional de pequenos negócios do setor de serviços de petróleo e gás", desenvolvida pela aluna Ludmylla da Silva Moreira, da Pontifícia Universidade Católica do Rio de Janeiro. Na seção 1 da dissertação encontram-se as questões de pesquisa e objetivos do estudo.

O principal objetivo deste protocolo é fornecer informações relevantes para conduzir o estudo de caso múltiplo e padronizar os procedimentos adequados para desenvolvimento da pesquisa. Yin (2013) indica que o protocolo do estudo de caso abrange a seleção das fontes de dados, os instrumentos de pesquisa para a coleta de dados, assim como descreve o uso apropriado das técnicas e procedimentos que orientam a coleta e análise dos dados.

Para manter a confidencialidade das informações obtidas, os nomes dos entrevistados ou documentos analisados, assim como os nomes das empresas ou as observações feitas pela pesquisadora sobre o ambiente das mesmas, não serão identificados.

Além da introdução presente nesta seção, este protocolo está subdividido em mais duas seções. A seção 2 apresenta uma síntese da fundamentação teórica da pesquisa e a seção 3 descreve os procedimentos metodológicos para desenvolvimento do estudo.

\section{2 \\ Fundamentação teórica do estudo de caso}

Esta pesquisa é fundamentada na teoria Resource Based View - RBV proposta por Barney (1991) e nas cinco forças competitivas de mercado determinadas por Porter (2008). Ao realizar uma busca na literatura para verificar 
evidências de recursos VRIN no desempenho operacional de serviços em pequenos negócios, identificou-se inovação e orientação ao mercado como determinantes frequentemente relacionados ao desempenho (ver subseção 4.1. da dissertação).

A proposição de pesquisa derivada destas duas vertentes teóricas é a de que os pequenos negócios têm uma maior propensão ao mercado e à inovação dependendo das forças de mercado explicitadas por Porter e baseadas nos recursos VRIN da empresa postulados pela teoria RBV (Barney, 1991).

\section{3 \\ Procedimentos}

Nesta seção há quatro subtópicos, primeiro são fornecidos critérios para identificação das unidades de análise (empresas) e o perfil dos potenciais respondentes de cada empresa. Posteriormente são descritos os procedimentos utilizados para a coleta de dados, os instrumentos de pesquisa e para a análise de dados, detalhando como utilizar os instrumentos de pesquisa, quais documentos analisar e o que deve ser observado em campo.

\section{1 \\ Critérios para a seleção das empresas}

Voss et al. (2002) afirmam que a seleção de casos é vital para a pesquisa que trabalha com estudo de casos múltiplos e essa seleção dos casos ocorre de acordo com diferentes critérios, nos quais devem estabelecer limites que definem o que pode ser estudado, criar um quadro de amostra para ajudar a descobrir, confirmar ou qualificar os processos ou constructos básicos que sustentam o estudo e identificar casos com características que irão destacar as diferenças estudadas. Os critérios adotados no presente estudo encontram-se no Quadro 17.

Quadro 17 - Síntese dos critérios de seleção das empresas

\begin{tabular}{|c|c|}
\hline Critérios & Meios de verificação \\
\hline Atuar no estado do Rio de Janeiro & Cadastro do SEBRAE \\
\hline $\begin{array}{l}\text { Estar filiada ao setor de óleo e gás } \\
\text { do SEBRAE }\end{array}$ & Cadastro do SEBRAE \\
\hline $\begin{array}{l}\text { Corresponder à definição SEBRAE } \\
\text { de pequenos negócios }\end{array}$ & $\begin{array}{l}\text { Microempreendedor individual: } \\
\text { renda bruta mensal igual ou } \\
\text { inferior } \quad \text { a } \\
\text { Microempresa: igual ou inferior }\end{array}$ \\
\hline
\end{tabular}




\begin{tabular}{|c|c|}
\hline Critérios & Meios de verificação \\
\hline & $\begin{array}{l}\text { a } \mathrm{R} \$ 360.000 ; \text { e } \\
\text { pequeno porte: superior } \\
\mathrm{R} \$ 360.000 \text { e igual ou inferior a } \\
\mathrm{R} \$ 4.800 .000 \text {. }\end{array}$ \\
\hline $\begin{array}{l}\text { Ser representativa de orientação ao } \\
\text { mercado }\end{array}$ & $\begin{array}{l}\text { Orientadas ao mercado na visão } \\
\text { do SEBRAE }\end{array}$ \\
\hline $\begin{array}{l}\text { Ser representativa de orientação à } \\
\text { inovação }\end{array}$ & Inovativas na visão do SEBRAE \\
\hline
\end{tabular}

Como pode ser observado no Quadro 17, para assegurar que a empresa possua práticas de inovação ou orientação ao mercado, buscar-se-á aquelas que são filiadas ao SEBRAE, cujas atividades possuem maior participação percentual no estado do Rio de Janeiro no setor de petróleo e gás, podendo ter participado de algum evento voltado ao tema.

Serão necessárias informações sobre os principais recursos da empresa, desempenho operacional, requisitos dos stakeholders, orientação à inovação e ao mercado, assim profissionais que sejam os principais dirigentes da empresa ou funcionários que tenham profundo conhecimento da mesma estariam mais aptos a responder questões relacionadas ao tema da pesquisa.

\section{2 \\ Coleta de dados}

Utilizar múltiplas fontes de evidência é uma forte característica das pesquisas com abordagem qualitativa do método de estudo de caso (Voss et al., 2002; Yin, 2013). As fontes primárias de informações para a coleta de dados empíricos de cada caso deste estudo serão: entrevistas semiestruturadas, documentos e observações diretas.

Os materiais que serão utilizados para o procedimento de coleta de dados são: roteiro de observação direta, roteiro das entrevistas e aparelho eletrônico de gravação. As entrevistas serão do tipo semiestruturadas com questões abertas para possibilitar flexibilidade e maior participação dos respondentes, sua condução será baseada nos tópicos contidos no roteiro da entrevista. A observação direta se dá para compreender o funcionamento e o ambiente da organização.

\section{3 Instrumentos de pesquisa}


Para realizar a coleta de dados, serão utilizados dois instrumentos de pesquisa: roteiro de observação direta e roteiro de entrevista, contendo o questionário.

O roteiro de observação direta, ilustrado no Quadro 18, contém questões mais focadas, baseadas no Manual de Oslo da OCDE (2005), para auxiliar a entrevistadora durante as visitas de campo a mapear as características de inovações presentes nas empresas e serve como checklist para garantir que todos os assuntos pertinentes sejam abordados durante a entrevista.

Quadro 18 - Diretrizes para observação

Tipos de inovação:

Inovação de produto ou serviço: é a introdução de um bem ou serviço novo ou significativamente melhorado no que concerne a suas características ou usos previstos. Incluem-se melhoramentos significativos em especificações técnicas, componentes e materiais, softwares incorporados, facilidade de uso ou outras características funcionais.

Inovação de processo: é a implementação de um método de produção ou distribuição novo ou significativamente melhorado. Incluem-se mudanças significativas em técnicas, equipamentos e/ou softwares.

Inovação de marketing: é a implementação de um novo método de marketing com mudanças significativas na concepção do produto ou em sua embalagem, no posicionamento do produto, em sua promoção ou na fixação de preços.

Inovação organizacional: é a implementação de um novo método organizacional nas práticas de negócios da empresa, na organização do seu local de trabalho ou em suas relações externas.

\begin{tabular}{|c|c|}
\hline \multicolumn{2}{|l|}{ Implementação da inovação: } \\
\hline $\begin{array}{l}\text { Inovações próprias (inovações novas criadas pelas } \\
\text { empresas ou em cooperação com outras empresas) } \\
\text { Inovações adotadas (inovações existentes desenvolvidas } \\
\text { por outras empresas) }\end{array}$ & $\begin{array}{l}\text { A empresa criou ou adaptou a inovação? } \\
\text { Como foram observados? }\end{array}$ \\
\hline \multicolumn{2}{|l|}{ Comportamento da empresa: } \\
\hline $\begin{array}{l}\text { Reativo (evitar perda de mercado) } \\
\text { Proativo (ganhar mercado) } \\
\end{array}$ & $\begin{array}{l}\text { Qual foi o comportamento da empresa ao } \\
\text { inovar? Como foram observados? }\end{array}$ \\
\hline \multicolumn{2}{|l|}{ Tipos de atividades de inovação: } \\
\hline $\begin{array}{l}\text { Bem-sucedidas } \\
\text { Em progresso } \\
\text { Abandonada }\end{array}$ & $\begin{array}{l}\text { Como foram as atividades de inovação? } \\
\text { Como foram observados? }\end{array}$ \\
\hline
\end{tabular}


(continua)

\section{Tipos de interações:}

Fontes abertas de informação: informações disponíveis que não exigem a compra de tecnologia ou de direitos de propriedade intelectual, ou interação com a fonte;

Aquisição de conhecimentos e tecnologia: compras de conhecimento externo e/ou conhecimentos e tecnologias incorporados em bens de capital (máquinas, equipamentos, softwares) e serviços, que não envolvem interação com a fonte;

Inovação cooperativa: cooperação ativa com outras empresas ou instituições públicas de pesquisa para atividades de inovação (que podem incluir compras de conhecimento e de tecnologia).

Para elaborar o questionário, inicialmente definiu-se os tópicos/constructos mais relevantes abordados na pesquisa, sendo: inovação, orientação ao mercado, tecnologia e desempenho operacional, ilustrados no Quadro 19. O roteiro das entrevistas encontra-se no Apêndice 2. 
Quadro 19 - Descrição das questões abordadas no questionário

\begin{tabular}{|c|c|c|c|}
\hline Tópico/constructo & Descrição & Questões & Referências \\
\hline \multirow{9}{*}{ 1. Inovação } & \multirow{9}{*}{$\begin{array}{l}\text { As perguntas referem-se } \\
\text { aos recursos de inovação, } \\
\text { recompensas pela } \\
\text { inovação, identificação } \\
\text { das barreiras e } \\
\text { facilitadores para } \\
\text { inovação. }\end{array}$} & $\begin{array}{l}\text { a) Você poderia indicar um caso significativo de inovação desenvolvido na empresa? Quais } \\
\text { foram os principais motivos/objetivos para implementar essa inovação? }\end{array}$ & \multirow{9}{*}{$\begin{array}{l}\text { OECD (2005); Jaw et } \\
\text { al. (2010); Henard e } \\
\text { Szymanski (2001); } \\
\text { Dougherty e Hardy } \\
\text { (1996); Sitkin (1992). }\end{array}$} \\
\hline & & b) Quais foram as principais fontes de informações para implementar essa inovação? & \\
\hline & & $\begin{array}{l}\text { c) Houve manutenção da participação no mercado após a implementação da inovação? E } \\
\text { conquista de mercados? Ocorreu aumento da capacidade competitiva? Houve valor } \\
\text { adicionado com a inovação? }\end{array}$ & \\
\hline & & d) Quais foram as principais dificuldades encontradas para implementar essa inovação? & \\
\hline & & e) Quais são os fatores (internos ou externos) que ajudam a empresa continuar inovando? & \\
\hline & & $\begin{array}{l}\text { f) Você considera que a empresa tem capacidade de se apropriar das inovações (proteger suas } \\
\text { inovações da imitação de seus concorrentes)? }\end{array}$ & \\
\hline & & $\begin{array}{l}\text { g) Qual foi a principal fonte de financiamento para implementar essa inovação? A empresa } \\
\text { tem orçamento suficiente para o desenvolvimento de novas inovações? }\end{array}$ & \\
\hline & & $\begin{array}{l}\text { h) Há tempo e recursos (materiais e humanos) suficientes para o desenvolvimento de } \\
\text { atividades de inovação? }\end{array}$ & \\
\hline & & $\begin{array}{l}\text { i) Os funcionários são incentivados a desenvolverem inovações? Há recompensas para o } \\
\text { mesmo? }\end{array}$ & \\
\hline \multirow{6}{*}{$\begin{array}{l}\text { 2. Orientação ao } \\
\text { mercado }\end{array}$} & \multirow{6}{*}{$\begin{array}{l}\text { As perguntas referem-se } \\
\text { à orientação ao cliente e } \\
\text { concorrente, além das } \\
\text { cinco forças competitivas } \\
\text { de Porter. }\end{array}$} & $\begin{array}{l}\text { a) As necessidades dos clientes são levadas em consideração na prestação ou criação de } \\
\text { serviços? Se sim, por que? Poderia dar um exemplo? }\end{array}$ & \multirow{6}{*}{$\begin{array}{l}\text { Narver e Slater (1990); } \\
\text { Porter (2008); Jaw et } \\
\quad \text { al. (2010). }\end{array}$} \\
\hline & & $\begin{array}{l}\text { b) A gerência geralmente discute os pontos fortes, capacidade e as estratégias dos } \\
\text { concorrentes? Se sim, com base na concorrência, você conhece quais são os pontos fortes e } \\
\text { pontos fracos da sua empresa? }\end{array}$ & \\
\hline & & $\begin{array}{l}\text { c) No segmento da sua empresa, há muitos concorrentes? Se sim, qual estratégia foi usada } \\
\text { para obter vantagens nessa rivalidade? (aumento ou diminuição de preços e custos, batalhas } \\
\text { de publicidade, aumento dos serviços ou das garantias ao cliente, por exemplo) }\end{array}$ & \\
\hline & & $\begin{array}{l}\text { d) Houve alguma barreira contra a entrada do novo produto/processo no mercado? Se sim, } \\
\text { qual estratégia foi utilizada para superar essa barreira? }\end{array}$ & \\
\hline & & $\begin{array}{l}\text { e) Quais estratégias vocês utilizam para superar os produtos/serviços substitutos aos seus } \\
\text { existentes no mercado? }\end{array}$ & \\
\hline & & f) Em relação à venda dos seus serviços aos clientes, geralmente quem detém maior poder na & \\
\hline
\end{tabular}




\begin{tabular}{|c|c|c|c|}
\hline Tópico/constructo & Descrição & Questões & Referências \\
\hline & & $\begin{array}{l}\text { negociação? Quais são os principais fatores levados em consideração na hora de negociar a } \\
\text { venda (qualidade, custos, padronização, por exemplo)? }\end{array}$ & \\
\hline & & $\begin{array}{l}\text { g) Em relação à compra dos fornecedores, geralmente quem detém maior poder na } \\
\text { negociação da compra? Quais são os principais fatores levados em consideração na hora de } \\
\text { negociar a compra (quantidade de fornecedores, insumo importante para a empresa, por } \\
\text { exemplo)? }\end{array}$ & \\
\hline \multirow{13}{*}{ 3. Tecnologia } & \multirow{13}{*}{$\begin{array}{l}\text { As perguntas referem-se } \\
\text { à identificação do uso de } \\
\text { tecnologias, seus } \\
\text { facilitadores e barreiras } \\
\text { para adoção. }\end{array}$} & a) Dentre as tecnologias listadas abaixo, alguma delas é utilizada na empresa? & \multirow{13}{*}{$\begin{array}{l}\text { Deloitte (2018); FNQ } \\
\text { (2018); CNI-Indicators } \\
\text { (2016). }\end{array}$} \\
\hline & & Internet das Coisas (IoT) ( ) & \\
\hline & & Inteligência artificial ( ) & \\
\hline & & Interface das Coisas ( ) & \\
\hline & & Machine Learning ( ) & \\
\hline & & Big Data () & \\
\hline & & Impressão 3D ( ) & \\
\hline & & Materiais avançados ( ) & \\
\hline & & Robótica avançada e automação cognitiva ( ) & \\
\hline & & Design digital, simulação e integração ( ) & \\
\hline & & b) Quais foram os principais motivos/objetivos para implementar essa(s) tecnologia(s)? & \\
\hline & & $\begin{array}{l}\text { c) Quais foram as principais barreiras (internas e externas) que dificultaram/dificultam a } \\
\text { adoção dessa(s) tecnologia(s)? }\end{array}$ & \\
\hline & & $\begin{array}{l}\text { d) Quais foram os principais facilitadores (internos e externos) para adoção dessa(s) } \\
\text { tecnologia(s)? }\end{array}$ & \\
\hline
\end{tabular}




\begin{tabular}{|c|c|c|c|}
\hline Tópico/constructo & Descrição & Questões & Referências \\
\hline \multirow{9}{*}{$\begin{array}{l}\text { 4. Desempenho } \\
\text { operacional }\end{array}$} & \multirow{9}{*}{\begin{tabular}{c|c} 
As perguntas referem-se \\
à identificação dos \\
indicadores de \\
desempenho e engloba as \\
cinco dimensões de \\
desempenho em serviços: \\
custo, flexibilidade, \\
qualidade, entrega e \\
esforços de inovação, \\
verificando se algum \\
determinante interferiu \\
nessas dimensões. \\
\cline { 2 - 3 } \\
\cline { 2 - 4 }
\end{tabular}} & $\begin{array}{l}\text { a) A empresa possui um sistema de medição de desempenho? Se sim, quais os principais } \\
\text { indicadores de desempenho? Se não, o que usam como base para saber o desempenho da } \\
\text { empresa? }\end{array}$ & \multirow{9}{*}{$\begin{array}{c}\text { Fitzgerald et al. } \\
\text { (1991); OECD (2005); } \\
\text { Ferdows e De Meyer } \\
\text { (1990); Woo et al. } \\
\text { (2001); Hallgren e } \\
\text { Olhager (2009); Kim e } \\
\text { Arnold (1993); } \\
\text { Parasuraman et al. } \\
\text { (1988). }\end{array}$} \\
\hline & & $\begin{array}{l}\text { b) Ocorre atrasos por parte da empresa para começar a atender o cliente? Os pedidos são } \\
\text { atendidos no prazo? O atendimento é realizado conforme prometido? }\end{array}$ & \\
\hline & & $\begin{array}{l}\text { c) A velocidade de entrega dos serviços/produtos é um dos principais fatores para a empresa } \\
\text { se manter competitiva? Com o processo de inovação, houve um aumento dessa velocidade? }\end{array}$ & \\
\hline & & $\begin{array}{l}\text { d) Houve redução nos custos (compras, distribuição, transações, custos unitários de produção, } \\
\text { por exemplo) com a implementação da inovação? Redução de custos é um dos principais } \\
\text { fatores para a empresa se manter competitiva? }\end{array}$ & \\
\hline & & $\begin{array}{l}\text { e) A empresa conhece quanto custa realizar um serviço? Se sim, esse custo está acima, abaixo } \\
\text { ou igual ao esperado? }\end{array}$ & \\
\hline & & $\begin{array}{l}\text { f) Ser flexível no atendimento aos clientes é um dos principais fatores para a empresa se } \\
\text { manter competitiva? Você poderia indicar se em algum momento no processo de inovação foi } \\
\text { necessário mudar ou adaptar a operação devido a mudanças nas necessidades dos clientes? }\end{array}$ & \\
\hline & & $\begin{array}{l}\text { g) A qualidade dos serviços é um dos principais fatores para a empresa se manter } \\
\text { competitiva? Com o processo de inovação, houve um aumento da qualidade dos serviços? }\end{array}$ & \\
\hline & & $\begin{array}{l}\text { h) Usam alguma ferramenta para medir o nível de satisfação dos clientes em relação à } \\
\text { qualidade do atendimento e do ambiente físico da empresa? }\end{array}$ & \\
\hline & & $\begin{array}{l}\text { i) Serviços inovadores são um dos principais fatores para a empresa se manter competitiva? } \\
\text { O processo de inovação implementado aumentou a capacidade da empresa para personalizar } \\
\text { e/ou desenvolver novos serviços? E para ganhar e criar conhecimentos? }\end{array}$ & \\
\hline
\end{tabular}




\section{4 \\ Análise de dados}

Serão realizados dois tipos de análise dos dados para os estudos de caso: primeiro a análise intracaso, que consiste em analisar os dados coletados em cada estudo de caso separadamente, e posteriormente a análise intercaso, que consiste em analisar os dados coletados dos estudos de casos em conjunto.

Para criar um banco de dados, as entrevistas serão transcritas e armazenadas em arquivos eletrônicos, que juntamente com os documentos e anotações compõem o material necessário para realizar a análise de conteúdo. Será utilizado software WebQDA de análise qualitativa para codificar e categorizar os textos originados da transcrição, reduzindo a quantidade de dados e estruturando as ideias temáticas. Além disso, essa redução de dados possibilitará incluir somente o que é relevante e está conectado com os objetivos da pesquisa.

Os entrevistados devem fornecer informações com o intuito de confirmar, complementar ou contrastar o referencial teórico. Assim, serão desenvolvidos painéis de dados referentes a cada tópico/constructo, ilustrado na Figura 9, os quais terão um resumo dos dados coletados em cada entrevista, observações e verificação de documentos, o que possibilitará a triangulação de dados para verificar a convergência ou divergência entre as fontes de informação.

A triangulação de dados compara as respostas das entrevistas, documentos e as observações da visita de campo de uma empresa, como compara as respostas entre empresas (Thomé et al., 2014). Assim, é válido ressaltar que estes painéis serão adaptados para serem usados tanto na análise intracaso quanto na análise intercaso.

\begin{tabular}{|l|l|l|l|}
\hline \multirow{2}{*}{ Fontes de dados } & \multicolumn{2}{|c|}{ Orientação à inovação } & \multirow{2}{*}{ Resumo das fontes } \\
\cline { 2 - 4 } & Barreiras & Facilitadores & \\
\hline Entrevistado \#1 & & & \\
\hline Entrevistado \#2 & & & \\
\hline Entrevistado \#3 & & & \\
\hline Observações (OBS1) & & & \\
\hline Documentos (DOC1) & & & \\
\hline Sintese & & & \\
\hline
\end{tabular}

Figura 9 - Exemplo ilustrativo do painel de dados 
Posteriormente será realizada uma análise denominada lógica de adequação ao padrão, utilizada para a verificação de correspondência entre as evidências empíricas (o padrão observado) e a teoria (proposições teóricas) (Yin, 2013). Além disso, será utilizada a técnica de linhas de síntese de argumentos que permite analisar o mesmo fenômeno por diferentes aspectos (Tranfield et al., 2003).

Desse modo, a análise de dados combinada de cada estudo de caso deve complementar um ao outro, apresentando as relações entre os determinantes e desempenho operacional de serviços em pequenas empresas. 


\section{APÊNDICE 2 - Roteiro de entrevista}

\section{Data:}

\section{Perfil do respondente:}

Cargo do(a) entrevistado(a):

Tempo que exerce este cargo:

\section{Perfil da empresa:}

Segmento:

Tamanho: Microempresa (receita bruta anual igual ou inferior a $\mathrm{R} \$$ 360.000,00) ( ); Empresa de pequeno porte (receita bruta anual superior a $\mathrm{R} \$$ $360.000,00$ e igual ou inferior a $\mathrm{R} \$ 4.800 .000,00)$ ( ); microempreendedor individual (receita bruta anual de até R \$ 81.000,00) ( ).

Principal atividade:

Tempo de atuação com o SEBRAE no segmento petroquímico:

Programas/eventos que já participou do SEBRAE:

\section{Orientação à inovação}

a) Você poderia indicar um caso significativo de inovação desenvolvido na empresa? Quais foram os principais motivos/objetivos para implementar essa inovação?

b) Quais foram as principais fontes de informações para implementar essa inovação?

c) Houve manutenção da participação no mercado após a implementação da inovação? E conquista de mercados? Ocorreu aumento da capacidade competitiva? Houve valor adicionado com a inovação?

d) Quais foram as principais dificuldades encontradas para implementar essa inovação?

e) Quais são os fatores (internos ou externos) que ajudam a empresa continuar inovando?

f) Você considera que a empresa tem capacidade de se apropriar das inovações (proteger suas inovações da imitação de seus concorrentes)?

g) Qual foi a principal fonte de financiamento para implementar essa inovação? A empresa tem orçamento suficiente para o desenvolvimento de novas inovações? 
h) Há tempo e recursos (materiais e humanos) suficientes para o desenvolvimento de atividades de inovação?

i) Os funcionários são incentivados a desenvolverem inovações? Há recompensas para o mesmo?

\section{Orientação ao mercado}

a) As necessidades dos clientes são levadas em consideração na prestação ou criação de serviços? Se sim, por que? Poderia dar um exemplo?

b) A gerência geralmente discute os pontos fortes, capacidade e as estratégias dos concorrentes? Se sim, com base na concorrência, você conhece quais são os pontos fortes e pontos fracos da sua empresa?

c) No segmento da sua empresa, há muitos concorrentes? Se sim, qual estratégia foi usada para obter vantagens nessa rivalidade? (aumento ou diminuição de preços e custos, batalhas de publicidade, aumento dos serviços ou das garantias ao cliente, por exemplo)

d) Houve alguma barreira contra a entrada do novo produto/processo no mercado? Se sim, qual estratégia foi utilizada para superar essa barreira?

e) Quais estratégias vocês utilizam para superar os produtos/serviços substitutos aos seus existentes no mercado?

f) Em relação à venda dos seus serviços aos clientes, geralmente quem detém maior poder na negociação? Quais são os principais fatores levados em consideração na hora de negociar a venda (qualidade, custos, padronização, por exemplo)?

g) Em relação à compra dos fornecedores, geralmente quem detém maior poder na negociação da compra? Quais são os principais fatores levados em consideração na hora de negociar a compra (quantidade de fornecedores, insumo importante para a empresa, por exemplo)?

\section{Tecnologias disruptivas}

a) Dentre as tecnologias listadas abaixo, alguma delas é utilizada na empresa?

\begin{tabular}{|l|l|}
\hline Internet das Coisas & \\
\hline Inteligência artificial & \\
\hline Interface das Coisas & \\
\hline Machine Learning & \\
\hline Big Data & \\
\hline Impressão 3D & \\
\hline Materiais avançados & \\
\hline Robótica avançada e automação cognitiva & \\
\hline Design digital, simulação e integração & \\
\hline
\end{tabular}

b) Quais foram os principais motivos/objetivos para implementar essa(s) tecnologia(s)?

c) Quais foram as principais barreiras (internas e externas) que dificultaram/dificultam a adoção dessa(s) tecnologia(s)?

d) Quais foram os principais facilitadores (internos e externos) para adoção dessa(s) tecnologia(s)?

\section{Desempenho Operacional}


a) A empresa possui um sistema de medição de desempenho? Se sim, quais os principais indicadores de desempenho? Se não, o que usam como base para saber o desempenho da empresa?

b) Ocorre atrasos por parte da empresa para começar a atender o cliente? Os pedidos são atendidos no prazo? O atendimento é realizado conforme prometido?

c) A velocidade de entrega dos serviços/produtos é um dos principais fatores para a empresa se manter competitiva? Houve um aumento dessa velocidade devido à inovação, tecnologia ou orientação ao mercado?

d) Houve redução nos custos (compras, distribuição, transações, custos unitários de produção, por exemplo) devido à inovação, tecnologia ou orientação ao mercado? Redução de custos é um dos principais fatores para a empresa se manter competitiva?

e) A empresa conhece quanto custa realizar um serviço? Se sim, esse custo está acima, abaixo ou igual ao esperado?

f) Ser flexível no atendimento aos clientes é um dos principais fatores para a empresa se manter competitiva? Você poderia indicar se em algum momento foi necessário mudar ou adaptar a operação devido à inovação, tecnologia ou orientação ao mercado?

g) A qualidade dos serviços é um dos principais fatores para a empresa se manter competitiva? Houve um aumento da qualidade dos serviços devido à inovação, tecnologia ou orientação ao mercado?

h) Usam alguma ferramenta para medir o nível de satisfação dos clientes em relação à qualidade do atendimento e do ambiente físico da empresa?

i) Serviços inovadores são um dos principais fatores para a empresa se manter competitiva? Houve aumento da capacidade da empresa para personalizar e/ou desenvolver novos serviços devido à inovação, tecnologia ou orientação ao mercado? E para ganhar e criar conhecimentos? 


\section{APÊNDICE 3 - Lista dos códigos para análise de conteúdo dos estudos de caso}

\section{0 - INFO_EMPRESAS}

0.1 - organizaçãoA

0.1 - organizaçãoB

0.1 - organizaçãoC

0.1 - organizaçãoD

0.2 - entrevistadoA

0.2 - entrevistadoB

0.2 - entrevistadoC

0.2 - entrevistadoD

0.3 - doc/siteA

$0.3-$ doc/siteB

0.3 - doc/siteC

0.3 - doc/siteD

0.4 - obsA

$0.4-$ obsB

0.4 - obsC

$0.4-$ obsD

\section{1 - INOVAÇÃO}

1.1 - tipo de inovação: produto ou serviço

1.1 - tipo de inovação: processo

1.1 - tipo de inovação: marketing

1.1 - tipo de inovação:

organizacional

1.2 - motivo/objetivo da inovação:

fatores externos

1.2 - motivo/objetivo da inovação:

fatores internos

1.3 - fonte de informação: sebrae

1.3 - fonte de informação: outros

1.4 - barreira para inovação

1.5 - facilitador para inovação

1.6 - esforços de inovação: recursos

1.6.1 - esforços de inovação:

recursos financeiros

1.6.1 - esforços de inovação:

recursos humanos

1.6.1 - esforços de inovação:

recursos materiais

1.7 - esforços de inovação:

recompensas
1.8 - implementação da inovação:

inovações próprias

1.8 - implementação da inovação:

inovações adotadas

1.9 - comportamento da empresa:

reativo

1.9 - comportamento da empresa:

proativo

1.10 - tipos de atividades de

inovação: em progresso

1.10 - tipos de atividades de inovação: bem-sucedidas

1.10 - tipos de atividades de inovação: abandonadas

1.11 - tipos de interações: fontes abertas de informação

1.11 - tipos de interações: aquisição de conhecimentos e tecnologia

1.11 - tipos de interações: inovação cooperativa

\section{2 - ORIENTAÇÃO AO MERCADO}

2.1 - orientação ao cliente

2.2 - orientação ao concorrente

2.3 - integração interfuncional

2.4 - forças de Porter: barreiras para novos entrantes

2.4 - forças de Porter: ameaça de produtos ou serviços substitutos 2.4 - forças de Porter: poder de negociação dos compradores 2.4 - forças de Porter: poder de negociação dos fornecedores 2.4 - forças de Porter: rivalidade entre os atuais concorrentes

\section{3 - TECNOLOGIA}

3.1 - tipo de tecnologia: IoT

3.1 - tipo de tecnologia: inteligência artificial 
3.1 - tipo de tecnologia: interface das coisas

3.1 - tipo de tecnologia: machine learning

3.1 - tipo de tecnologia: big data

3.1 - tipo de tecnologia: impressão $3 \mathrm{D}$

3.1 - tipo de tecnologia: materiais avançados

3.1 - tipo de tecnologia: robótica avançada e/ou automação cognitiva 3.1 - tipo de tecnologia: design digital, simulação e integração 3.2 - motivo/objetivo: necessidade interna

3.2 - motivo/objetivo: necessidade externa

3.3 - barreira para tecnologia

3.4 - facilitador para tecnologia

\section{4 - DESEMPENHO} OPERACIONAL

4.1.1 - md operacional: custo
4.1.2 - md operacional: flexibilidade 4.1.2.1 - md operacional:

flexibilidade Volume

4.1.2.1 - md operacional:

flexibilidade Velocidade de entrega 4.1.2.1 - md operacional:

flexibilidade Especificação

4.1.3 - md operacional: qualidade

4.1.3.1 - md operacional: qualidade Confiabilidade

4.1.3.1 - md operacional: qualidade Prontidão

4.1.3.1 - md operacional: qualidade Segurança

4.1.3.1 - md operacional: qualidade Empatia

4.1.3.1 - md operacional: qualidade Aspectos tangíveis

4.1.4 - md operacional: entrega

4.1.5 - md operacional: inovação

4.2 - md operacional: não

4.2.1 - desempenho: financeiro

4.2.1 - desempenho: outros 